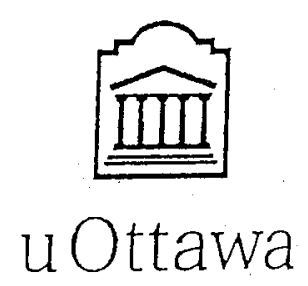

1. Unitersilć canadicime Camacla's universily 
FACULTÉ DES ÉTUDES SUPÉRIEURES ET POSTOCTORALES

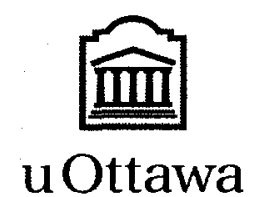

untawa

l.'Univerate canadienne Canada's university

\section{FACULTY OF GRADUATE AND POSDOCTORAL STUDIES}

Somaieh Salehpour

AUTEUR DE LA THESE I AUTHOR OF THESIS

M.A.Sc. (Chemical Engineering) GRADE /DEGREE

Department of Chemical Engineering FACULTE, ECOLE, DEPARTEMENT / FACULTY, SCHOOL, DEPARTMENT

Biodiesel: A Green Polymerization Solvent

TITRE DE LA THESE / TITLE OF THESIS

Dr. Marc Dubé

DIRECTEUR (DIRECTRICE) DE LA THESE I THESIS SUPERVISOR

CO-DIRECTEUR (CO-DIRECTRICE) DE LA THESE ITHESIS CO-SUPERVISOR

EXAMINATEURS (EXAMINATRICES) DE LA THĖSE / THESIS EXAMINERS

Dr. Kruczek

Dr. Ternan

Gary W. Slater

Le Doyen de la Faculté des études supérieures et postdoctorales / Dean of the Faculty of Graduate and Postdoctoral Studies 


\title{
BIODIESEL: A GREEN POLYMERIZATION SOLVENT
}

\author{
by \\ Somaieh Salehpour
}

\begin{abstract}
A thesis submitted to the Faculty of Graduate and Postdoctoral Studies in fulfillment of the requirements for the degree of
\end{abstract}

Master of Applied Science

Chemical Engineering

Department of Chemical Engineering

UNIVERSITY OF OTTAWA 


$\begin{array}{ll}\begin{array}{l}\text { Library and } \\ \text { Archives Canada }\end{array} & \begin{array}{l}\text { Bibliothèque et } \\ \text { Archives Canada }\end{array} \\ \begin{array}{l}\text { Published Heritage } \\ \text { Branch }\end{array} & \begin{array}{l}\text { Direction du } \\ \text { Patrimoine de l'édition }\end{array} \\ \begin{array}{l}\text { 395 Wellington Street } \\ \text { Ottawa ON K1A 0N4 } \\ \text { Canada }\end{array} & \begin{array}{l}\text { 395, rue Wellington } \\ \text { Ottawa ON K1A 0N4 } \\ \text { Canada }\end{array}\end{array}$

Your file Votre référence ISBN: 978-0-494-49275-8 Our file Notre référence ISBN: 978-0-494-49275-8

NOTICE:

The author has granted a nonexclusive license allowing Library and Archives Canada to reproduce, publish, archive, preserve, conserve, communicate to the public by telecommunication or on the Internet, loan, distribute and sell theses worldwide, for commercial or noncommercial purposes, in microform, paper, electronic and/or any other formats.

The author retains copyright ownership and moral rights in this thesis. Neither the thesis nor substantial extracts from it may be printed or otherwise reproduced without the author's permission.
AVIS:

L'auteur a accordé une licence non exclusive permettant à la Bibliothèque et Archives Canada de reproduire, publier, archiver, sauvegarder, conserver, transmettre au public par télécommunication ou par l'Internet, prêter, distribuer et vendre des thèses partout dans le monde, à des fins commerciales ou autres, sur support microforme, papier, électronique et/ou autres formats.

L'auteur conserve la propriété du droit d'auteur et des droits moraux qui protège cette thèse. $\mathrm{Ni}$ la thèse ni des extraits substantiels de celle-ci ne doivent être imprimés ou autrement reproduits sans son autorisation.
In compliance with the Canadian Privacy Act some supporting forms may have been removed from this thesis.

While these forms may be included in the document page count, their removal does not represent any loss of content from the thesis.
Conformément à la loi canadienne sur la protection de la vie privée, quelques formulaires secondaires ont été enlevés de cette thèse.

Bien que ces formulaires aient inclus dans la pagination, il n'y aura aucun contenu manquant.

\section{Canada}




\section{Statement of Contributions of Collaborators}

I hereby declare that I am the sole author of this thesis. I performed the polymerization experiments, polymer characterization and data analysis for paper I and paper II. For paper III, all polymerization experiments and most GPC analyses were performed by Maya Murphy. I trained her in the laboratory techniques and directly supervised her work in the laboratory. All modeling, NMR sample preparation, NMR data analyses and some GPC analyses were done by me. The acquisition of NMR data was contracted out to the Department of Chemistry at the University of Ottawa.

The scientific guidance throughout the project and editorial comments for the written work were provided by my supervisor Dr. Marc A. Dubé.

Somaieh Salehpour

Date: $\operatorname{Sep} 17 / 2007$ 


\begin{abstract}
ABSTRAIT
Un certain nombre de produits de polymère sont traditionnellement faits en utilisant une technique de polymérisation en solution. Cependant, prenant conscience des effets environnementaux et ainsi, aux soucis du contenu organique volatil (COV) lié à de divers processus de polymère, il y a un effort continu de trouver des alternatifs aux solvants traditionnels.

Dans un effort d'employer des technologies plus propres, l'ester méthylique d'acide gras (EMAG) a été employé pour la première fois comme solvant de polymérisation. Le biodiésel ou EMAG a recueilli beaucoup d'attention ces dernières années comme alternative au carburant diesel. Il est ambiant-bénin et a une basse volatilité. Puisque le biodiesel est un solvant à haut point d'ébullition, son utilisation peut augmenter la productivité en permettant les polymérisations aux températures élevées. Ceci aurait comme conséquence des vitesses de réaction plus rapides et ainsi, des temps de réaction plus courts.

Dans la première partie de cette étude, des polymérisations en solution de quatre monomères commercialement importants (c.-à-d., méthacrylate de méthyle (MMA), styrène, acrylate de butyle (BA) et acétate de vinyle (VAc)) ont été étudiées à $60^{\circ} \mathrm{C}$ en utilisant la EMAG produite à partir de l'huile de canola comme solvant. Des réactions ont été effectuées à différentes concentrations dissolvantes pour vérifier l'effet de la EMAG sur les polymérisations. Les paramètres de transfert à chaînes aux solvants ont été obtenus en utilisant la méthode de Mayo. En outre, l'effet du solvant sur des polymérisations en solution de chaque monomère a été étudié. Ceci a été suspecté d'avoir
\end{abstract}


contribué à un changement du paramètre cinétique $\mathrm{k}_{\mathrm{p}} / \mathrm{k}_{\mathrm{t}}{ }^{1 / 2}$. Les données expérimentales cinétiques ont été modelées à l'aide d'un simulateur de polymérisation.

Dans la deuxième partie de cette thèse, la EMAG basée au canola a été employée comme solvant dans la polymérisation en solution des monomères mentionnés ci-dessus à $120^{\circ} \mathrm{C}$. Les paramètres de transfert à chaînes aux solvants ont été calculés et ont été utilisés dans un simulateur de polymérisation pour prévoir les taux de polymérisation et les poids moléculaires moyens cumulatifs du polymère. Comme dans l'étude à $60^{\circ} \mathrm{C}$, les changements du paramètre cinétique $\mathrm{k}_{\mathrm{p}} / \mathrm{k}_{\mathrm{t}}^{1 / 2}$ avec la concentration du solvant ont été incorporés au simulateur de polymérisation; ces changements ont considérablement amélioré les prévisions des modèles.

Dans la troisième partie de la thèse, l'effet de l'EMAG produit à partir de différentes matières de base d'huile sur la cinétique de polymérisation a été étudié pour des homopolymerizations de styrène à $60^{\circ} \mathrm{C}$. L'huile de soja, et un mélange de graisse jaune et d'huile de canola à 50\%/50\% ont été utilisées comme matières de base dans cette étude. Les résultats expérimentaux ont été comparés à ceux utilisant l'EMAG préparé de

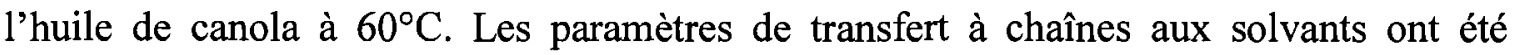
estimés pour chaque solvant en utilisant la méthode de Mayo et aucune différence significative entre les valeurs obtenues à partir de la polymérisation dans l'EMAG différente n'a été trouvée. D'autre part, on a observé des effets différents sur le taux de polymérisation. Ceux-ci ont été montrés à se relier au degré de non-saturation de chaque EMAG. Des prévisions des modèles des taux de réaction et des poids moléculaires pour les systèmes étudiés sont également présentées. 


\section{ACKNOWLEDGEMENT}

Finding suitable words to acknowledge everyone who helped in enriching my thoughts and guiding my ideas is not less difficult than the research process itself. The following few words are symbolic of my indebtedness to a few of the many who have refined my path.

The most important landmark on my journey is my intellectual supervisor, Dr. Marc A. Dubé. The various discussions with him opened new doors for my mind besides enriching many of my perceptions. His consistent support, both moral and substantial, enabled me to transcend many of the obstacles faced in my journey.

Also, I am indebted to the professors and staffs of the Department of Chemical Engineering, who provided me with all the knowledge and help I required through all the different stages of development, especially Louis Tremblay, for making numerous glass ampoules and all those assistances that were needed for the smooth running of this project.

I should express my boundless gratitude and thanks to my family: to my loving mother, whose encouragement and support enabled me to be here; my caring father, whose support never reached a limit; and my younger brother who tried to help me by all means possible.

Thanks to my university, my homeland, this great hosting country and all my friends, especially Gabriela for all her help.

Special thanks go to my husband, Mohammad, who has been and will undoubtedly continue to be in the future, a perpetual source of inspiration and love. 


\section{TABLE OF CONTENTS}

Statements of Contributions of Collaborators..................................................................... ii

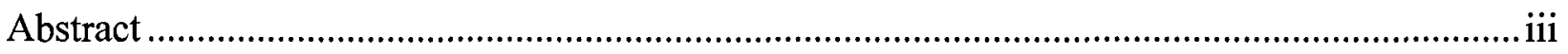

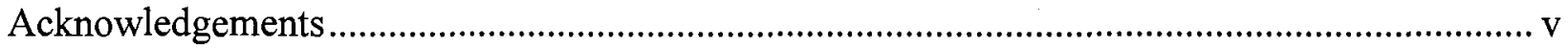

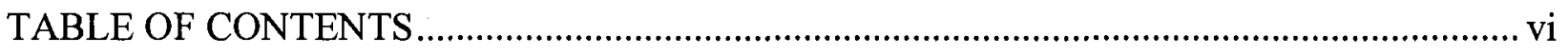

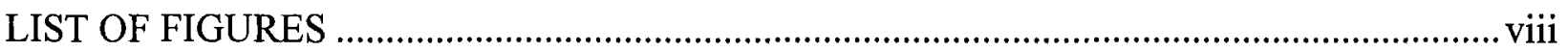

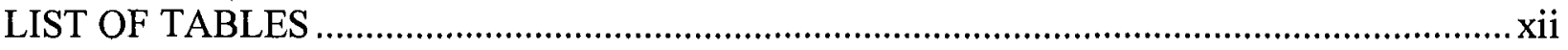

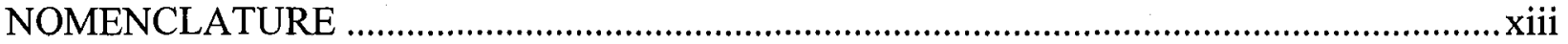

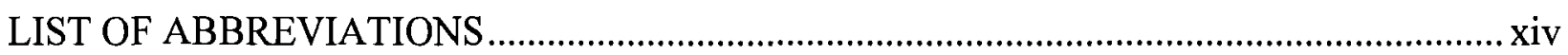

Chapter 1 INTRODUCTION ................................................................................................... 1

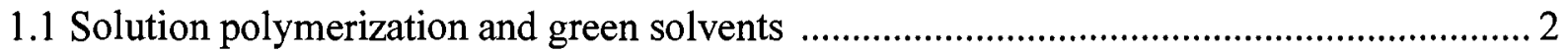

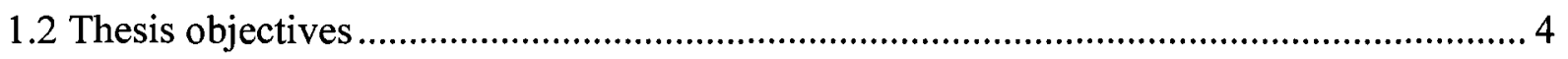

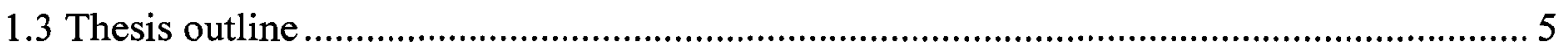

Chapter 2 THEORETICAL BACKGROUND .......................................................................... 7

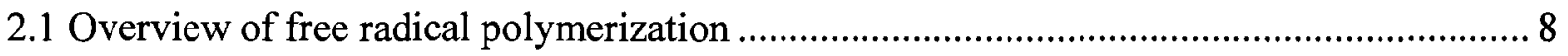

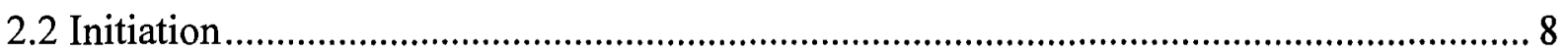

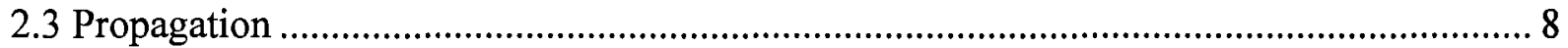

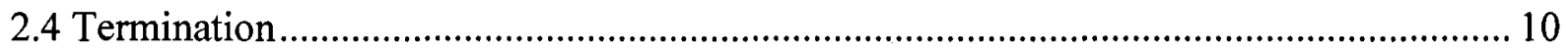

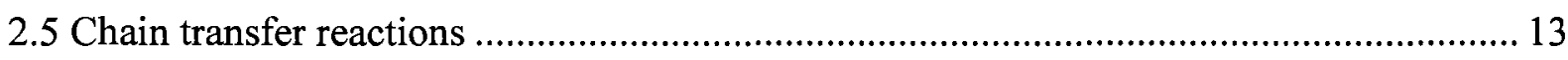

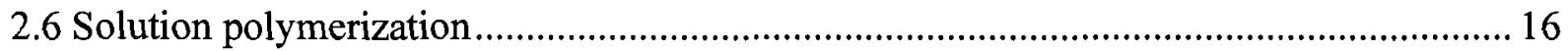

2.7 Free radical polymerization modeling ................................................................ 18

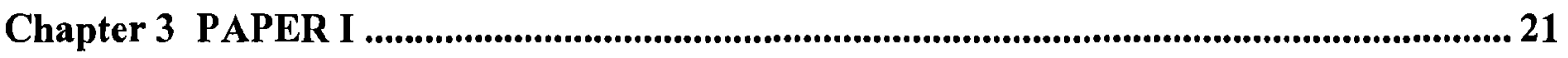

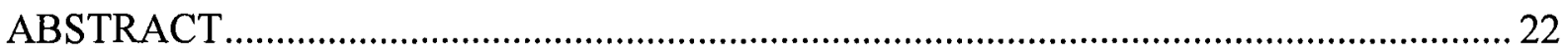

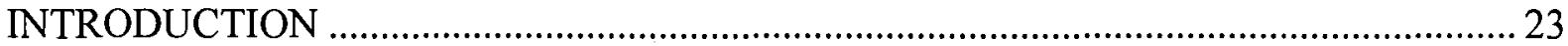

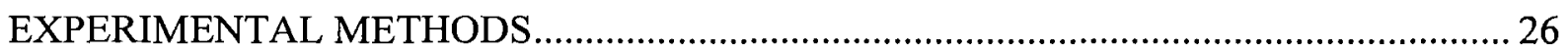

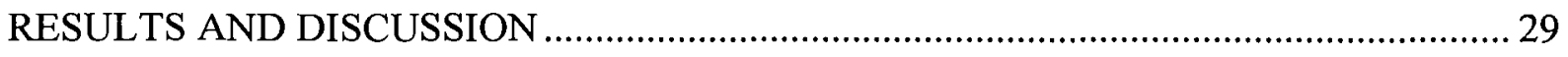

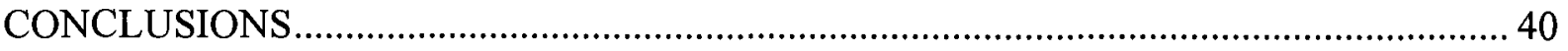

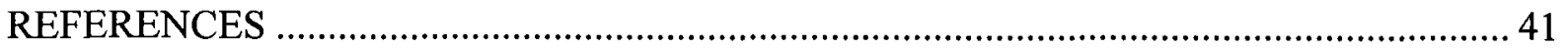




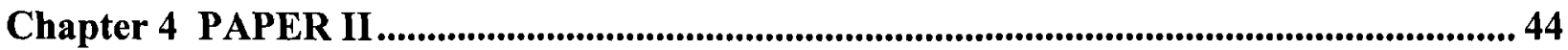

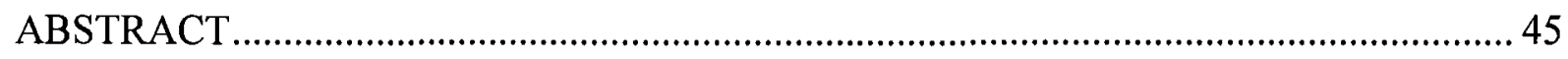

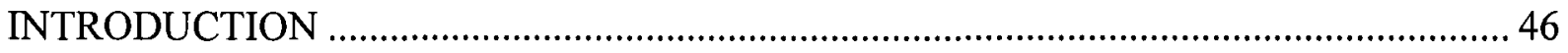

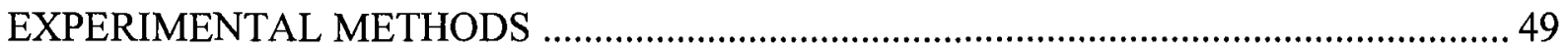

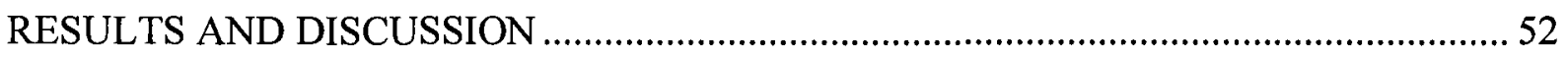

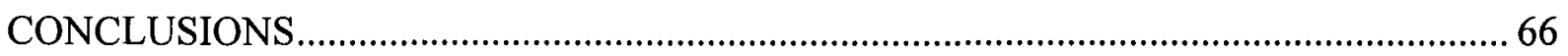

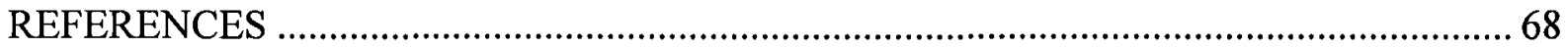

Chapter 5 PAPER III ...................................................................................................................... 71

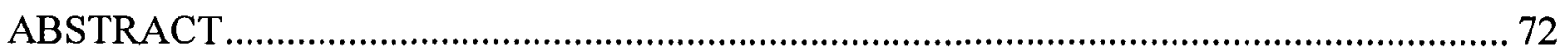

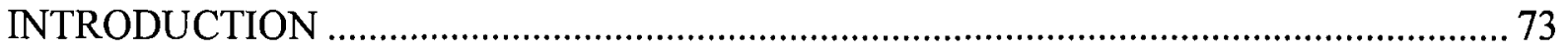

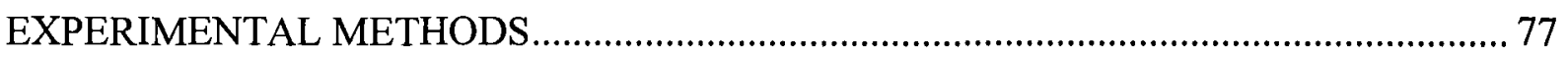

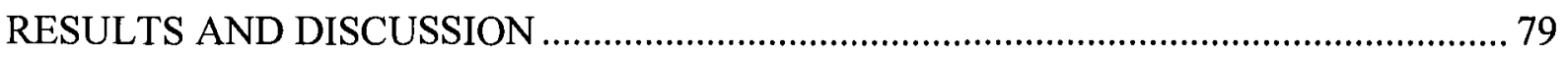

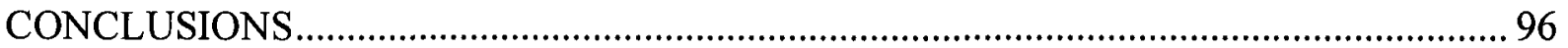

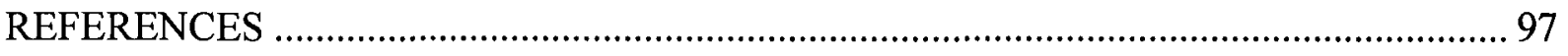

Chapter 6 GENERAL DISCUSSION ............................................................................................. 100

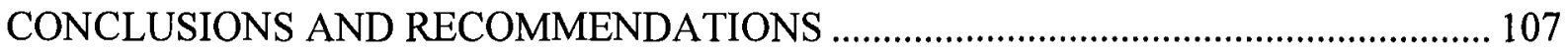

Appendix A experimental data and model predictions............................................................. 110 


\section{LIST OF FIGURES}

\section{Chapter 1}

Figure 1.1 Elementary reaction scheme for transesterification of triglyceride

\section{Chapter 2}

Figure 2.1 Termination by combination ............................................................................. 10

Figure 2.2 Termination by disproportionation ...................................................................... 11

Figure 2.3 Transfer to polymer chain in an acrylic polymer .................................................... 14

Figure 2.4 Intramolecular hydrogen abstraction ................................................................... 15

\section{Chapter 3}

Figure 3.1 Mayo plot - reciprocal number-average degree of polymerization versus the solvent/monomer ratio for the monomers polymerized in FAME....................................31

Figure 3.2 MMA homopolymerization in FAME: Conversion versus time at different solvent concentrations.

Figure 3.3 Sty homopolymerization in FAME: Conversion versus time at different solvent concentrations..

Figure 3.4 VAc homopolymerization in FAME: Conversion versus time at different solvent concentrations.

Figure 3.5 BA homopolymerization in FAME: Conversion versus time at different solvent concentrations.

\section{Chapter 4}

Figure 4.1 Mayo plot - reciprocal number-average degree of polymerization versus the solvent/monomer ratio for the monomers polymerized in FAME.

Figure 4.2. MMA homopolymerization in FAME: Conversion versus time at different solvent concentrations.

Figure 4.3 Sty homopolymerization in FAME: Conversion versus time at different solvent concentrations.

Figure 4.4 VAc homopolymerization in FAME: Conversion versus time at different solvent concentrations.

Figure 4.5 BA homopolymerization in FAME: Conversion versus time at different 
solvent concentrations.

Figure 4.6 Cumulative average molecular weight versus conversion for MMA solution homopolymerization in FAME (50/50 wt \%)

Figure 4.7 Cumulative average molecular weight versus conversion for MMA solution homopolymerization in FAME (80/20 wt \%)

Figure 4.8 Cumulative average molecular weight versus conversion for Sty solution homopolymerization in FAME (50/50 wt \%)

Figure 4.9 Cumulative average molecular weight versus conversion for VAc solution

homopolymerization in FAME (80/20 wt \%).

Figure 4.10 Cumulative average molecular weight versus conversion for BA solution homopolymerization in FAME (80/20 wt \%)

\section{Chapter 5}

Figure 5.1 General reaction of the transesterification of triglyceride.

Figure 5.2 Reciprocal number-average degree of polymerization as a function of the solvent to monomer ratio for the various FAME types

Figure 5.3 Conversion versus time for canola-based FAME

Figure 5.4 Conversion versus time for soybean-based FAME

Figure 5.5 Conversion versus time for 50\% yellow grease - 50\% canola based FAME.

Figure 5.6 Conversion versus time for 50/50 wt $\%$ monomer/FAME

Figure 5.7 Weight-average molecular weight versus conversion for soybean-based FAME

Figure $5.8{ }^{\mathrm{l}} \mathrm{H}-\mathrm{NMR}$ spectrum of polystyrene in $\mathrm{CDCl}_{3}$. Polymerization was performed in canola-based FAME

Figure $5.9{ }^{1} \mathrm{H}-\mathrm{NMR}$ spectrum of polystyrene in $\mathrm{CDCl}_{3}$. Polymerization was performed in soybean-based FAME.

Figure 5.10 ${ }^{1} \mathrm{H}-\mathrm{NMR}$ spectrum of polystyrene in $\mathrm{CDCl}_{3}$. Polymerization was performed in $50 \%$ yellow grease - $50 \%$ canola-based FAME

Figure $5.11{ }^{13} \mathrm{C}\left\{{ }^{1} \mathrm{H}\right\}$-NMR spectrum of polystyrene in $\mathrm{CDCl}_{3}$. Polymerization was performed in canola-based FAME 
Figure 5.12 ${ }^{13} \mathrm{C}\left\{{ }^{1} \mathrm{H}\right\}$-NMR spectrum of polystyrene in $\mathrm{CDCl}_{3}$. Polymerization was performed in soybean-based FAME

Figure $5.13{ }^{13} \mathrm{C}\left\{{ }^{1} \mathrm{H}\right\}$-NMR spectrum of polystyrene in $\mathrm{CDCl}_{3}$. Polymerization was performed in 50\% yellow grease - 50\% canola-based FAME

Figure 6.1 Mayo plot - reciprocal number-average degree of polymerization versus the solvent/monomer ratio for Sty and MMA polymerized in canola-based FAME at 60 and $120^{\circ} \mathrm{C}$.

Figure 6.2 Sty homopolymerization in biodiesel: Conversion versus time at different solvent concentrations.

Figure 6.3 Cumulative average molecular weight versus conversion for Sty solution homopolymerization in biodiesel (50/50 wt \%).

Figure 6.4 Conversion versus time for 50/50 wt $\%$ monomer/FAME

Figure A.1 Cumulative average molecular weight versus conversion for MMA solution homopolymerization in FAME (80/20 wt \%)

Figure A.2 Cumulative average molecular weight versus conversion for MMA solution homopolymerization in FAME (60/40 wt \%)

Figure A.3 Cumulative average molecular weight versus conversion for MMA solution homopolymerization in FAME (50/50 wt \%).

Figure A.4 Cumulative average molecular weight versus conversion for Sty solution homopolymerization in FAME (80/20 wt \%)

Figure A.5 Cumulative average molecular weight versus conversion for Sty solution homopolymerization in FAME (60/40 wt \%)

Figure A.6 Cumulative average molecular weight versus conversion for Sty solution homopolymerization in FAME (50/50 wt \%)

Figure A.7 Cumulative average molecular weight versus conversion for VAc solution homopolymerization in FAME (80/20 wt \%)

Figure A.8 Cumulative average molecular weight versus conversion for VAc solution homopolymerization in FAME (60/40 wt \%) 
Figure A.9 Cumulative average molecular weight versus conversion for VAc solution homopolymerization in FAME (50/50 wt \%)

Figure A.10 Cumulative average molecular weight versus conversion for BA solution homopolymerization in FAME (80/20 wt \%).

Figure A.11 Cumulative average molecular weight versus conversion for BA solution homopolymerization in FAME (60/40 wt \%)

Figure A.12 Cumulative average molecular weight versus conversion for BA solution homopolymerization in FAME (50/50 wt \%)

Figure A.13 Conversion versus time for 60/40 wt\% monomer/FAME.................................... 117

Figure A. 14 Conversion versus time for $80 / 20 \mathrm{wt} \%$ monomer/FAME. 


\section{LIST OF TABLES}

\section{Chapter 3}

Table 3.1 Comparison of biodiesel to some polymerization solvents ....................................26

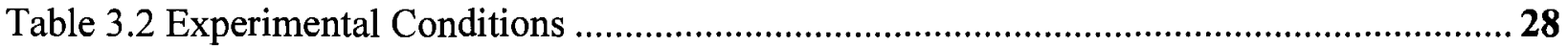

Table 3.3 Mark-Houwink Parameters for samples in tetrahydrofuran ................................... 29

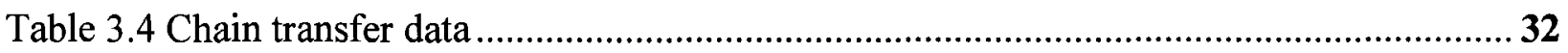

Table 3.5 Comparison of chain transfer to solvent data for different polymerization solvents.

\section{Chapter 4}

Table 4.1 Experimental conditions 50

Table 4.2 Mark-Houwink Parameters for samples in tetrahydrofuran 50

Table 4.3 Chain transfer data.

\section{Chapter 5}

Table 5.1 Comparison of polymerization solvents.

Table 5.2 Biodiesel fatty acid alkyl esters composition from commonly used feedstocks.

Carbon chain length: number of unsaturations. 75

Table 5.3 Polymerization reaction conditions .................................................................. 77

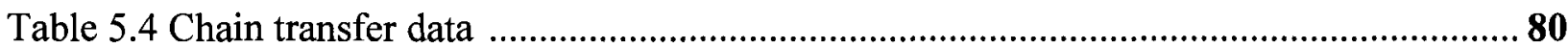




\section{NOMENCLATURE}

\section{Symbols}

$C_{f m}=$ chain transfer to monomer rate constant [dimensionless]

$C_{f s}=$ chain transfer to solvent rate constant [dimensionless]

$f=$ initiator efficiency [dimensionless]

$I=$ initiator [dimensionless]

$\mathrm{K}=$ Mark-Houwink parameter $\left[\mathrm{L} \mathrm{g}^{-1}\right]$

$k_{d}=$ initiator decomposition rate constant $\left[\mathrm{s}^{-1}\right]$

$k_{p}=$ propagation rate constant $\left[\mathrm{L} \mathrm{mol}^{-1} \mathrm{~s}^{-1}\right]$

$k_{t}=$ termination rate constant $\left[\mathrm{L} \mathrm{mol}^{-1} \mathrm{~s}^{-1}\right]$

$k_{t c}=$ termination by combination rate constant $\left[\mathrm{L} \mathrm{mol}^{-1} \mathrm{~s}^{-1}\right]$

$k_{t d}=$ termination by disproportionation rate constant $\left[\mathrm{L} \mathrm{mol}^{-1} \mathrm{~s}^{-1}\right]$

$k_{t r}=$ chain transfer to solvent rate constant $\left[\mathrm{L} \mathrm{mol}^{-1} \mathrm{~s}^{-1}\right]$

$\left[M^{\bullet}\right]=$ total concentration of all chain radicals $\left[\mathrm{mol} \mathrm{L}{ }^{-1}\right]$

$M_{n}=$ instantaneous number average molecular weight $\left[\mathrm{g} \mathrm{mol}^{-1}\right]$

$M_{w}=$ instantaneous weight average molecular weight $\left[\mathrm{g} \mathrm{mol}^{-1}\right]$

$R^{\bullet}=$ primary radical [dimensionless]

$R_{I}=$ rate of initiation $\left[\mathrm{L} \mathrm{mol}^{-1} \mathrm{~s}^{-1}\right]$

$R_{m}^{\bullet}=$ growing polymer chains size of $m$ [dimensionless]

$R_{n}^{\bullet}=$ growing polymer chains size of $n$ [dimensionless]

$R_{p}=$ rate of polymerization $\left[\mathrm{L} \mathrm{mol}{ }^{-1} \mathrm{~s}^{-1}\right]$

$R_{t}=$ rate of termination $\left[\mathrm{L} \mathrm{mol}{ }^{-1} \mathrm{~s}^{-1}\right]$ 
$[S]=$ solvent concentration $\left[\mathrm{mol} \mathrm{L}^{-1}\right]$

$\mathrm{t}=$ time $[\mathrm{s}]$

Greek Leters

$\alpha=$ Mark-Houwink parameter [dimensionless]

\section{LIST OF ABBREVIATIONS}

AIBN $=2,2$ '-azobisiso-butyronitrile

ASTM $=$ American Society for Testing and Materials

$\mathbf{B A}=$ butyl acrylate

FAME $=$ fatty acid methyl esters

$\mathbf{G P C}=$ gel permeation chromatography

MMA = methyl methacrylate

OSHA = Occupational Safety and Health Administration

PEL $=$ permissible exposure limits

Sty $=$ styrene

$\mathbf{T H F}=$ tetrahydrofuran

$\mathbf{V A c}=$ vinyl acetate

${ }^{1} \mathrm{H}-\mathrm{NMR}={ }^{1} \mathrm{H}$-nuclear magnetic resonance

${ }^{1} \mathrm{C}$-NMR $={ }^{1} \mathrm{C}$-nuclear magnetic resonance 
Chapter 1

\section{INTRODUCTION}




\subsection{SOLUTION POLYMERIZATION AND GREEN SOLVENTS}

Polymers are macromolecules made up of much smaller repeating units called monomers. They are used in a wide range of applications such as adhesives, packaging, construction materials, and coatings, to name just a few. Polymers are very versatile due to the unique properties they exhibit compare to small molecules. They can be tailored to suit particular needs by choosing proper monomer(s) and reaction conditions that will result in desired physical and chemical properties.

A number of polymer products have been traditionally been made using solution polymerization for over half a century to produce polymers with valuable properties. The use of a solvent as a polymerization media prevents increases in viscosity due to the generation of high molecular weight polymer chains by diluting the reaction mixture. This translates into improved heat transfer and prevention of thermal runaway by absorbing the heat of polymerization (Rodriguez, 1996).

Many polymer products have been developed over time, which present desirable molecular weight qualities and other final properties that can not be met by other polymerization technologies (i.e., bulk or emulsion polymerization). However, with the growing need to create a cleaner environment along with strict regulation and concerns over the volatile organic compound (VOC) of various polymer production processes, industry has been trying to find alternatives to conventional solvents. Alternatives to traditional solvents such as supercritical water and ionic liquids have been successfully employed but usually present various technical difficulties and a high cost.

In this thesis, FAME was tested for the first time as a green polymerization solvent. Biodiesel is more commonly known as an environmentally friendly alternative to 
petroleum diesel. It has the chemical structure of fatty acid alkyl esters (FAAE) and is produced by the transesterification of vegetable oils, animal fats or grease with an alcohol in the presence of a catalyst. The reaction scheme is shown in Figure 1.1.

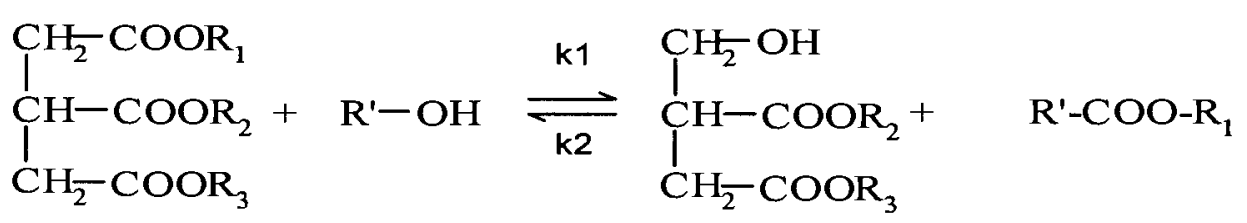

Triglyceride Alcohol Diglyceride Alkyl ester

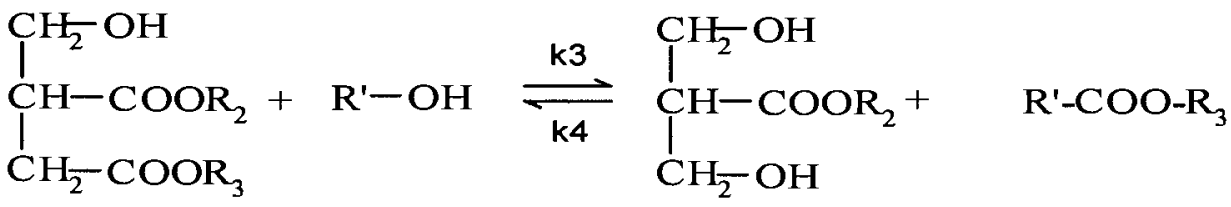

Diglyceride Alcohol Monoglyceride Alkyl ester

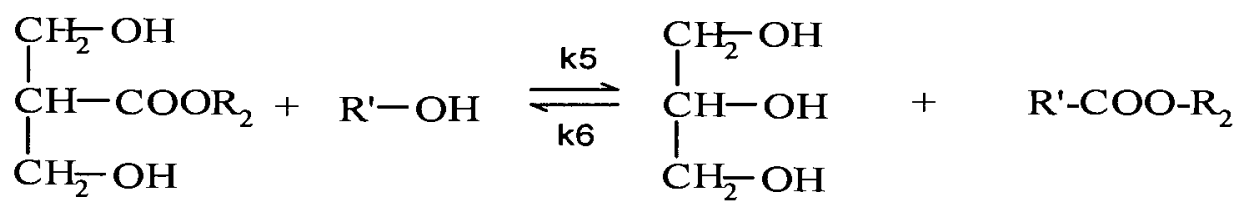

Monoglyceride Alcohol Glycerol Alkyl ester

Figure 1.1 Elementary reaction scheme for transesterification of triglyceride.

Aside from the obvious environmental benefits of using biodiesel, it has low viscosity, good solubility properties and can be obtained at reasonable price. Its high boiling point is another physical property that makes it an interesting polymerization solvent as it would enable polymerizations at elevated temperatures. There has been mounting interest in carrying out polymerizations at elevated temperatures $\left(80\right.$ to $\left.180^{\circ} \mathrm{C}\right)$ (McManus et al, 2004). Advantages of using high temperatures include:

- Reduction of potential impurities in the reaction mixture by decreasing the concentration of chain transfer agents and initiators; this would also reduce costs. 
- Increase in the rate of reaction and therefore, an increase in productivity.

- Decrease in the polymer molecular weight without using chain transfer agents.

However, there are disadvantages inherent to running the reactions at elevated temperature such as increased energy consumption, safety considerations and possible undesired side reactions that may occur, i.e., intramolecular chain transfer and depropagation (Quan et al., 2005).

Considering aforementioned advantages of using biodiesel as an alternative to traditional solvents, feasibility of biodiesel as a polymerization solvent, merits thorough investigation.

\subsection{THESIS OBJECTIVES}

The objectives of this thesis were to evaluate the suitability of biodiesel as a "green" polymerization solvent and study the effects of fatty acid methyl ester (FAME or biodiesel) on polymerization kinetics.

The first step was to use FAME from canola oil for polymerization of four commercially important monomers at $60^{\circ} \mathrm{C}$ to see if it could meet the requirements of a solution polymerization solvent. To study the effect of solvent on polymerization kinetics, chain transfer to solvent constants were studied and model predictions were performed using a free radical polymerization simulator.

The second step was to perform polymerizations at elevated temperatures and evaluate FAME as a high boiling solvent. 
The third step was to investigate the effect of FAME from different feedstocks on polymerization kinetics and study the contribution of different FAMEs to the final polymer product composition.

The collected information should help one evaluate the effect of different FAMEs on polymerization kinetics and polymer composition at different temperatures.

\subsection{THESIS OUTLINE}

This thesis is composed of three manuscripts that will be submitted for publication in refereed journals.

Chapter 2 (paper 1) demonstrates the application of FAME as a green polymerization solvent. Results from solution polymerization of four commercially important monomers (i.e, methacrylate (MMA), styrene (Sty), butyl acrylate (BA) and vinyl acetate (VAc)) along with model prediction at $60^{\circ} \mathrm{C}$ are presented.

Chapter 3 (paper 2) presents the use of FAME as a polymerization solvent at $120^{\circ} \mathrm{C}$. Results from solution polymerization of MMA, Sty, BA and VAc along with model prediction are showed.

Chapter 4 (paper 3) this chapter is an extension to Chapter 2 that presents the use of FAME as a polymerization solvent at $120^{\circ} \mathrm{C}$. Results from solution polymerization of MMA, Sty, BA and VAc along with model predictions are showed.

The final section is general discussion based on abovementioned papers and also conclusion and recommendations for future works are presented. The Appendix includes all experimental data along with model predictions, which are not included in the papers. 


\section{REFERENCES}

McManus, N.T., G. Hsieh and A. Penlidis, "Free Radical Terpolymerization of Butyl Acrylate/Methyl Methacrylate and Alpha Methyl Styrene At High Temperature", Polymer, 45, 5837 (2004)

Quan, A., M. Soroush, M.C. Grady, E. Hansen and W.J. Simonsick, "High-Temperature Homopolymerization of Ethyl Acrylate and n-Butyl Acrylate: Polymer Characterization", Macromolecules, 38, 7619 (2005)

Rodriguez, F., "Principles of Polymer Systems", 4 th ed., Taylor \& Francis, Washington, D.C., (1996), pp. 87-104. 
Chapter 2

THEORETICAL BACKGROUND 
According to modern approaches in polymerization kinetics, there are two classes of polymerization reactions: step growth polymerization (involving the elimination of small molecules by reaction of monomer(s) with functional groups) and chain growth polymerization (involving the reactions at unsaturated carbon bond site(s) on monomer(s)). A subclass of the chain growth mechanism, free radical polymerization, is of interest in this study. In this section, the mechanism of free radical homopolymerization is discussed.

\subsection{OVERVIEW OF FREE RADICAL POLYMERIZATION}

Free radical polymerization consists of a sequence of at least three steps: the formation of radicals (initiation), the growth of radicals to form long chains (propagation) and finally, the termination of these radical chains. Slow initiation, fast propagation (each growing chain has a lifetime of less that a second) and rapid termination are characteristics of free radical polymerization. In order to form long chain polymer, the rate of propagation should be significantly higher than other reaction rates (Odian, 1991).

\subsection{INITIATION}

There are many ways to form radicals, but the common method practiced industrially is the creation of highly reactive free radicals. This is accomplished by the decomposition of initiator molecules by thermal or photochemical means. The initiator, I, undergoes hemolytic decomposition and primary radicals, $R^{\circ}$, are formed. The decomposition reaction can be written as:

$$
I \stackrel{k_{d}}{\longrightarrow} 2 R^{\bullet}
$$


And the rate of initiation of new radicals, $R_{i}$, is:

$$
R_{i}=2 f k_{d}[I]
$$

Where $k_{d}$ is the temperature dependent rate constant for initiator dissociation, $f$ is the initiator efficiency and $[I]$ is the concentration of initiator. $f$ varies between $0.2-0.7$ for most initiators (Rudin, 1999). The need for an initiator efficiency term is because the radicals produced in the decomposition reaction may also undergo reactions to form neutral molecules (Odian, 1991).

Initiators are usually chosen based on their solubility, reactivity and half-life at reaction temperature. Azo-, nitrogen-based and peroxy initiators are common.

The next step of initiation involves the fast addition of the first monomer molecule to form a polymer radical (primary radical) of length $1, P_{1}^{\bullet}$

$$
R^{\bullet}+M \stackrel{k_{i}}{\longrightarrow} P_{1}^{\bullet}
$$

where $k_{i}$ represents the propagation rate coefficient for addition of monomer to an initiator fragment.

It should be noted that most monomers are stabilized with an inhibitor to prohibit any polymerization during transport. When using the monomer, if the inhibitor is not removed, it will lower the initiator efficiency by consuming free radicals. However, in practice, the effect of the inhibitor is assumed to be negligible due to the large amount of initiator used compared to the amount of inhibitor present in the monomer.

\subsection{PROPAGATION}

In this step, chain growth occurs through the sequential addition of monomer to the radical chain-end. The reaction can be written as follows: 


$$
\begin{aligned}
& P_{1}^{\bullet}+M \stackrel{k_{p}}{\longrightarrow} P_{2}^{\bullet} \\
& P_{2}^{\bullet}+M \stackrel{k_{p}}{\longrightarrow} P_{3}^{\bullet} \\
& P_{n}^{\bullet}+M \stackrel{k_{p}}{\longrightarrow} P_{n+1}^{\bullet}
\end{aligned}
$$

The rate of propagation can be expressed as

$$
R_{P}=k_{p}\left[P^{\bullet}\right][M]
$$

\subsection{TERMINATION}

Termination involves the annihilation of the radicals which results in ceasing the propagation. Termination reactions are usually very fast and under most conditions, are often diffusion-controlled. The primary termination pathway for many secondary propagating radicals such as polyacrylates and polystyrene is combination. In this case, two unstable, and hence highly reactive, radical species combine to form a single bond (see Fig. 2.2).
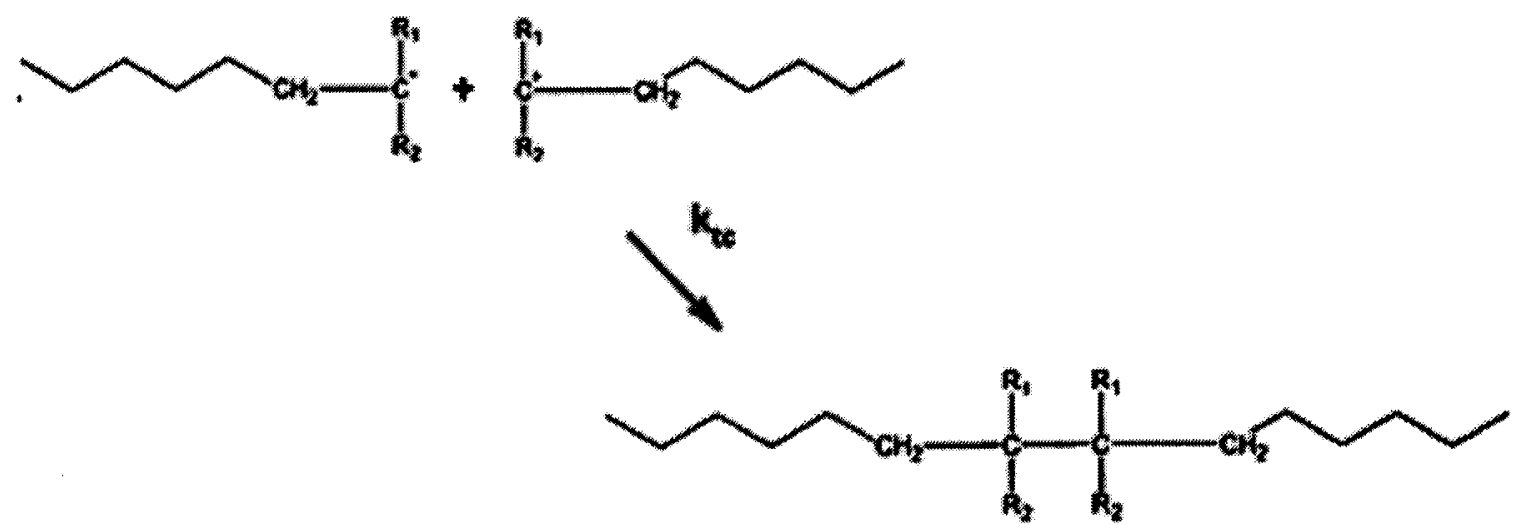

Figure 2.1 Termination by combination

The termination by combination reaction can be written as

$$
P_{n}^{\bullet}+P_{m}^{\bullet} \stackrel{k_{t c}}{\longrightarrow} D_{m+n}
$$


Where $k_{t c}$ is the rate constant for termination by combination and $D_{m+n}$ represents the dead polymer molecule of chain length $m+n$.

Another pathway for termination is disproportionation, which involves the transfer of a hydrogen atom (see Fig. 2.3).

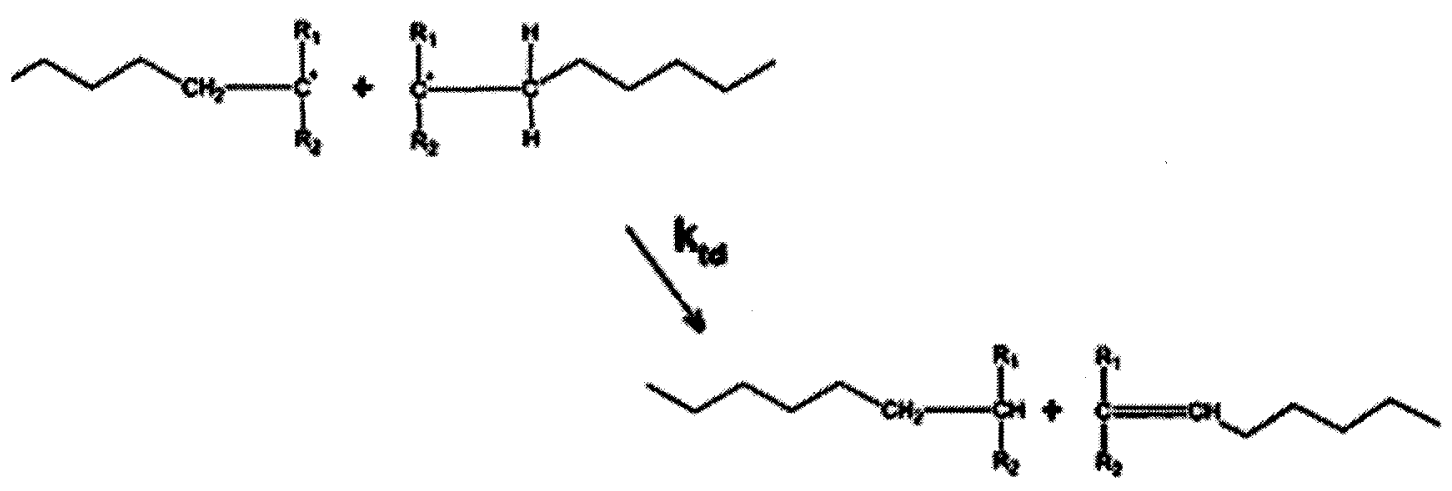

Figure 2.2 Termination by disproportionation

The termination by disproportionation reaction can be written as

$$
P_{n}^{\bullet}+P_{m}^{\bullet} \stackrel{k_{t d}}{\longrightarrow} D_{n}+D_{m}
$$

where $k_{t d}$ is the termination by disproportionation rate constant.

In many cases, termination is a mixture of combination and disproportionation. The molecular structures of the radical centers, which come into contact with each other, ascertain how much of either termination mechanism will occur. The substitution of the radical center will play a significant role; for example, tertiary radicals tend to disproportionate because of crowded radical environment, therefore, abstraction of $\beta$ hydrogen is more likely to happen. Alternatively, secondary carbon radicals tend to terminate by combination due to sterically hindered environments. 
In general, the termination process can be written as

$$
P_{n}^{\bullet}+P_{m}^{\bullet}-\frac{k_{t}}{\rightarrow} D
$$

The overall termination rate constant is a sum of the combination and disproportionation rate constants. They can be on the order of $10^{9} \mathrm{~L} / \mathrm{mol}$ 's which are typical of diffusion-controlled processes. The rate of termination, $R_{t}$, is given as

$$
R_{t}=k_{t}\left[P^{\cdot}\right]^{2}
$$

The termination rate constant, $k_{t}$, is not really constant but changes as the polymerization proceeds and the viscosity of the reaction medium increases, i.e., it is diffusion-controlled. The possibility of diffusion-controlled termination, even in very dilute solutions, has been reported (McKenna et al., 1999). Termination rate constants are usually several orders of magnitude larger than propagation rate constants but the propagation rate is usually higher than that of termination. This can be explained by comparing the rate expressions for propagation and termination (see Eqns. 2 and 3, respectively).

As long as the monomer concentration remains greater than the radical concentration, the propagation rate is much higher than the termination rate because $k_{p}[M]>>k_{t}[P]$ and the polymer chain is propagating.

The polymerization rate can be derived using a quasi-steady state assumption (Rosen, 1993), i.e., as many radicals are formed by initiation as disappear by termination $\left(R_{i}=R_{t}\right)$. Substituting the expressions in Eqns. 2 and 3, one gets:

$$
2 f k_{d}[I]=k_{t}\left[P^{\bullet}\right]^{2}
$$

Consequently, 


$$
\begin{aligned}
& {[P]=\left(\frac{2 f k_{d}[I]}{k_{t}}\right)^{1 / 2}} \\
& R_{p}=\frac{k_{p}}{k_{t}^{1 / 2}}[M]\left(f k_{d}[I]\right)^{1 / 2}
\end{aligned}
$$

$R_{p}$, as shown in Eqn. 6, above, is the classical or ideal polymerization rate, which is first order in monomer concentration. The term $k_{p} /\left(k_{t}\right)^{1 / 2}$ is a lumped constant and it can be obtained directly from experimental measurements, using simple techniques such as gravimetry. The absolute values of the rate constants can only be obtained using more complex techniques such as pulsed laser polymerization (PLP) (Hutchinson et al., 1994). However, systems with high propagation and termination rate constants are difficult to study using the PLP method (Hutchinson et al., 1994).

\subsection{CHAIN TRANSFER REACTIONS}

The growth of a polymer chain can be terminated by reactions other than termination by combination and disproportionation. A polymer radical may be terminated by atom transfer or atom abstraction reactions with subsequent propagation of the new radical species in the reaction system. The effect of such a reaction is a reduction in the polymer molecular weight

The species involved in chain transfer reactions can be monomer, polymer, initiator, solvent, chain transfer agent (a substance which is added to the reaction mixture in order to control the molecular weight), or other small molecules. These reactions can be represented with the general reaction scheme:

$$
R M_{n}^{\cdot}+X \stackrel{k_{t r, x}}{\longrightarrow} P_{n}+X^{\bullet}
$$


where $X$ can be the initiator, monomer, polymer, solvent or chain transfer agent and $k_{t r}$ is the chain transfer rate constant. The transferred radical may or may not continue propagating:

$$
X^{\bullet}+M_{i} \stackrel{k_{p}^{1}}{\longrightarrow} R_{1, i}^{\bullet}
$$

Studying the chain transfer constant, $C_{f x}$, is one conventional way to observe the effect of solvent on polymerization kinetics, where

$$
C_{f x}=\frac{k_{t r, x}}{k_{p}}
$$

In the absence of chain transfer agent and high transfer to solvent reactions, the most common form of chain transfer is transfer to monomer. VAc is one of the monomers which has considerable chain transfer to monomer and polymer constants. Acrylate monomers tend to present significant chain transfer to polymer. Since transfer to polymer leads to a new radical species on the polymer backbone, chain transfer to polymer can result in the production of branched polymer chains. The general scheme for an acrylic polymer can be seen in Figure 2.3.

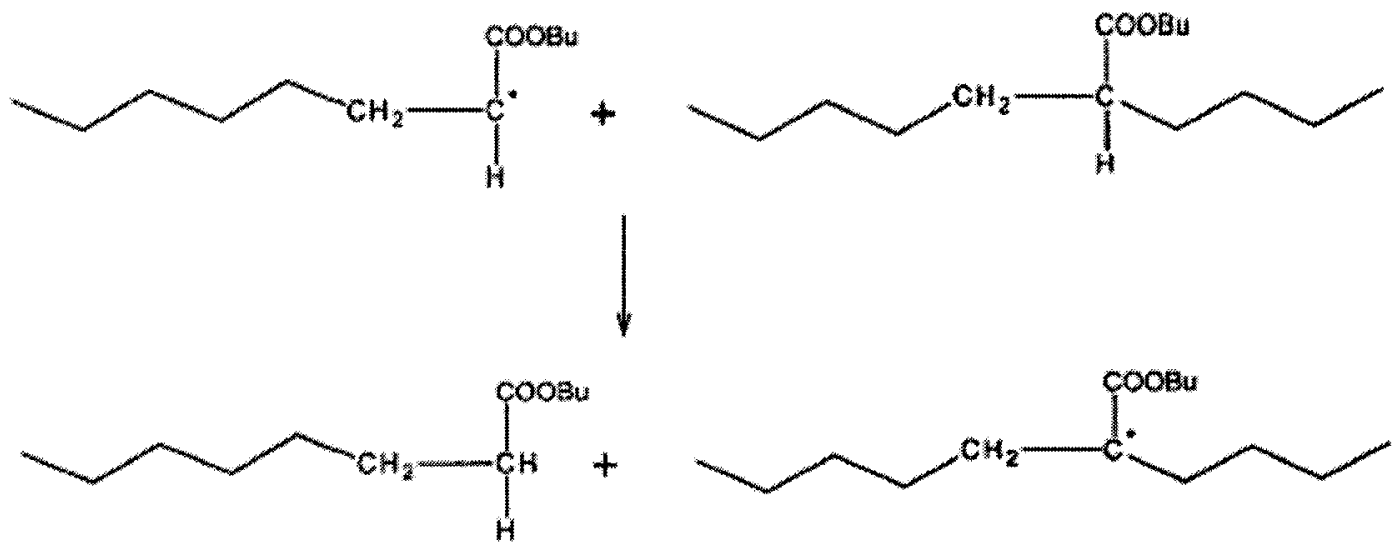

Figure 2.3 Transfer to polymer chain in an acrylic polymer (Quan et al., 2005) 
This type of transfer, which is a transfer to a different polymer molecule, is known as intermolecular transfer. The mid-chain radical can propagate and cause branched chains. Intramolecular chain transfer, also termed backbiting, refers to transfer to the backbone of the same propagating polymer chain and not to another species. This kind of transfer can occur at elevated polymerization temperatures for some monomers (e.g., acrylic monomers) and a radical of reduced propagation reactivity can be generated (Scott and Senogles, 1970).

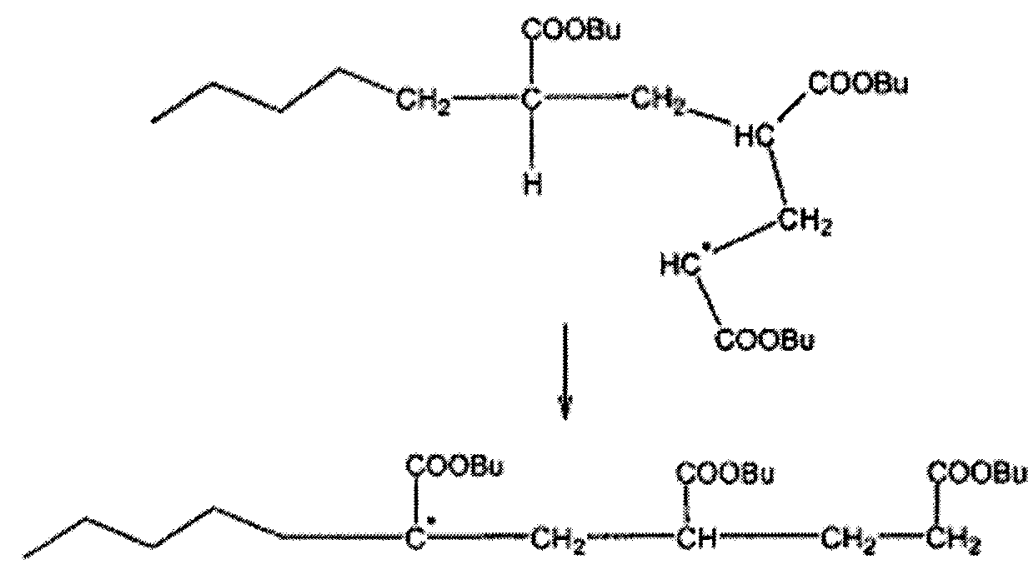

Figure 2.4 Intramolecular hydrogen abstraction (Quan et al., 2005).

In many cases, a chain transfer agent is added deliberately to the reaction mixture to control the molecular weight. Mercaptans (a.k.a. thiols) are the most common ones. The sulfur-centered radical reinitiates very efficiently. Therefore, a decrease of the molecular weight occurs without changing the overall rate of conversion of monomer to polymer.

For the case in which the chain transfer to an agent occurs but the new radical is incapable of reinitiating, the agent would be an inhibitor.Transfer to solvent can take 
place in solution polymerization, unless the solvent is inert. Transfer to solvent effectiveness depends on the solvent amount, the strength of the breaking bond, and the stability of the solvent radical formed. Transfer to solvent phenomena relate to solvent structure and reactivity. In many cases, the addition of active radical sites to monomer or polymer is thwarted since solvent radicals are usually more stable than monomer radicals. Therefore, the nature of the solvent is important. For example, benzene has a low transfer to solvent constant because of strong $\mathrm{C}-\mathrm{H}$ bonds and also transfer to solvent in this case appears to occur through the addition of the propagating radical to the benzene ring. In toluene, weaker benzylic bonds result in a higher transfer constant compared to benzene. The radical is resonance stabilized, which makes the abstraction of benzylic $\mathrm{C}-\mathrm{H}$ easier. A significant decrease in polymer chain length is found when polymerization is carried out in solution rather than in the undiluted state (Odian, 2004).

\subsection{SOLUTION POLYMERIZATION}

Free radical polymerization in solvents, known as solution polymerization, has been a traditional technique for making many polymer products (e.g., solvent-borne polymer resins), because it is compatible with an extensive variety of solvents and tolerant to a wide range of functional groups such as hydroxyls, acids and amides (Moad et al., 1990). The presence of solvent keeps the viscosity low and results in lessening of viscosity-related problems in heat transfer, processing, mixing and material handling. Solution polymerization may also present some chain transfer to solvent reactions which can regulate a polymer product's molecular weight. There are other ways to control the molecular weight such as using chain transfer agents or high initiator concentrations, 
although these approaches can present some challenges. Since initiators are expensive substances, an increase in the amount of initiator is not usually desirable. In addition, most of the chain transfer agents affect the long-term durability of the final products or cause colour and offensive smell in polymer products.

Studying the chain transfer to solvent constant, $C_{f s}$, is one conventional way to observe the effect of solvent on polymerization kinetics. Traditionally, the Mayo method (Mayo, 1943), which shows the quantitative effect of various transfer reactions on the number-average degree of polymerization, has been used.

The presence of solvent is known to present some effects on kinetic reaction rate constants and therefore on the rate of polymerization. The dilution effect of the solvent decreases the concentration of monomer, thereby decreasing the rate of polymerization. In addition, the presence of solvent may affect the propagation and termination steps in free-radical polymerization (McKenna et al., 1999). There is evidence of either a radicalsolvent or radical-monomer complex, which participates in propagation reactions and modifies the reactivity of the reactants. Regarding the effect of solvent on termination reactions, increasing the solvent concentration leads to more transfer to solvent reactions and results in shorter radicals, which move and terminate more quickly. Hence, a decrease in chain length leads to an increase in termination rate (Buback et al., 2002).However, as already mentioned, there are experimental difficulties involving the determination of absolute rate parameter (Hutchinson et al., 1994). Therefore, instead of individual rate parameters, the lumped rate parameter $\left(k_{p} /\left(k_{t}\right)^{1 / 2}\right)$ is studied in many cases, which can be obtained directly from experimental measurements, using simple techniques such as gravimetry, 


\subsection{FREE RADICAL POLYMERIZATION MODELING}

Models are important engineering tools for prediction and optimization of certain unmeasured properties and process design. Free radical polymerization modeling is based on homogenous and heterogeneous reaction scheme, molecular weight development equations and equations for mass and energy balance. In practice, most accurate models are complicated and solution of the equations can be obtained with use of numerical methods Implemented in computer codes.

There are many practical aspect of free radical polymerization modeling including segmental diffusion control model (Mahabadi and O'Driscoll, 1977), the reaction diffusion control model (Stickler et al., 1984), diffusion-controlled $k_{t}$ and its chain length dependency (Russell et al., 1992) which have been summarized by Dubé et al. (1997) and Gao and Penlidis (1996).

In this thesis the collected kinetic experimental data are modeled using a comprehensive visual basic-based model (WATPOLY polymerization simulator), developed by Gao and Penlidis (1996) for bulk/solution free radical polymerization.

\section{REFERENCES}

Beuermann, S. and M. Buback, "Rate Coefficients of Free-Radical Polymerization Deduced from Pulsed Laser Experiments", Prog. Polym. Sci., 27, 191 (2002)

Clay, P.A. and R.G. Gilbert, "Molecular Weight Distributions in Free-Radical Polymerizations.1. Model Development and Implications for Data Interpretation", Macromolecules, 28, 552 (1995) 
Dubé, M.A., J.B.P. Soares, A. Penlidis and A.E. Hamielec, "Mathematical Modeling of Multicomponent Chain-Growth Polymerizations in Batch, Semibatch, and Continuous Reactors: A Review", Ind. Eng. Chem. Res., 36, 966 (1997)

Gao, J. and A. Penlidis, "A Comprehensive Simulator/Database Package for Reviewing Free-Radical Homopolymerizations" J. Macromol. Sci. Rev. Macromol. Chem. Phys., 36, 199 (1996)

Heuts, J.P.A., T.P. Davis and G.T. Russell, "Comparison of the Mayo and Chain Length Distribution Procedures for the Measurement of Chain Transfer Constant", Macromolecules, 32, 6019 (1999)

Hutchinson, R.A., J.R. Richards and M.T. Aronson, "Determination of Propagation Rate Coefficients by Pulsed-Laser Polymerization for Systems with Rapid Chain Growth: Vinyl Acetate", Macromolecules, 27, 4530 (1994)

Mahabadi, K. and K.F. O'Driscoll, "Termination Rate Constant in Free-Radical Polymerization", J. Polym. Sci., Polym. Chem. Ed., 15, 283 (1977)

Mayo, F.R., "Chain Transfer in the Polymerization of Styrene: The Reaction of Solvents with Free Radicals", J. Amer. Chem. Soc. 65, 2324 (1943)

McKenna, T.F., A. Villanueva and M. Santos, "Effect of Solvent on the Rate Constants in Solution Polymerization. Part I. Butyl Acrylate”, J. Polym. Sci. Polym. Chem., 37, 589 (1999)

Moad, G., D.H Solomon, "Understanding and Controlling Radical Polymerization" J. Chem., 43, 215 (1990)

Odian, G., "Principles of Polymerization", $4^{\text {th }}$ Ed., John Wiley and Sons, Inc. (2004)

Rosen, S.L., "Fundamental Principles of Polymeric Materials," $2^{\text {nd }}$ Ed., Wiley Interscience, (1993) 
Rudin, A. "The Elements of Polymer Science and Engineering", 2 nd Ed. Academic Press. (1999)

Russell, G.T., R.G. Gilbert and D.H. Napper, "Chain-Length-Dependent Termination Rate Processes in Free-Radical Polymerizations. 1. Theory", Macromolecules, 25, 2459 (1992)

Scott, G.E. and E. Senogles, "Polymerization Kinetics of n-Lauryl Acrylate", Macromol. Sci. Chem., 4(5), 1105 (1970)

Stickler, M., D. Panke and A.E. Hamielec, "Polymerization of Methyl Methacrylate up to High Degrees of Conversion: Experimental Investigation of Diffusion-controlled Polymerization", J. Polym. Sci., Polym. Chem., 22, 2243 (1984) 
Chapter 3

\section{PAPER I}




\title{
Biodiesel: A Green Polymerization Solvent
}

\author{
Somaieh Salehpour, Marc A. Dubé* \\ Department of Chemical Engineering, University of Ottawa, \\ 161 Louis Pasteur St., Ottawa, ON, K1N 6N5 Canada \\ *Marc.Dube@uOttawa.ca
}

In an effort to use clean technologies, fatty acid methyl esters (FAME) produced from canola has been used as a polymerization solvent. Solution polymerizations of four commercially important monomers have been studied using FAME as a solvent. A series of methyl methacrylate (MMA), styrene (Sty), butyl acrylate (BA) and vinyl acetate (VAc) homopolymerizations in FAME was carried out at $60^{\circ} \mathrm{C}$ at different solvent concentrations.

Chain transfer to solvent rate constants were obtained using the Mayo method. The transfer constants increased in the order: MMA $<$ Sty $<$ BA $<$ VAc. Under the conditions studied, the MMA solution polymerization in FAME was observed to behave as a precipitation polymerization. The estimated chain transfer to solvent rate constants were employed in a polymerization simulator to predict the polymerization rates and average molecular weights. 


\section{INTRODUCTION}

The solution polymerization method, an important polymer production technology, has faced several ecological criticisms in the last decade. Many of the solvents which are used in this technique are known to have a negative impact on our ecosystem by diminishing the ozone layer and participating in reactions that form tropospheric pollution. Moreover, they can cause cancer, infertility and genetic disorders in individuals frequently exposed to them (Sherman et al., 1998).One of the ways to avoid some of these side effects is to use technologies which do not employ solvents such as bulk polymerization, although other difficulties can arise. For example, the presence of solvent keeps the viscosity low as polymers are formed, which translates into improved heat transfer and prevention of thermal runaway. Solution polymerization may also present some chain transfer to solvent reactions which can have an impact on the polymer product's molecular weight. Emulsion polymerization can be an attractive alternative to solution polymerization although desirable end-use properties are not always achieved (Jovanović and Dubé, 2004). Therefore, the superior properties of polymers prepared by solution polymerization suggest that rather than altering the polymerization technology, one could look for more environmentally friendly solvents to replace more harmful conventional solvents (Hu et al., 2004).

The choice of polymerization solvent is influenced by a number of issues. It should be non-toxic and reasonably non-hazardous, but versatile. Water as a nontoxic, inexpensive and abundantly available solvent is a good candidate, but its polarity makes it extremely difficult to be a substitute for organic solvents because of solubility issues. Recently, non-classical solvents such as supercritical fluids have been considered as an alternative media (Duan et al., 2006). 
Supercritical water and carbon dioxide were investigated as green solvents for polymerization (DeSimone, 2002). In view of the fact that water exists in the supercritical state at temperatures above $647 \mathrm{~K}$ and pressures above $217 \mathrm{~atm}(21987 \mathrm{kPa})$, it can perform as a non-polar solvent mainly due to the absence of hydrogen bonding under these extreme conditions. However, implementation of this technology can cause corrosion problems. Considering economic reasons, one can surmise that supercritical water may not be a convenient solvent alternative (DeSimone, 2002).

With growing concerns over the volatile organic content (VOC) of common solvents, ionic liquids have attracted attention as an environmentally friendly alternative (Kubisa, 2004). I onic liquids are organic salts which are in the liquid state at ambient temperatures. Ionic liquids are composed of ions, unlike conventional solvents which are molecular liquids; i.e., chloro-aluminate compounds such as 1-butylpyridinium chloride/aluminium(III) chloride mixture can exist at room temperature with very low vapor pressures (Seddon, 1996) In general, ionic liquids are not miscible with many organic solvents, particularly when the latter are non-polar, such as hexane (Yang and Pan, 2005). However, there is appreciable cynicism and uncertainty surrounding their use because they cannot be considered environmentally friendly simply due to their low volatility (DeSimone, 2002). Ionic liquids have yet to be commonly applied in industry, perhaps because of their high cost and the lack of data concerning their toxicity and biodegradability (Sheldon, 2005).

Another interesting alternative to conventional polymerization solvents is biodiesel. While primarily used as an environmentally friendly alternative or extender to petroleum diesel as a fuel source, some studies have been done on the solvent power of biodiesel (Hu et al., 2004). Biodiesel is environmentally benign, has a low volatility and is 
also a renewable material with low viscosity and good solubility properties. Based on the definition of the American Society for Testing and Materials (ASTM), biodiesel can be defined as alkyl esters of long chain fatty acids derived from a lipid feedstock. The most common method to produce biodiesel is via base-catalyzed transesterification of vegetable oils and animal fats with an alcohol (Mittelbach et al., 2004). Typically, methanol is the alcohol of choice, and the resulting esters are fatty acid methyl esters (FAMEs). The C16-18 methyl esters that comprise the largest part of biodiesel are readily biodegradable due to their chemical nature and can be domestically produced and obtained at a competitive price (Zhang et al., 2003).

The Occupational Safety and Health Administration (OSHA) in the United States reports permissible exposure limits (PEL) for chemical concentrations to which one may be exposed with no harmful health effects (Sherman et al., 1998). In Table 3.1, the toxicity, PEL values and approximate prices for biodiesel and some common polymerization solvents are shown.

There are no reported uses of biodiesel as a polymerization solvent. A major component of biodiesel, methyl oleate, has previously been used as a polymerization solvent in the 1960's (Jordan et al., 1969). However, pure methyl oleate comes at a high cost. In the work presented here, the application of FAME as a polymerization solvent is reported for four commercially important monomers: methyl methacrylate (MMA), styrene (Sty), butyl acrylate (BA) and vinyl acetate (VAc). Chain transfer to solvent rate constants are also estimated. Finally, the collected kinetic experimental data are modeled using the WATPOLY polymerization simulator (Gao and Penlidis, 1996). 
Table 3.1 Comparison of biodiesel to some polymerization solvents

\begin{tabular}{|l|l|c|c|}
\hline \multicolumn{1}{|c|}{ Solvent } & \multicolumn{1}{|c|}{ Toxicity } & $\begin{array}{c}\text { OSHA PEL 8h } \\
\text { ppm }\end{array}$ & $\begin{array}{c}\text { Price } \\
\text { US } \$ / \mathrm{L}\end{array}$ \\
\hline Toluene $^{\mathrm{a}}$ & $\begin{array}{l}\text { Narcotic, liver and } \\
\text { kidney damage in } \\
\text { high concentration }\end{array}$ & 200 & 35.00 \\
\hline Benzene $^{\mathrm{a}}$ & Carcinogen & 10 & 49.00 \\
\hline Ethyl acetate $^{\mathrm{a}}$ & $\begin{array}{l}\text { Narcotic, liver and } \\
\text { kidney damage at } \\
\text { high concentrations }\end{array}$ & 400 & 46.00 \\
\hline Xylene $^{\mathrm{a}}$ & $\begin{array}{l}\text { Narcotic at high } \\
\text { concentrations }\end{array}$ & 100 & 43.00 \\
\hline Methyl Oleate $^{\mathrm{a}}$ & $\begin{array}{l}\text { Non-hazardous } \\
\text { material }\end{array}$ & None & 1200.00 \\
\hline Biodiesel $^{\mathrm{b}}$ & $\begin{array}{l}\text { Non-hazardous } \\
\text { material }\end{array}$ & None & 0.60 \\
\hline
\end{tabular}

a) Sigma-Aldrich anhydrous, 99+\%, MSDS. Toxicity information from (Budavari et al., 1989: Sitting, 1991).

b) Toxicity information from (Mittelbach et al., 2004).

\section{EXPERIMENTAL METHODS}

The monomers MMA, BA, VAc and Sty (Sigma-Aldrich, Milwaukee, WI) were received inhibited by $0.05 \mathrm{ppm}$ hydroquinone. To remove the inhibitor, VAc was solely distilled under vacuum while BA, MMA and Sty were washed 3 times with a $10 \%(\mathrm{v} / \mathrm{v})$ sodium hydroxide solution, then washed 3 times with distilled de-ionized water and dried over calcium chloride prior to vacuum distillation. Distillations were completed a maximum of $24 \mathrm{~h}$ prior to polymerization, and the monomers were stored at $-10^{\circ} \mathrm{C}$.

The initiator 2,2-azobisisobutyronitrile (AIBN, DuPont Chemicals) was recrystallized 3 times in absolute methanol. FAME was obtained by transesterification of 
canola oil (No Name ${ }^{\circledR}$ ) with methanol (Commercial Alcohols Inc.) in the presence of sodium hydroxide catalyst in a membrane reactor process (Dubé et al., 2007). The FAME product from the reactor was washed 5 times with de-ionized water and distilled under vacuum to remove the water. Hexane and methanol (Sigma-Aldrich) and all other solvents used for sample characterization were employed without further purification.

\section{Procedures}

Polymerizations were performed in sealed glass ampoules $(17-\mathrm{cm}$ length, $0.8-\mathrm{cm}$ outer diameter) at $60^{\circ} \mathrm{C}$ in a water bath. The feed was prepared by weighing the monomer, FAME solvent and initiator into a flask and delivered into a series of 5-mL glass ampoules. The same ratio of initiator to monomer, $0.4 \mathrm{phm}$ (parts per 100 parts by weight of monomer) of initiator was utilized for all concentrations of monomers. The ampoules were degassed by several freeze-pump-thaw cycles under high vacuum, were flame sealed and then submerged in a constant temperature water bath. At the appropriate time interval, ampoules were removed from the bath and quenched in an ice bath to stop the reaction. The ampoules were broken and the contents poured into a pre-weighed beaker. The solution was diluted with $5 \mathrm{~mL}$ of acetone. The extraction of polymer was done by precipitation in hexane (for MMA, VAc and Sty) and in methanol (for BA) at room temperature. The polymer/monomer/FAME solution was added slowly to the nonsolvent (i.e., hexane or methanol) while stirring and generally appeared as a fine white fiber or a milky dispersion. After settling $(\sim 24 \mathrm{~h})$, and decantation and evaporation of the non-solvent, extracted polymer was dried in a vacuum oven at $40^{\circ} \mathrm{C}$ until a constant weight was reached. The solution polymerization experimental conditions are summarized in Table 3.2 . 
Conversion was calculated by gravimetry. The cumulative number- and weightaverage molecular weights were determined using a Waters Associates gel permeation chromatograph equipped with a Waters model 410 refractive index detector. Three Waters Ultrastyragel packed columns $(103,104$, and $106 \AA)$ were installed in series. THF was filtered and used as the eluent at a flow rate of $0.3 \mathrm{~mL} / \mathrm{min}$ at $38^{\circ} \mathrm{C}$. The Universal calibration method was used with 10 standard samples of polystyrene (SHODEX, Showa, Denko, Tokyo, Japan) with peak molecular weights between $1.3 \times 10^{3}$ and $3.15 \times 10^{6}$ $\mathrm{g} / \mathrm{mol}$. Standards and samples were prepared in THF $0.2 \%(\mathrm{w} / \mathrm{v})$ solutions and filtered prior to injection through $0.45-\mu \mathrm{m}$ PTFE filters to remove any gel or impurity, if present. Millennium $32^{\mathrm{TM}}$ software (Waters) was used for data acquisition. The Mark-Houwink parameters used as part of the universal calibration technique are given in Table 3.3.

Table 3.2 Experimental Conditions

\begin{tabular}{|c|c|c|}
\hline Monomer & Experiment & $\begin{array}{c}\text { Monomer/FAME } \\
\text { (wt.-\%) }\end{array}$ \\
\hline \multirow{3}{*}{ Methyl methacrylate } & M1 & $50 / 50$ \\
\cline { 2 - 3 } & M2 & $60 / 40$ \\
\cline { 2 - 3 } Styrene & M3 & $80 / 20$ \\
\hline & S1 & $50 / 50$ \\
\cline { 2 - 3 } & S2 & $60 / 40$ \\
\cline { 2 - 3 } & S3 & $80 / 20$ \\
\hline \multirow{3}{*}{ Vinyl acetate } & V1 & $50 / 50$ \\
\cline { 2 - 3 } & V2 & $60 / 40$ \\
\cline { 2 - 3 } & V3 & $80 / 20$ \\
\hline \multirow{3}{*}{ Butyl acrylate } & B1 & $50 / 50$ \\
\cline { 2 - 3 } & B2 & $60 / 40$ \\
\cline { 2 - 3 } & B3 & $80 / 20$ \\
\hline
\end{tabular}


Table 3.3 Mark-Houwink Parameters for samples in tetrahydrofuran.

\begin{tabular}{|c|c|c|}
\hline Polymer & $\mathrm{K}\left(\times 10^{3} \mathrm{~mL}^{-1} \mathrm{~g}^{-1}\right)$ & $a$ \\
\hline Poly(butyl acrylate) ${ }^{\mathrm{a}}$ & 11 & 0.708 \\
\hline Poly(vinyl acetate) ${ }^{b}$ & 15.6 & 0.708 \\
\hline Poly(methyl methacrylate) & 12.8 & 0.690 \\
\hline Polystyrene $^{b}$ & 16 & 0.700 \\
\hline
\end{tabular}

${ }^{a}$ McKenna and Villanueva, 1999

${ }^{\mathrm{b}}$ Brandrup et al., 1999

\section{RESULTS AND DISCUSSION}

The presence of solvent is known to present some effect on kinetic reaction rate constants and therefore on the rate of polymerization. Studying the chain transfer to solvent constant, $C_{f s}$, is one conventional way to observe the effect of solvent on polymerization kinetics, where

$$
C_{f s}=\frac{k_{f s}}{k_{p}}
$$

$k_{f s}$ is the chain transfer to solvent rate parameter and $k_{p}$ is the propagation rate parameter.

Various methods can be employed to determine the value of $C_{f s}$ (Heuts et al., 1999). Traditionally, the Mayo method (Mayo, 1943), which shows the quantitative effect of various transfer reactions on the number-average degree of polymerization, has been used. This method is based on overall chain growth and chain stopping rates under the assumption of steady state and uses the long-chain approximation (Heuts et al., 1999). An 
alternative is the CLD method, which has been developed by Gilbert and co-workers (Clay and Gilbert, 1995). This latter procedure is based on the calculation of the high molecular weight slope for the number molecular weight distribution. Both procedures yield very similar results, especially in chain transfer-dominated systems (Heuts et al., 1999). In the work presented here, transfer constants were obtained using the Mayo equation (Odian, 2004):

$\frac{1}{\bar{X}_{n}}=\frac{k_{t} R_{p}}{k_{p}^{2}[M]^{2}}+C_{f m}+C_{f s} \frac{[S]}{[M]}+C_{f_{i}} \frac{k_{t} R_{p}^{2}}{k_{p}^{2} f k_{d}[M]^{3}}$

where $\bar{X}_{n}$ is the number-average degree of polymerization, $R_{p}$ is the rate of polymerization, $k_{t}, k_{p}$ and $k_{d}$ are the termination, propagation and initiator decomposition rate coefficients, respectively. $f$ is the initiator efficiency, $[M]$ and $[S]$ are the concentration of the monomer and solvent, respectively, and $C_{f m}, C_{f s}$ and $C_{f \hat{i}}$ are the transfer constants to monomer, solvent and initiator, respectively.

On the right hand side of Eqn. 2, the first term represents the contribution of the rate of polymerization and termination, the second term corresponds to the effect of transfer to monomer on polymer chain size, the third term describes the role of transfer to solvent reactions and the last term expresses contributions of the initiator. In our case, the third term on the right hand side of Eqn. 2 makes the biggest contribution to the degree of polymerization. By using low concentrations of initiator or initiators with very small $C_{f i}$ values (e.g., AIBN), the last term in Eqn. 2 becomes negligible and rate retardation becomes minimal (Odian, 2004). In addition, by keeping $k_{t} R_{p} /[M]^{2}$ constant, the first term on the right hand side may be kept constant by adjusting the initiator concentration over a series of separate polymerizations. Nonetheless, this term will change with changes in 
$[S] /[M]$ because the termination rate parameter, $k_{t}$, is chain length dependent and will vary due to the effect of $[\mathrm{S}] /[\mathrm{M}]$ on the average chain length. This is a weakness of the Mayo method; however, the effect is not significant for all practical purposes (Heuts et al., 1999). Under these conditions, Eqn. 2 is reduced to

$$
\frac{1}{\bar{X}_{n}}=\frac{1}{\bar{X}_{n 0}}+C_{f s} \frac{[S]}{[M]}
$$

where $\left(1 / \bar{X}_{n 0}\right)$ is the value of $\left(1 / \bar{X}_{n}\right)$ in the absence of solvent. The value of $C_{f s}$ is obtained from the slope of the line by plotting $\left(1 / \bar{X}_{n}\right)$ versus $[S] /[M]$. All data regarding the calculation of $C_{f s}$ for each monomer are given in Table 3.4. The corresponding Mayo plots are given in Figure 3.1 .

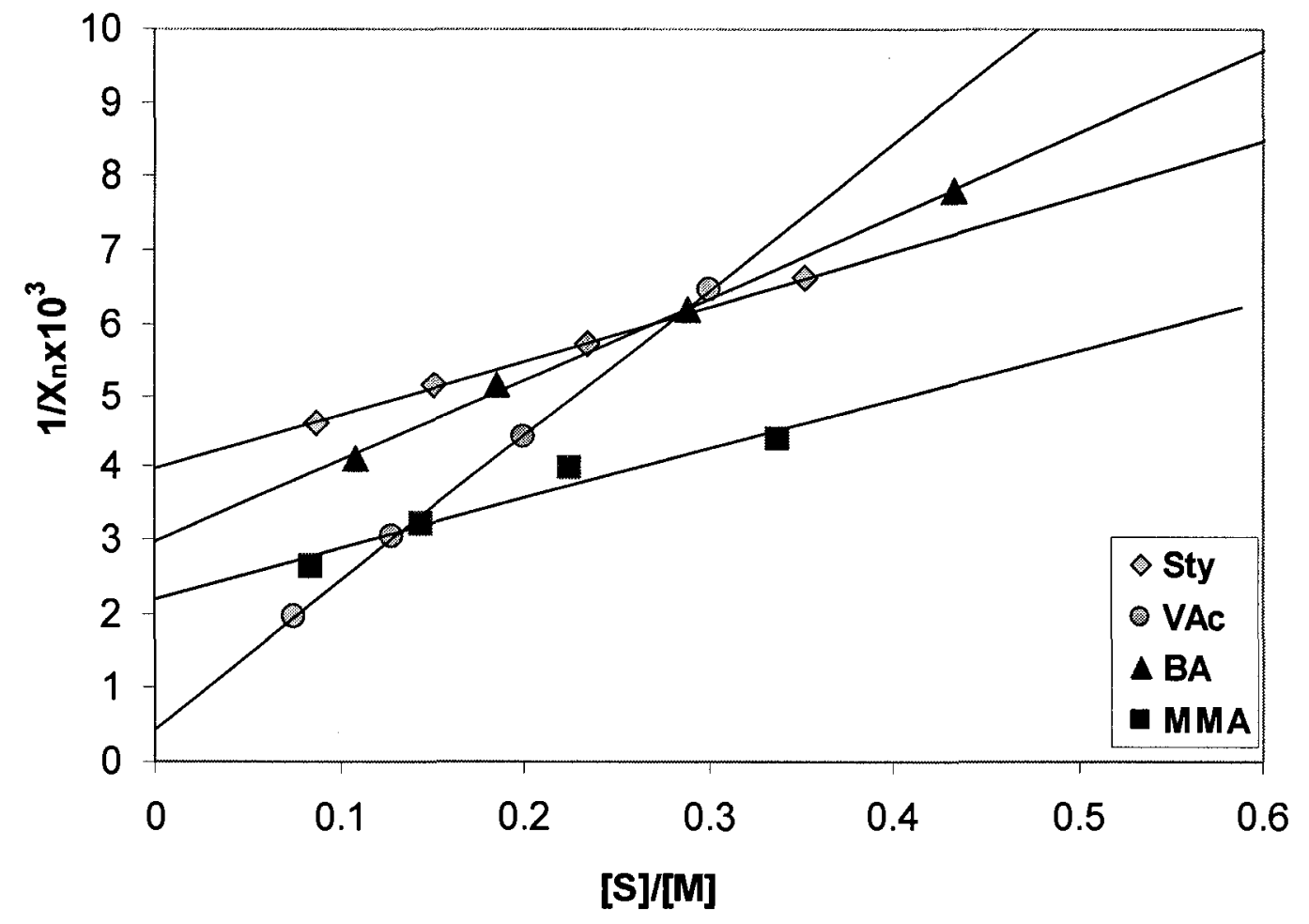

Figure 3.1 Mayo plot - reciprocal number-average degree of polymerization versus the solvent/monomer ratio for the monomers polymerized in FAME. 
Table 3.4 Chain transfer data

\begin{tabular}{|c|c|c|c|c|c|}
\hline Experiment & $\bar{M}_{n}$ & $1 / \bar{X}_{n} \times 10^{3}$ & {$[S] /[M]$} & $\begin{array}{c}\text { Conversion } \\
\text { (wt.-\%) }\end{array}$ & $C_{f s} \times 10^{4}$ \\
\hline \multicolumn{6}{|c|}{ Methyl methacrylate, AIBN/monomer $=0.4 \mathrm{phm}$} \\
\hline M1 & 22906 & 4.3722 & 0.3383 & 9.96 & 68.79 \\
\hline M2 & 25201 & 3.9740 & 0.2255 & 10.37 & \\
\hline M3 & 31250 & 3.2000 & 0.1450 & 8.74 & \\
\hline M4 & 37892 & 2.6430 & 0.0846 & 9.96 & \\
\hline \multicolumn{6}{|c|}{ Styrene, AIBN/monomer $=0.4 \mathrm{phm}$} \\
\hline $\mathrm{S} 1$ & 15724 & 6.6237 & 0.3518 & 8.27 & 74.88 \\
\hline $\mathrm{S} 2$ & 18212 & 5.7188 & 0.2346 & 11.74 & \\
\hline S3 & 20187 & 5.1593 & 0.1508 & 9.17 & \\
\hline $\mathrm{S} 4$ & 22500 & 4.6219 & 0.0879 & 9.12 & \\
\hline \multicolumn{6}{|c|}{ Vinyl acetate, $\mathrm{AIBN} / \mathrm{monomer}=0.4 \mathrm{phm}$} \\
\hline V1 & 13764 & 6.4723 & 0.3010 & 10.25 & 190.98 \\
\hline $\mathrm{V} 2$ & 20219 & 4.4061 & 0.2006 & 8.35 & \\
\hline V3 & 29490 & 3.0210 & 0.1290 & 11.24 & \\
\hline V4 & 45663 & 1.9510 & 0.0752 & 8.36 & \\
\hline \multicolumn{6}{|c|}{ Butyl acrylate, AIBN $/$ monomer $=0.4 \mathrm{phm}$} \\
\hline B1 & 16409 & 7.8002 & 0.4329 & 10.23 & 110.20 \\
\hline $\mathrm{B} 2$ & 20607 & 6.2112 & 0.2886 & 12.30 & \\
\hline B3 & 24781 & 5.1652 & 0.1855 & 8.99 & \\
\hline B4 & 31184 & 4.1046 & 0.1082 & 11.20 & \\
\hline
\end{tabular}


All polymers except pMMA were soluble in FAME and the values of the chain transfer constant for any compound increased in order: MMA $<$ Sty $<$ BA $<$ VAc. This matches the order of increased resonance stabilization by the particular substituent of the radical produced from the monomer (Odian, 2004).

Chain transfer values were all larger than that for polymerization in conventional solvents such as toluene or benzene. Transfer constants for these and some other polymerization solvents are shown in Table 3.5.

This corresponds to a major issue in transfer to solvent phenomena which relates to solvent structure and reactivity. In many cases, the addition of active radical sites to monomer is thwarted since solvent radicals are more stable than monomer radicals. Therefore, the nature of the solvent is important. For example, benzene has a low $C_{f s}$ value (see Table 3.5) because of strong $\mathrm{C}-\mathrm{H}$ bonds and also transfer to solvent in this case appears to occur through the addition of the propagating radical to the benzene ring. In toluene, weaker benzylic bonds result in a higher $C_{f s}$ value compared to benzene (see Table 3.5). The radical is resonance stabilized, which makes the abstraction of benzylic $\mathrm{C}-\mathrm{H}$ easier. On the other hand, esters like FAMEs would be expected to have higher transfer constants compared to aliphatic and aromatic hydrocarbons because of $\mathrm{C}-\mathrm{-H}$ breakage and stabilization of the radical by an adjacent carbonyl group.

As expected, the cumulative number-average molecular weights increased by decreasing the solvent concentration (see Table 3.4). The molecular weight was higher at low MMA conversions compared to the other systems at the same stage of reaction. This can be due to the effect of delayed termination in the precipitation polymerization mechanism. (Eastwood, 1967). For pVAc, low molecular weight polymer was produced 
because of a high rate of transfer to solvent (i.e., $C_{f s}=190.98 \times 10^{4}$ ) which is an effect of low monomer reactivity in addition to the high transfer to monomer rate constant (Jordan et al., 1969).

Table 3.5 Comparison of chain transfer to solvent data for different polymerization solvents.

\begin{tabular}{|l|c|c|c|c|}
\hline \multirow{2}{*}{ Solvent } & \multicolumn{4}{|c|}{$C_{f s} \times 10^{4}$ for polymerization of } \\
\cline { 2 - 5 } & MMA & Sty & VAc & BA \\
\hline Benzene $^{\mathrm{a}}$ & 0.83 & 0.023 & 6 & 0.4 \\
\hline Toluene $^{\mathrm{a}}$ & 0.96 & 0.125 & 35 & 1.8 \\
\hline Methyl Oleate $^{\mathrm{b}}$ & 1.68 & 3.52 & 217 & - \\
\hline Xylene $^{\mathrm{a}}$ & 0.50 & 0.78 & 140 & - \\
\hline FAME & 68.79 & 74.88 & 190.98 & 110.20 \\
\hline
\end{tabular}

${ }^{a}$ Brandrup et al., 1999.

${ }^{b}$ Jordan et al., 1969

In Figures 3.2 through 3.5, conversion vs. time data are shown for the four different monomers at three different solvent concentrations, along with model predictions from the WATPOLY simulator (Gao and Penlidis, 1996). The parameters for the FAME, which include physical property data and the estimated $C_{f s}$ values, were added to the simulator's database. The model was fitted to the experimental conversion and molecular weight data by changing the lumped rate parameter $\left(k_{p} / k_{t}^{1 / 2}\right)$ for each individual monomer concentration. As can be seen in Figures 3.2 through 3.5, within 
experimental error, the model demonstrates reliable predictions in almost all cases using a single lumped parameter for each monomer. The value of the modified parameters $\left(k_{p} / k_{t}^{1 / 2}\right)$ were $0.2,0.24$ and 0.31 for VAc and $1.09,1.16$ and 1.22 for BA at 50,40 and 20 wt.\% concentration of solvent, respectively, while it was kept constant at 0.39 for Sty and 1.16 for MMA at all solvent concentrations. This indicates different effects of solvent on propagation and termination rate constants for each individual monomer. All molecular weight data along with model predictions are presented in Appendix. 


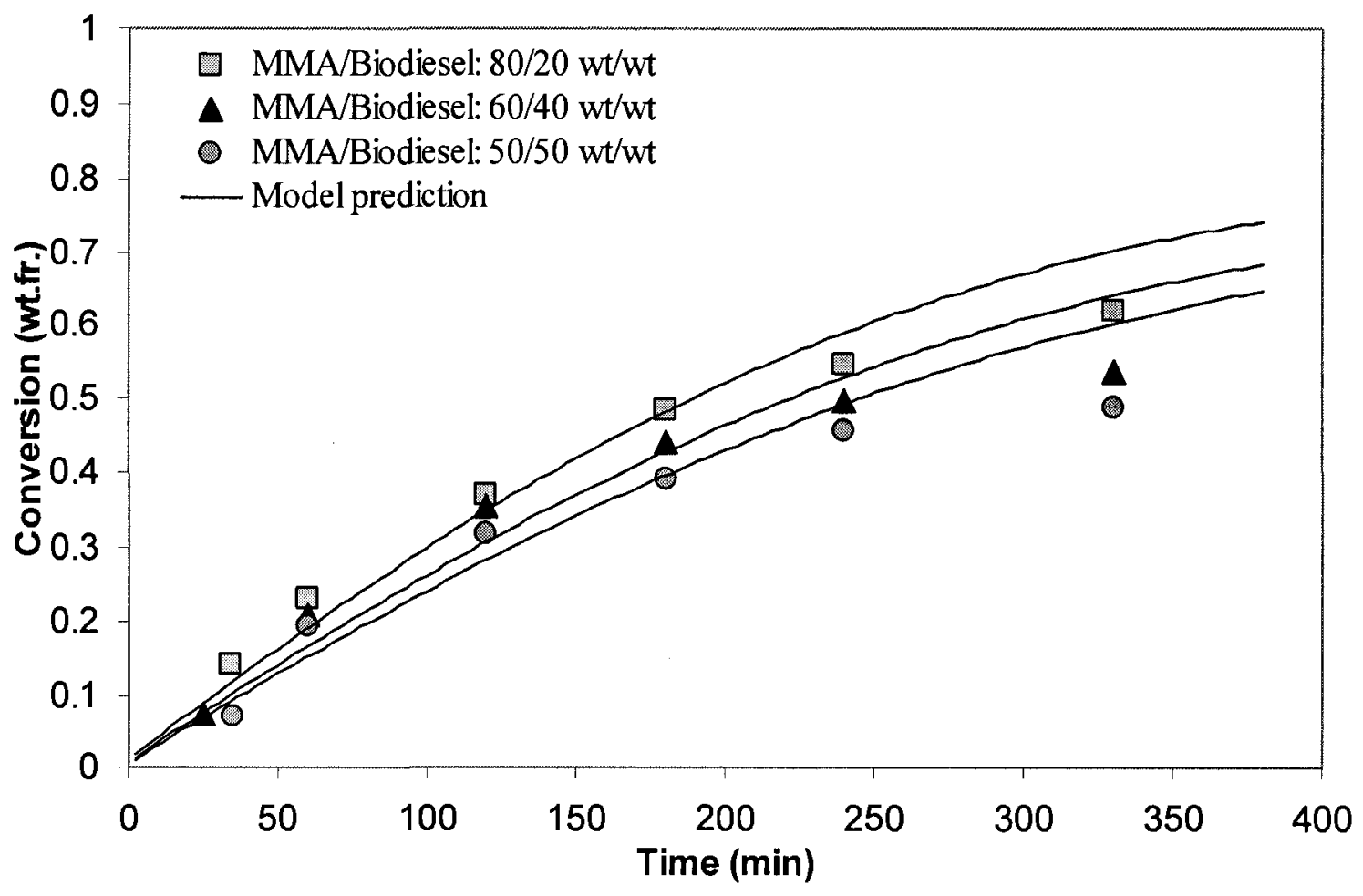

Figure 3.2 MMA homopolymerization in FAME: Conversion versus time at different solvent concentrations. 


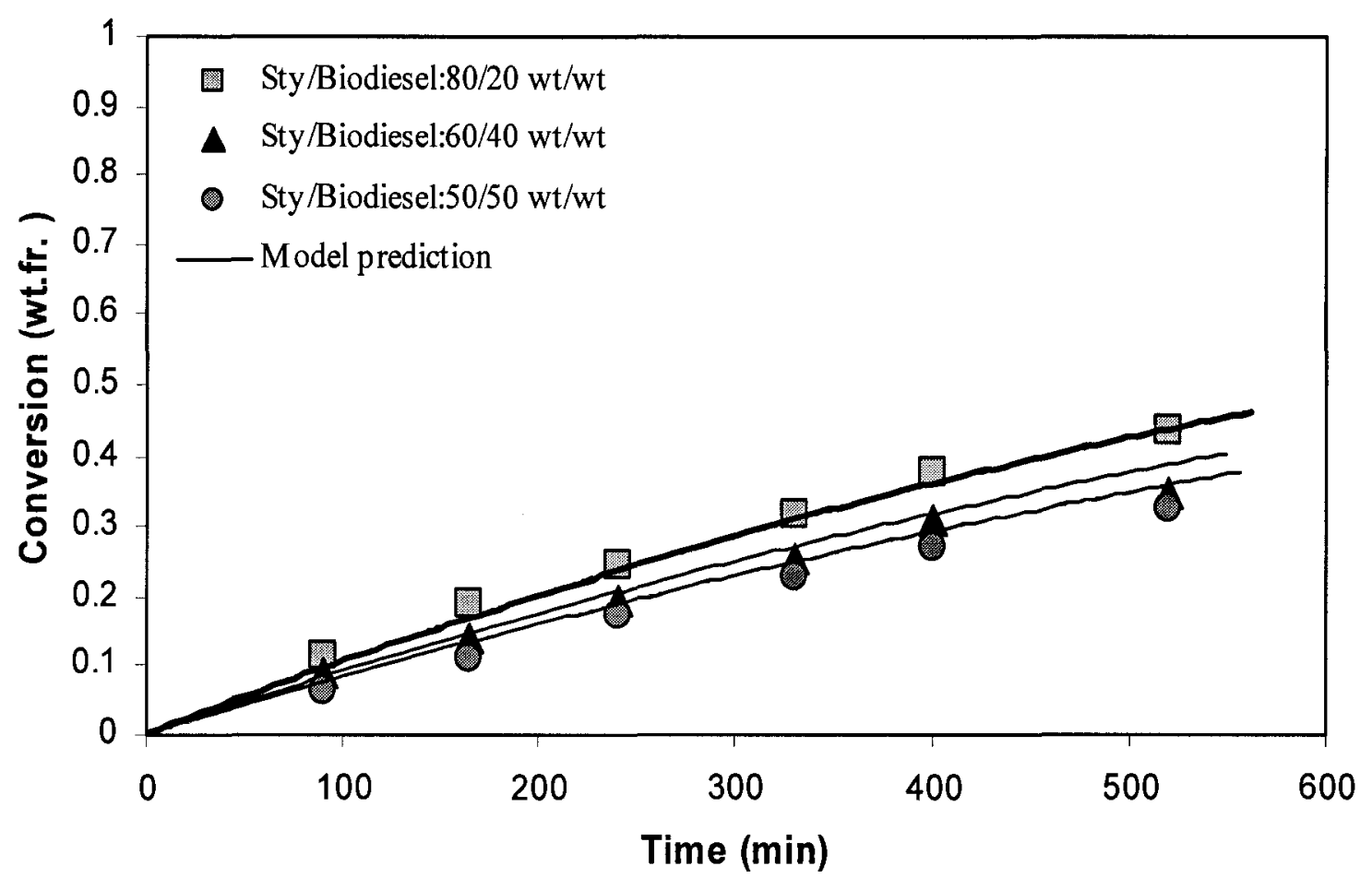

Figure 3.3 Sty homopolymerization in FAME: Conversion versus time at different solvent concentrations. 


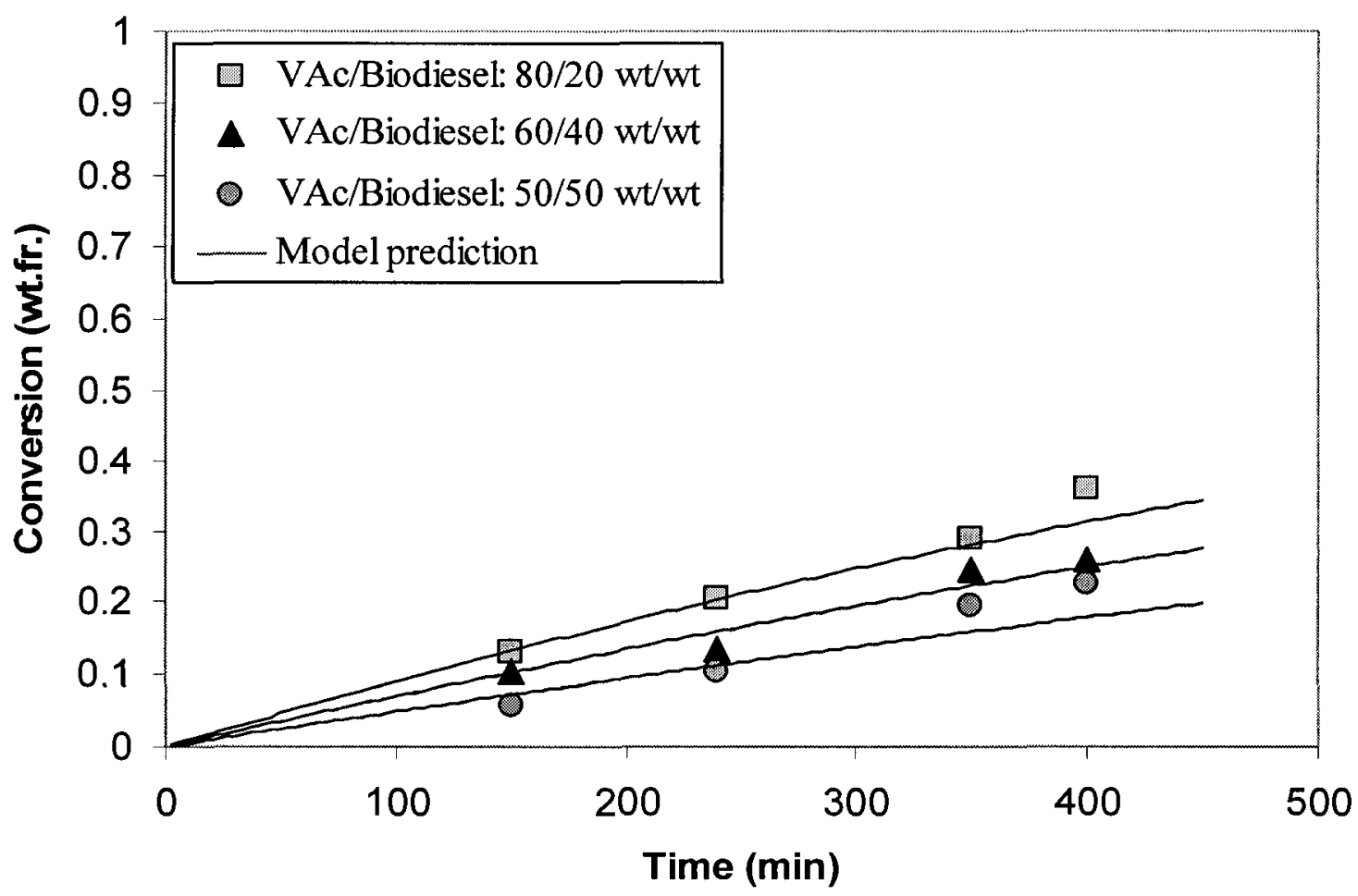

Figure 3.4 VAc homopolymerization in FAME: Conversion versus time at different solvent concentrations. 


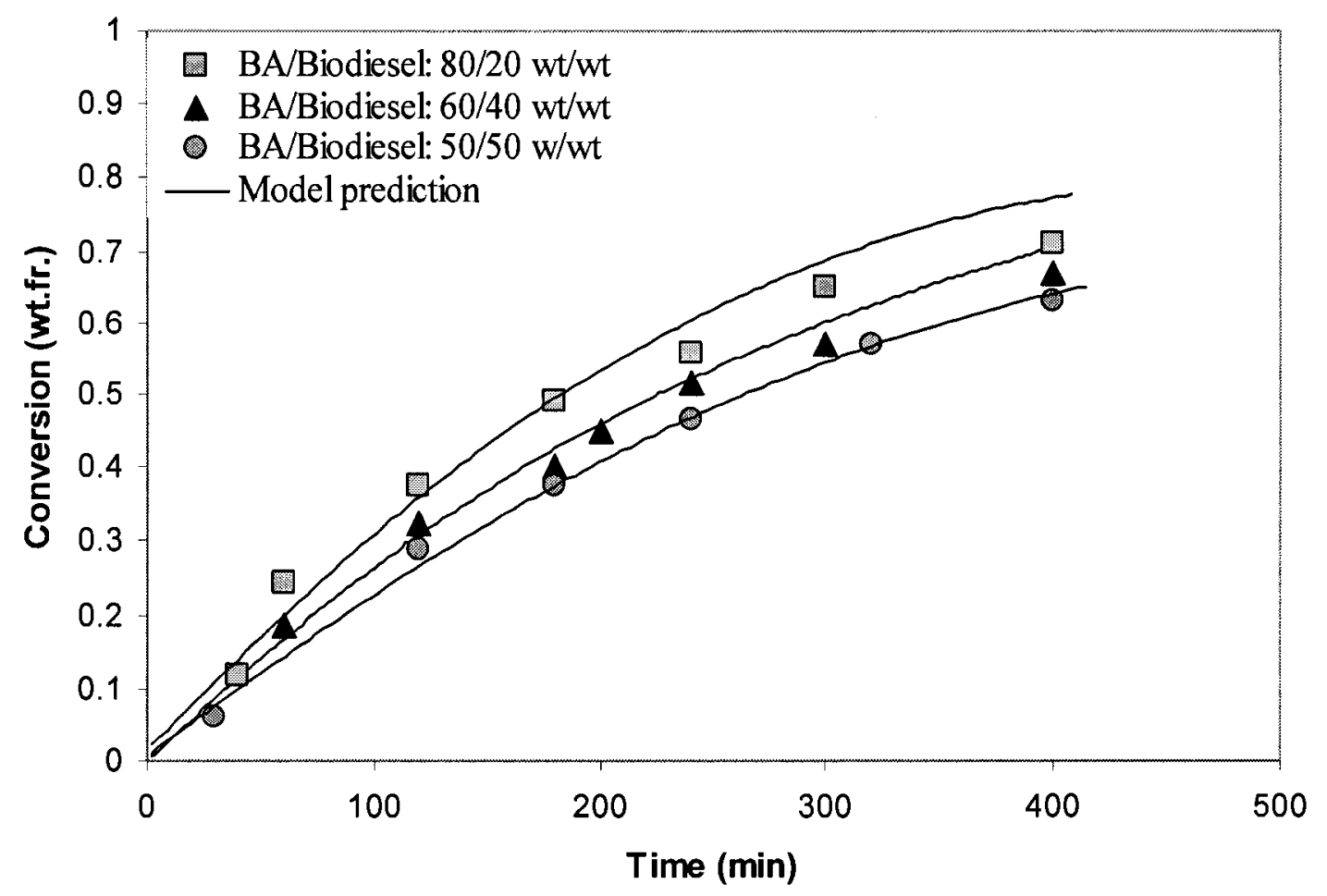

Figure 3.5 BA homopolymerization in FAME: Conversion versus time at different solvent concentrations.

Solvent can affect the individual propagation and termination rate parameters (McKenna et al., 1999). Despite difficulties in calculating $k_{p}$, some studies conducted using PLP-SEC have shown that there is a small solvent effect on $k_{p}$ for most acrylate monomers, MMA and Sty (Morrison et al., 1993).The PLP data show that changing solvent viscosity and polarity has no significant effect on the propagation rate coefficient of Sty and MMA but preferential solvation of the radical site seems to occur when polymer precipitation takes place, thus increasing the monomer concentration at the free radical site and increasing the apparent $k_{p}$ (Olaj et al., 2001). There is evidence of either a radical-solvent or radical-monomer complex, which participates in propagation reactions 
and modifies the propagation rate parameter. The stability and reactivity of these complexes determines the effect on $k_{p}$ (Zammit et al., 1997). Regarding the effect on $k_{t}$, it is known that $k_{t}$ is nearly always diffusion-controlled (Buback et al., 2002). By increasing the solvent concentration, more transfer to solvent reactions are possible, resulting in faster termination reactions due to the generation of shorter and more mobile chains. This leads to an increase in $k_{t}$ and therefore, to a decrease in the rate of polymerization (Jovanović and Dubé, 2004). Regardless of the effect of solvent on the individual rate

parameters, it is the lumped rate parameter, $k_{p} / k_{t}^{I / 2}$, which should be manipulated because the individual parameters are coupled.

A considerable difference in the polymerization rate was observed for all monomers by changing the concentration of solvent. Therefore, the solvent must be a major contributing factor to the change in rate in addition to the effect of dilution. The lowest polymerization rate was at the monomer/FAME ratio of 50/50 wt.- $\%$, whereas the highest was observed for a ratio of $80 / 20 \mathrm{wt} .-\%$ for each polymer system. In general, the lowest rate of polymerization was observed for VAc, which for is not surprising given its high transfer to solvent coefficient compared to other monomers. No thermal polymerization was noted at this temperature. All polymers were soluble except pMMA, which precipitated in the FAME. The same behavior was observed for pMMA in methyl oleate (Jordan et al., 1969).

\section{CONCLUSIONS}

FAMEs derived from canola oil fulfills the demands of a solution polymerization solvent for homopolymerization of MMA, Sty, BA and VAc. Reactions at different 
solvent concentrations have been investigated to verify the effect of this solvent on polymerizations. Increasing solvent concentration from 20 to $50 \%$ with all other factors kept constant was more pronounced for VAc. MMA was precipitated in FAME during polymerization. Transfer constants to solvent were in the order, MMA $<$ Sty $<$ BA $<$ VAc. Model predictions showed reasonable agreement for all monomers with experimental data when new solvent data and changes in $k_{t}$ and $k_{p}$ were incorporated into the model.

Given its high boiling point, using FAMEs as a polymerization solvent can increase productivity by enabling polymerizations at elevated temperatures. This would result in faster reaction rates and shorter reaction times. A high degree of chain transfer to solvent when using FAME as the polymerization medium will lead to lower molecular weight polymer products, which may be desirable in many product applications.

\section{ACKNOWLEDGMENTS}

The authors gratefully acknowledge the financial support of the University of Ottawa and the Natural Science and Engineering Research Council (NSERC) of Canada.

\section{REFERENCES}

Brandrup, J., E.H. Immergut and E.A. Grulke, Eds. "Polymer Handbook", $4^{\text {th }}$ Ed., WileyInterscience, New York (1999)

Buback, M., M. Egorov, R.G. Gilbert , V. Kaminsky, O.F. Olaj, G.T. Russell , P. Vana and G. Zifferer, "Critically Evaluated Termination Rate Coefficients for Free-Radical Polymerization,1.The Current Situation", Macromol. Chem. Phys., 203, 2570 (2002)

Budavari, S., M. O'Neil, A. Smith and P.E. Heckelman, Eds. The Merck Index. Rahway: Merck and Co., (1989) 
Clay, P.A. and R.G. Gilbert, "Molecular Weight Distributions In Free-Radical Polymerizations. 1. Model Development and Implications for Data Interpretation", Macromolecules, 28, 552 (1995)

DeSimone, J.M., "Practical Approaches to Green Solvents", Science, 297, 5582 (2002)

Duan, J., Y. Shim and H.J. Kim, "Solvation in Supercritical Water", J. Chem. Phys., 20, 124, (2006)

Dubé, M.A., A.Y. Tremblay and J. Liu, "Biodiesel Production Using A Membrane Reactor" Biores. Tech., 98, 639 (2007)

Eastwood. G.C., "Encyclopedia of Polymer Science and Technology", Vol. 7, Interscience, New York (1967)

Gao, J. and A. Penlidis, "A Comprehensive Simulator/Database Package For Reviewing Free-Radical Homopolymerizations" J. Macromol. Sci. Rev. Macromol. Chem. Phys., 36, 199 (1996)

Heuts, J.P.A., T.P. Davis and G.T. Russell, "Comparison of the Mayo and Chain Length Distribution Procedures for the Measurement of Chain Transfer Constant", Macromolecules, 32, 6019 (1999)

Hu, J., Z. Du, Z. Tang and E. Min, "Study on the Solvent Power of a New Green Solvent: Biodiesel”, Ind. Eng. Chem. Res. 43, 7928 (2004)

Jordan, E.F., Jr, B. Artymyshyn and A.N. Wrigley, "Chain Transfer Constants for Vinyl Monomers Polymerized in Methyl Oleate and Methyl Stearate", J. Polym. Sci. Polym. Chem. 7, 2605 (1969)

Jovanović, R. and M.A. Dubé, "Solvent Effects in Butyl Acrylate and Vinyl Acetate Homopolymerizations in Toluene", J. Macromol. Sci. Polym. Rev., 44, 1 (2004)

Jovanović, R. and M.A. Dubé, "Solvent Effects in Butyl Acrylate and Vinyl Acetate Homopolymerizations in Toluene", J. Appl. Polym. Sci., 94, 871 (2004)

Kubisa, P., "Ionic Liquids for the Convenient Synthesis of Functional Nanoparticles and Other Inorganic Nanostructures", Prog. Polym. Sci., 29, 3 (2004)

Mayo, F.R., "Chain Transfer in the Polymerization of Styrene: The Reaction of Solvents with Free Radicals", J. Amer. Chem. Soc. 65, 2324 (1943)

McKenna, T.F., A. Villanueva and M. Santos, "Effect of Solvent on the Rate Constants in Solution Polymerization. Part II. Vinyl Acetate", J. Polym. Sci. Polym. Chem., 37, 571 (1999) 
McKenna, T.F., A. Villanueva and M. Santos, "Effect of Solvent on the Rate Constants in Solution Polymerization. Part I. Butyl Acrylate", J. Polym. Sci. Polym. Chem., 37, 589 (1999)

Mittelbach, M. and C. Remschmidt, "Biodiesel: The Comprehensive Handbook", Martin Mittelbach Paperback (2004)

Morrison, B.R., M.C. Piton, M.A. Winnik, R.G. Gilbert and D.H. Napper, "Solvent Effects on the Propagation Rate Coefficient for Free Radical Polymerization" Macromolecules, 26, 4368 (1993)

Odian, G., "Principles of polymerization", $4^{\text {th }}$ Ed., John Wiley and Sons, Inc. (2004)

Olaj, O.F., M. Zoder and P. Vana, "Chain Length Dependent Termination in PulsedLaser Polymerization. 9. The Influence of Solvent on the Rate Coefficient of Bimolecular Termination in the Polymerization of Styrene", Macromolecules, 34, 441 (2001)

Seddon, K.R., "Polarity Study of Some 1-Alkyl-3-Methylimidazolium AmbientTemperature Ionic Liquids with the Solvatochromic Dye, Nile Red", Kinet. Catal., 37, 693 (1996)

Sheldon, R.A., "Green Solvents for Sustainable Organic Synthesis: State of the Art", Green Chem., 7, 267 (2005)

Sherman, J., B. Chin, P. Huibers, R. Garcia-Valls, T. Hatton,"Solvent Replacement for Green Processing", Environ. Health Perspect., 106 (Suppl 1), 253 (1998)

Yang, Z. and W. Pan, "Ionic Liquids: Green Solvents for Nonaqueous Biocatalysis", Enzyme Microb. Technol., 37, 19 (2005)

Zammit, M.D., T.P. Davis, G.D. Willett and K.F. O'Driscoll, "The Effect of Solvent on the Homo-Propagation Rate Coefficients of Styrene and Methyl Methacrylate" J. Polym. Sci. Polym. Chem., 35, 2311 (1997)

Zhang, Y., M.A. Dubé, D.D. McLean and M. Kates, "Biodiesel Production from Waste Cooking Oil: 2. Economic Assessment and Sensitivity Analysis" Biores. Tech., 90, 229 (2003) 
Chapter 4

PAPER II 


\title{
The Use of Biodiesel as a Green Polymerization Solvent
}

\author{
at Elevated Temperatures \\ Somaieh Salehpour, Marc A. Dubé* \\ Department of Chemical Engineering, University of Ottawa, \\ 161 Louis Pasteur St., Ottawa, ON, KIN 6 N5 Canada \\ *Marc.Dube@uOttawa.ca
}

In pursuit of a "green" polymerization solvent, canola-based FAME was used as a high boiling solvent for solution polymerizations at elevated temperatures. Chain transfer to solvent rate constants were obtained for methacrylate (MMA), styrene, butyl acrylate (BA) and vinyl acetate (VAc). The rates of polymerization for these commercially important monomers in FAME (fatty acid methyl ester or biodiesel) were studied at different solvent concentrations at $120^{\circ} \mathrm{C}$. Chain transfer to solvent rate constants were obtained using the Mayo method. These new solvent data were employed in a polymerization simulator to predict rate of polymerization, and number- and weightaverage molecular weights for the investigated systems. Improvements to model predictions were obtained by allowing the lumped rate parameter $\left(k_{p} / k_{t}^{1 / 2}\right)$ to vary with solvent concentration. 


\section{INTRODUCTION}

Many polymer products are made traditionally via free radical polymerizations. Over half of these are produced using solution polymerization techniques (Odian, 1991), which can be applied to a broad range of monomers. The presence of solvent keeps the viscosity low and results in the lessening of viscosity-related problems in heat transfer, processing, mixing and material handling. Despite these advantages, solution polymerizations are seen in a negative light due to the use of volatile organic compounds (VOCs) as solvents, which cause health and environmental problems. An example is ethylbenzene, an anticipated carcinogen (Budavari, 1989), which is a common solvent for the commercial production of polystyrene. From US production alone, over 4,000 tons of ethylbenzene are released into the atmosphere yearly (Benton and Brazel, 2002). In terms of environmental effects, these solvents can cause tropospheric pollution and deplete the ozone layer (Sherman et al., 1998).

With an increased environmental awareness and thus, concern over the VOC content in various polymer products, significant attention has been devoted to finding alternatives to harmful solvents or to the elimination of their use. Solvent-free polymerization is one possibility. However, it is not feasible in many cases and alternative techniques such as bulk or emulsion polymerization cannot always deliver the same product properties (Jovanović and Dubé, 2004). The use of environmentally friendly solvents such as supercritical fluids (e.g., carbon dioxide and water) and roomtemperature ionic liquids (RTILs) has emerged as an important development in polymer production technology (Duan et al., 2006). Supercritical carbon dioxide is a non-toxic, benign, inexpensive and widely available solvent, which can be easily separated from the polymer product and recycled (Quadir and DeSimone, 1998). However, using solvents at 
a supercritical state can cause corrosion problems with process equipment and the technology can be expensive to implement (Sherman et al., 1998). Ionic liquids are another class of non-classical polymerization solvents that offer a substitute to conventional solvents in many chemical applications. They usually consist of organic cationic species and inorganic anionic species, which are liquids at room temperature with very low vapor pressures (Nelson, 2002). However, they have yet to be applied at the industrial scale as a "green" solvent because their distribution into the environment, toxicity and biodegradability are not fully known (Sheldon, 2005). Moreover, the use of the RTILs does not lead to less energy expenditures compared to conventional solvents and yields a higher cost (Nelson, 2002).

Recently, FAME produced from canola oil has been used as a green polymerization solvent (Salehpour and Dubé, 2007). Biodiesel is environmentally benign, has a low volatility and is a renewable material with low viscosity and good solubility properties. Biodiesel is more commonly known as an environmentally friendly alternative to petroleum diesel. The solvent power of biodiesel has only recently started to be investigated (Hu et al., 2004). It can be defined as alkyl esters of long chain fatty acids, which are commonly produced by the base-catalyzed transesterification of vegetable oils, grease or animal fats with an alcohol (Mittelbach et al., 2004). Methanol is the typical alcohol for biodiesel transesterification reactions and results in esters named fatty acid methyl esters (FAMEs). The largest component of biodiesel consists of C16-18 methyl esters that are readily biodegradable due to their chemical nature, can be domestically produced and obtained at a competitive price (Zhang et al., 2003).

In 1969, methyl oleate, a major component of biodiesel produced from canola oil, was used as a polymerization solvent for several monomers at $60^{\circ} \mathrm{C}$ (Jordan et al., 1969). 
It has never been applied extensively in industrial settings, perhaps because of the high cost of the pure compound. In our previous work, a comparison of biodiesel to methyl oleate and some common solvents in terms of their toxicity, cost and permissible exposure limit (PEL) was presented The synthesis of some widely-used commodity polymers in FAME at $60^{\circ} \mathrm{C}$ was also studied (Salehpour and Dubé, 2007). FAME shows good promise for economical and "green" polymer synthesis.

Aside from the obvious environmental benefits of using biodiesel, one can also consider its high boiling point and its low cost. Biodiesel boils at temperatures beyond $300^{\circ} \mathrm{C}\left(326^{\circ} \mathrm{C}\right.$ for canola-based biodiesel). This means that it will not pose a hazard in the workplace due to evaporation and reactions can be carried out at elevated temperatures without fear of excessive pressure buildup aside from the contributions of the monomers. Solution polymerization at elevated temperatures enables the production of low molecular weight polymers without the use of chain transfer agents. This strategy leads to higher reaction rates, and consequently shorter reaction times and lower viscosity, which can dissipate autoacceleration effects (McManus et al., 2004).

To our knowledge, no one has used unsaturated FAMEs as a polymerization solvent at elevated temperatures. In the present study, we have focused on the solution polymerization at $120^{\circ} \mathrm{C}$ of four commercially important monomers: methyl methacrylate (MMA), styrene (Sty), butyl acrylate (BA) and vinyl acetate (VAc) in FAME produced from canola oil. The average molecular weights of the polymers and the rate of polymerization were studied and the chain transfer to solvent rate constants were calculated. Finally, the collected kinetic experimental data were modeled using the WATPOLY polymerization simulator (Gao and Penlidis, 1996). 


\section{EXPERIMENTAL METHODS}

Monomers obtained from the Sigma-Aldrich Chemical Company (Milwaukee, WI) were received inhibited with 10 to $50 \mathrm{ppm}$ hydroquinone. To remove the inhibitor, BA, MMA and Sty were washed 3 times with a $10 \%(\mathrm{v} / \mathrm{v})$ sodium hydroxide solution, washed 3 times with distilled de-ionized water and then dried over calcium chloride prior to vacuum distillation. VAc was distilled under vacuum and all distillations were completed a maximum of $24 \mathrm{~h}$ prior to polymerization. Monomers were stored at $-10^{\circ} \mathrm{C}$. Di-t-butyl peroxide ('Trigonox B'), $\geq 95 \%$ pure, was obtained from the Sigma-Aldrich Chemical Company and used without purification. FAME was obtained by transesterification of canola oil (No Name ${ }^{\circledR}$, purchased at a local supermarket) with methanol ( $\geq 99 \%$ pure, Sigma-Aldrich Chemical Company) in the presence of sodium hydroxide catalyst using a membrane reactor process (Dubé et al., 2007). The FAME product from the reactor was washed 5 times with de-ionized water and distilled under vacuum to remove the water. Hexane and methanol (Sigma-Aldrich) and all other solvents used for sample characterization were employed without further purification.

\section{Procedures}

Experiments were carried out in sealed glass ampoules (17-cm length, $0.8-\mathrm{cm}$ outer diameter) at $120^{\circ} \mathrm{C}$ in a silicone oil bath. The feed was prepared by weighing the monomer, FAME solvent and initiator into a flask and delivered into a series of glass ampoules. For easier comparison of results, the same ratio of initiator to monomer, 0.2 phm (parts per 100 parts by weight of monomer) of initiator was utilized for all experiments. The ampoules were degassed by several freeze-pump-thaw cycles under high vacuum, were flame sealed and then submerged in a constant temperature silicone oil bath. At the appropriate time interval, ampoules were removed from the bath and 
quenched in an ice bath to stop the reaction. The ampoules were opened and the contents poured into a pre-weighed beaker. These were each diluted with $5 \mathrm{~mL}$ of acetone. The extraction of polymer was done by precipitation in hexane (for MMA, VAc and Sty) and in methanol (for BA) at room temperature. The polymer/monomer/FAME solution was added slowly to the non-solvent (i.e., hexane or methanol) while stirring, and generally appeared as a fine white fiber or a milky dispersion. After settling $(\sim 24 \mathrm{~h})$, decantation and evaporation of the non-solvent, the extracted polymer was dried in a vacuum oven at $30^{\circ} \mathrm{C}$ until a constant weight was reached. Details of the experimental feed compositions and conditions are presented in Table 4.1.

Conversion was estimated using gravimetry. The cumulative number- and weightaverage molecular weights were determined using a Waters Associates gel permeation chromatograph equipped with a Waters model 410 refractive index detector. Three Waters Ultrastyragel packed columns $(103,104$, and $106 \AA)$ were installed in series. THF was filtered and used as the eluent at a flow rate of $0.3 \mathrm{~mL} / \mathrm{min}$ at $38^{\circ} \mathrm{C}$. The Universal calibration method was used with 10 standard samples of polystyrene (SHODEX, Showa, Denko, Tokyo, Japan) with peak molecular weights between $1.3 \times 10^{3}$ and $3.15 \times 10^{6} \mathrm{~g} / \mathrm{mol}$. Standards and samples were prepared in THF $0.2 \%(\mathrm{w} / \mathrm{v})$ solutions and filtered prior to injection through $0.45-\mu \mathrm{m}$ PTFE filters to remove any gel or impurity, if present. Millennium $32^{\mathrm{TM}}$ software (Waters) was used for data acquisition. The Mark-Houwink K and $\alpha$ parameters used as part of the universal calibration technique are given in Table 4.2 . 
Table 4.1 Experimental Conditions

\begin{tabular}{|c|c|c|}
\hline Monomer & Experiment & $\begin{array}{c}\text { Monomer/FAME } \\
\text { (wt.-\%) }\end{array}$ \\
\hline \multirow{4}{*}{ Methyl methacrylate } & M1 & $50 / 50$ \\
\cline { 2 - 3 } & M2 & $60 / 40$ \\
\cline { 2 - 3 } & M3 & $80 / 20$ \\
\hline \multirow{4}{*}{ Styrene } & S1 & $50 / 50$ \\
\cline { 2 - 3 } & S2 & $60 / 40$ \\
\cline { 2 - 3 } & S3 & $80 / 20$ \\
\hline \multirow{3}{*}{ Vinyl acetate } & V1 & $50 / 50$ \\
\cline { 2 - 3 } & V2 & $60 / 40$ \\
\cline { 2 - 3 } & V3 & $80 / 20$ \\
\hline \multirow{3}{*}{ Butyl acrylate } & B1 & $50 / 50$ \\
\cline { 2 - 3 } & B2 & $60 / 40$ \\
\cline { 2 - 3 } & B3 & $80 / 20$ \\
\hline
\end{tabular}

Table 4.2 Mark-Houwink Parameters for samples in tetrahydrofuran

\begin{tabular}{|l|c|c|}
\hline Polymer & $\mathrm{K}\left(\times 10^{3} \mathrm{~mL}^{-1}\right)$ & $\alpha$ \\
\hline Poly(butyl acrylate) $^{\mathrm{a}}$ & 11 & 0.708 \\
\hline Poly(vinyl acetate) $^{\mathrm{b}}$ & 15.6 & 0.708 \\
\hline Poly(methyl methacrylate) $^{\mathrm{b}}$ & 12.8 & 0.690 \\
\hline Polystyrene $^{\mathrm{b}}$ & 16 & 0.700 \\
\hline
\end{tabular}

${ }^{a}$ McKenna and Villanueva, 1999

${ }^{\mathrm{b}}$ Brandrup et al., 1999 


\section{RESULTS AND DISCUSSION}

Solvent effects on the free radical polymerization of many monomers have been widely documented (Coote and Davis, 1998). In general, according to the classical or ideal polymerization rate, $R_{p}$, (see Eq.1) the dilution effect of the solvent decreases the concentration of monomer, thereby decreasing the rate of polymerization. In addition, the presence of solvent may affect the propagation and termination steps in free-radical polymerization (McKenna et al., 1999). The overall rate of polymerization is expressed as follows (Rosen, 1993):

$$
R_{p}=\frac{k_{p}}{k_{t}^{1 / 2}}[M]\left(f k_{d}[I]\right)^{1 / 2}
$$

where $k_{p}, k_{d}$, and $k_{t}$ are the propagation, initiator decomposition, and termination rate constants, respectively. $f$ is the initiator efficiency. [M] and [I] are the monomer and initiator concentrations, respectively. The term $k_{p} /\left(k_{t}\right)^{1 / 2}$ is a lumped parameter and it can be obtained directly from experimental measurements, using simple techniques such as gravimetry.

Transfer to solvent reactions can take place in solution polymerization and may affect the polymerization kinetics. The effect can be investigated by studying the chain transfer to solvent constant, $C_{f s}$, defined as the ratio of the chain transfer rate constant to the propagation constant:

$$
C_{f s}=\frac{k_{f s}}{k_{p}}
$$

where $k_{f s}$ is the chain transfer to solvent rate constant. Chain transfer constants for numerous solvent/monomer systems have been traditionally determined using the Mayo method (Mayo, 1943). This method is based on overall chain growth and chain stopping 
rates under the assumption of steady state and uses the long-chain approximation (Heuts et al., 1999). Another technique known as the CLD method, is based on the calculation of the high molecular weight slope for the number molecular weight distribution (Clay and Gilbert, 1995). In chain transfer-dominated systems, both methods yield very similar results (Heuts et al., 1999). In this study, the transfer to solvent constants for the polymerization of different monomers in FAME were calculated using the Mayo equation:

$\frac{1}{\bar{X}_{n}}=\frac{k_{t} R_{p}}{k_{p}^{2}[M]^{2}}+C_{f i n}+C_{f s} \frac{[S]}{[M]}+C_{f i} \frac{k_{t} R_{p}^{2}}{k_{p}^{2} f k_{d}[M]^{3}}$

where $\bar{X}_{n}$ is the number-average degree of polymerization, $C_{f m}, C_{f s}$ and $C_{f i}$ are the transfer constants to monomer, solvent and initiator, respectively.

As discussed previously (Salehpour and Dubé, 2007, Heuts et al., 1999), under certain conditions, Eq. 3 is reduced to

$$
\frac{1}{\bar{X}_{n}}=\frac{1}{\bar{X}_{n 0}}+C_{f s} \frac{[S]}{[M]}
$$

where $\left(1 / \bar{X}_{n 0}\right)$ is the value of $\left(1 / \bar{X}_{n}\right)$ in the absence of solvent. The value of $C_{f s}$ is obtained from the slope of the line by plotting $\left(1 / \bar{X}_{n}\right)$ versus $[S] /[M]$. All data regarding the calculation of $C_{f s}$ for each monomer are given in Table 4.3. The corresponding Mayo plots are given in Figure 4.1. All polymers were soluble in FAME at the polymerization temperature $\left(120^{\circ} \mathrm{C}\right)$ and we have assumed that long-chain branching is negligible.

Transfer to solvent effectiveness depends on the solvent's amount, structure, strength of the breaking bond and the stability of the solvent radical formed. Transfer to solvent phenomena relate to propagating radical reactivity (Odian, 2004). A comparison 
of transfer to solvent constants for FAME and some common solvents at $60^{\circ} \mathrm{C}$ was shown in our previous study (Salehpour and Dubé, 2007). For example, benzene has a low $C_{f s}$ value because of strong $\mathrm{C}-\mathrm{H}$ bonds. Transfer to solvent in this case appears to occur through the addition of the propagating radical to the benzene ring. Solvents with weaker benzylic bonds such as toluene and ethylbenzene have higher $C_{f_{s}}$ values. In addition, the abstraction of benzylic $\mathrm{C}-\mathrm{H}$ is easier due to the stabilization of the radical by resonance (Odian, 2004).

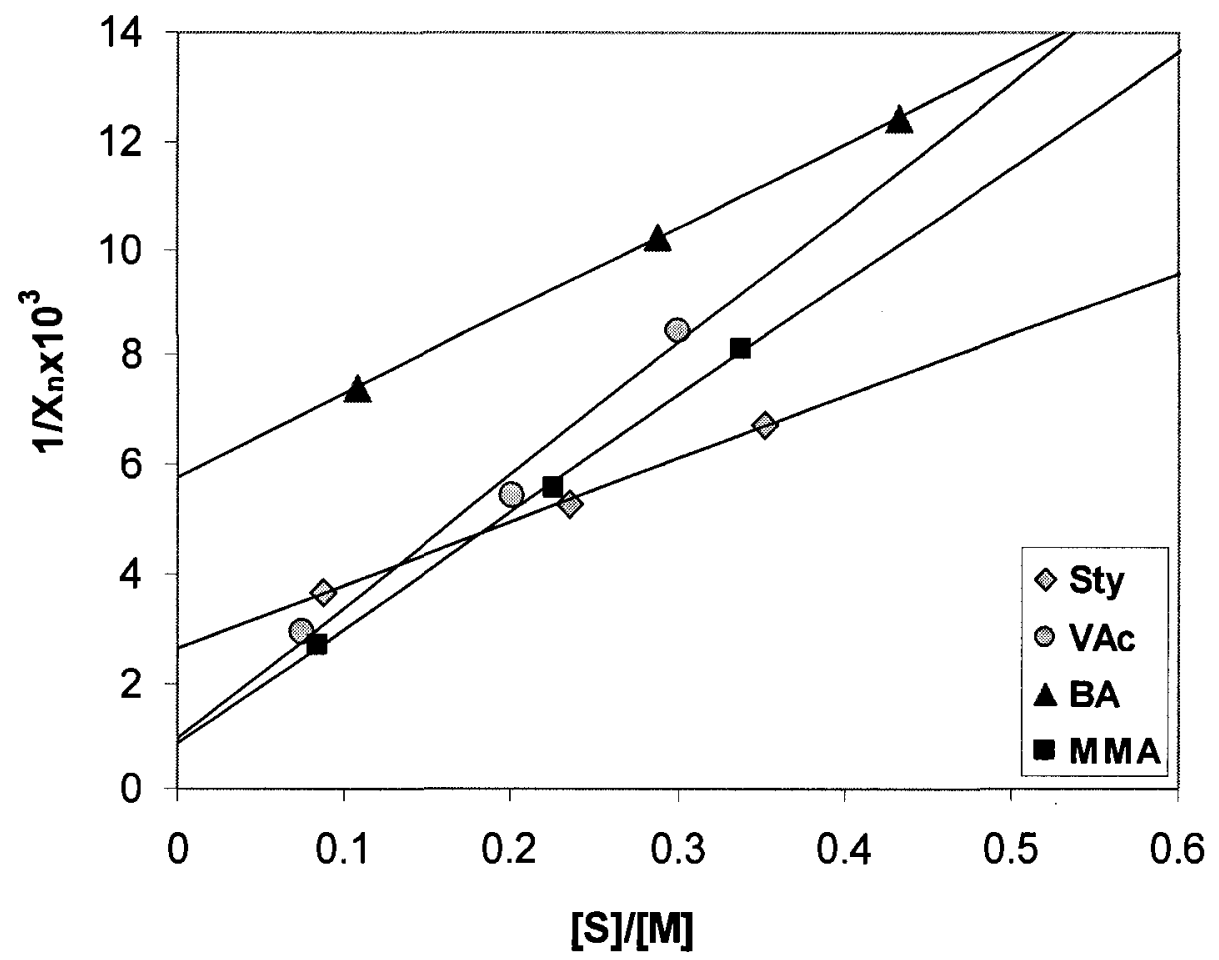

Figure 4.1 Mayo plot - reciprocal number-average degree of polymerization versus the solvent/monomer ratio for the monomers polymerized in FAME. 
Table 4.3 Chain transfer data

\begin{tabular}{|c|c|c|c|c|c|}
\hline Experiment & $\bar{M}_{n}$ & $1 / \bar{X}_{n} \times 10^{3}$ & {$[S] /[M]$} & $\begin{array}{c}\text { Conversion } \\
\text { (wt.-\%) }\end{array}$ & $C_{f_{s}} \times 10^{4}$ \\
\hline \multicolumn{6}{|c|}{ Methyl methacrylate, AIBN $=0.2 \mathrm{phm}$} \\
\hline M1 & 14200 & 7.0050 & 0.3383 & 10.6 & \multirow{3}{*}{160} \\
\hline M2 & 20900 & 4.7786 & 0.2255 & 12.5 & \\
\hline M3 & 36900 & 2.7086 & 0.0846 & 9.2 & \\
\hline \multicolumn{6}{|c|}{ Styrene, AIBN = $0.2 \mathrm{phm}$} \\
\hline S1 & 15400 & 6.7207 & 0.3518 & 9.5 & \multirow{3}{*}{155} \\
\hline S2 & 19700 & 5.2723 & 0.2346 & 10.2 & \\
\hline S3 & 28200 & 3.6904 & 0.0879 & 11.4 & \\
\hline \multicolumn{6}{|c|}{ Vinyl acetate, $\mathrm{AIBN}=0.2 \mathrm{phm}$} \\
\hline V1 & 10500 & 6.4723 & 0.3010 & 15.4 & \multirow{3}{*}{330} \\
\hline V2 & 16400 & 4.4061 & 0.2006 & 12.2 & \\
\hline V3 & 30100 & 1.9510 & 0.0752 & 10.6 & \\
\hline \multicolumn{6}{|c|}{ Butyl acrylate, AIBN $=0.2 \mathrm{phm}$} \\
\hline B1 & 10400 & 10.5925 & 0.4329 & 11.2 & \multirow{3}{*}{130} \\
\hline B2 & 12500 & 8.6630 & 0.2886 & 10.5 & \\
\hline B3 & 17300 & 6.1413 & 0.1082 & 13.1 & \\
\hline
\end{tabular}

Accordingly, FAME would be expected to have higher transfer constants compared to aliphatic and aromatic hydrocarbons because of $\mathrm{C}-\mathrm{H}$ breakage and stabilization of the radical by an adjacent carbonyl group. This is consistent with our 
experimental results that showed that chain transfer to FAME was significantly greater than benzene, toluene and xylene (Salehpour and Dubé, 2007). In addition, transfer to internal double bonds of FAME compounds is possible. FAME from canola oil consists of 55-65 wt.\% methyl oleate with one internal double bond, $20-26$ wt. $\%$ methyl linoleate with two internal double bonds and 8-10 wt.\% linolenate with three internal allylic unsaturations. In an early study on chain transfer constants for vinyl monomers polymerized in methyl oleate and methyl stearate estimated $C_{f s}$ values for methyl oleate, with 18-carbon structure and one internal double bond, were considerably higher at $60^{\circ} \mathrm{C}$ compare to that for methyl stearate, with 18-carbon structure and no internal bond (Jordan et al., 1969). The difference was even more pronounced for polymerizations at higher temperature as shown in the thermal polymerization of styrene carried out at $90^{\circ} \mathrm{C}$ in the same study. Therefore, it can be postulated that internal allylic double bonds play a considerable role in the transfer to solvent reaction, which leads to high $C_{f s}$ values (see Table 4.3).

In Figures 4.2 through 4.5, conversion vs. time data for the four different monomers at three different solvent concentrations are presented together with model predictions from the WATPOLY simulator (Gao and Penlidis, 1996). Physical property data and the calculated $C_{f s}$ values for FAME were added to the simulator's database. At the same time, the "lumped" kinetic rate parameter $\left(k_{p} / k_{t}^{1 / 2}\right)$ for each monomer was modified to fit the experimental conversion data at each concentration. The model demonstrated reliable predictions of reaction rate and cumulative average molecular weight for all monomers. The value of the modified parameters $\left(k_{p} / k_{t}^{1 / 2}\right)$ were $1.52,1.62$ and 2.35 for MMA polymerization, $0.16,0.22$ and 0.33 for VAc and $0.37,0.56$ and 0.63 for $\mathrm{BA}$ at 50, 40 and $20 \mathrm{wt} . \%$ concentration of solvent, respectively, while it was kept 
constant at 2.46 for Sty at all solvent concentrations. This indicates different effects of solvent on propagation and termination rate constants for each individual monomer.

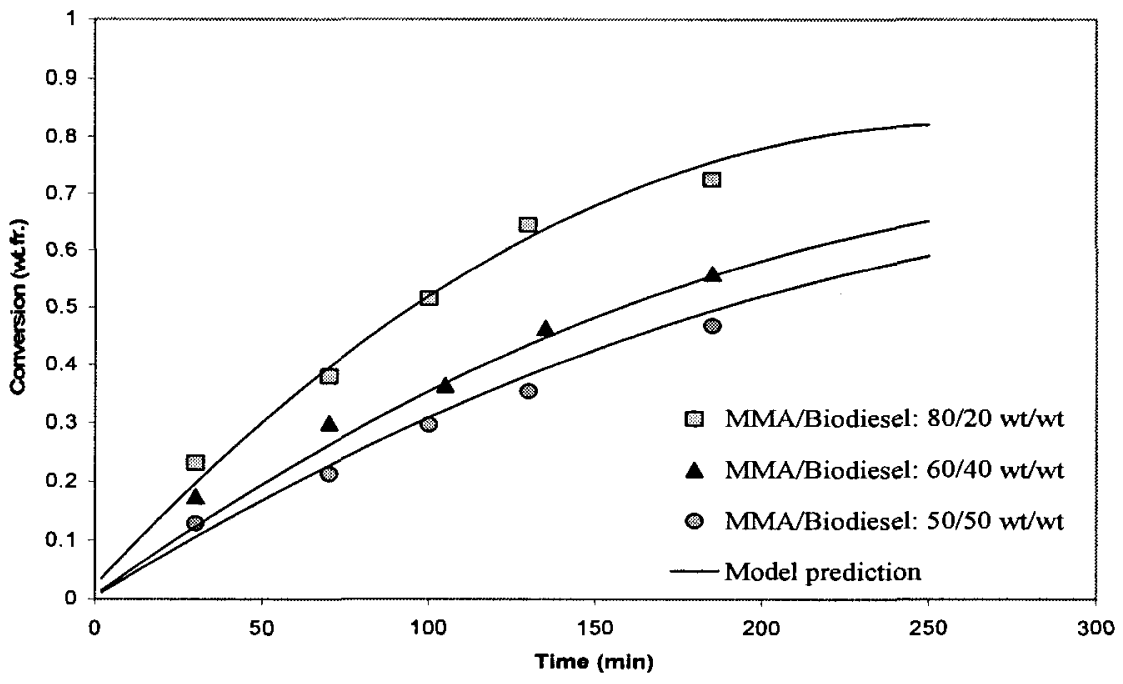

Figure 4.2 MMA homopolymerization in FAME: Conversion versus time at different solvent concentrations. 


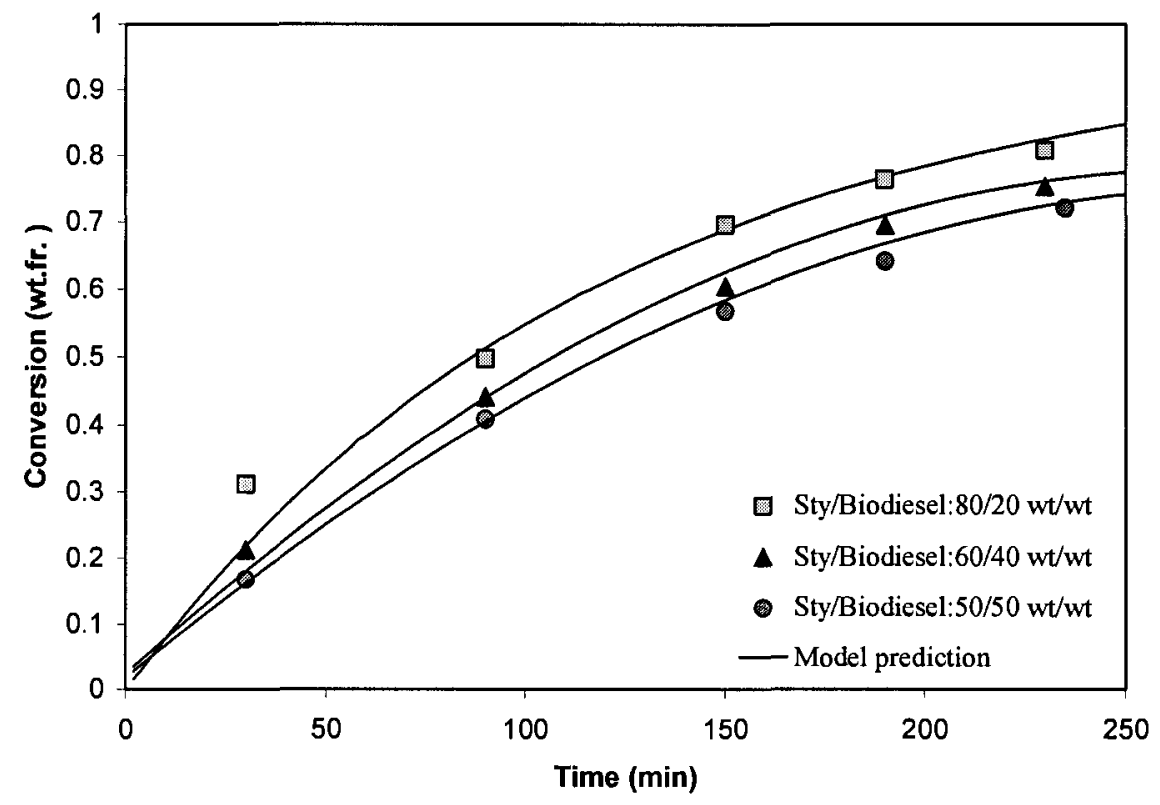

Figure 4.3 Sty homopolymerization in FAME: Conversion versus time at different solvent concentrations. 


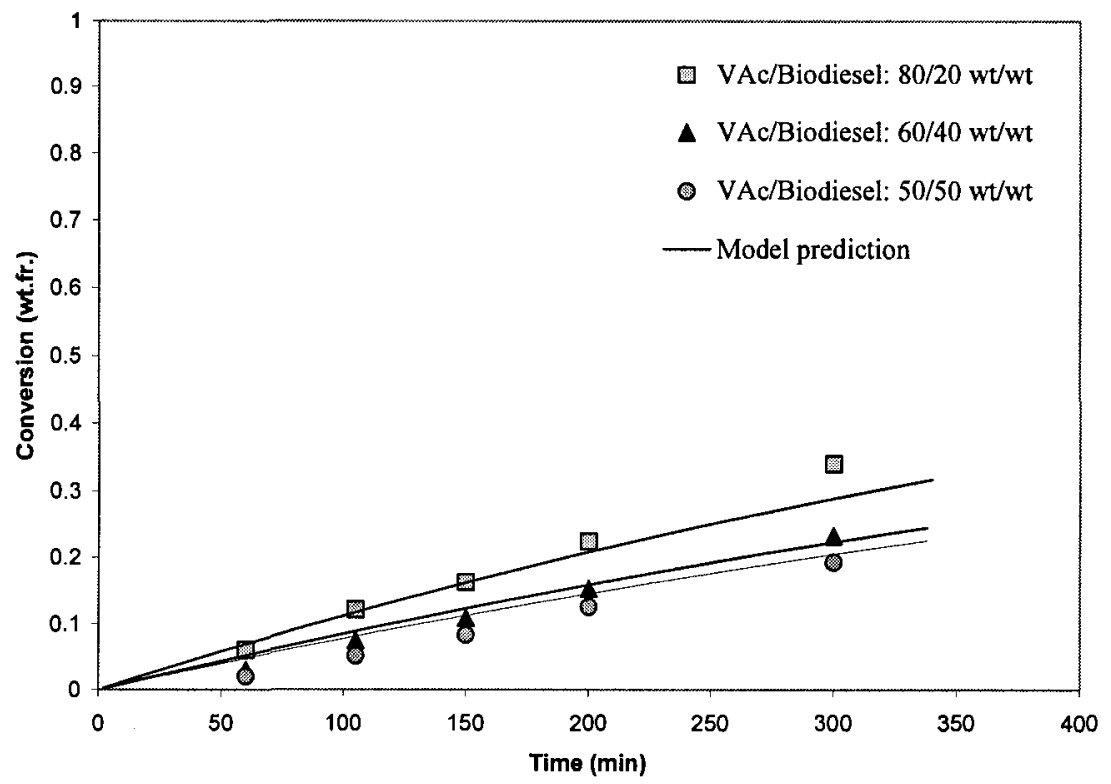

Figure 4.4 VAc homopolymerization in FAME: Conversion versus time at different solvent concentrations. 


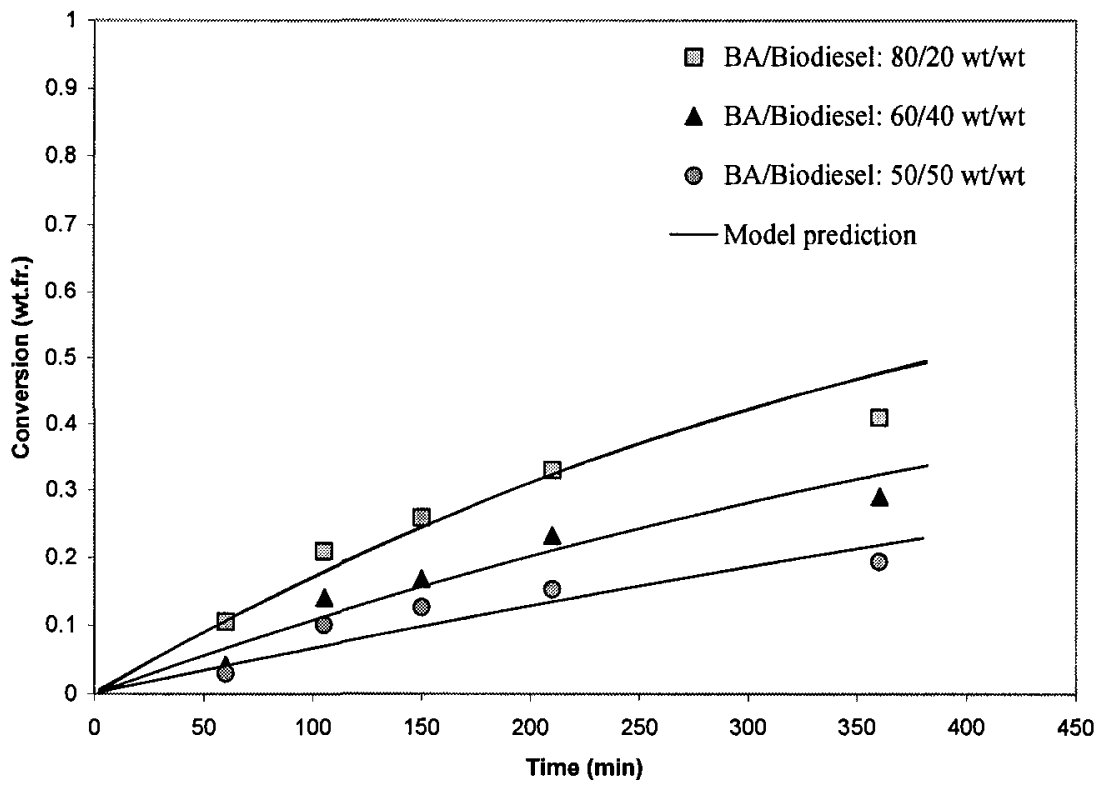

Figure 4.5 BA homopolymerization in FAME: Conversion versus time at different solvent concentrations. 
The highest reaction rate was observed for Sty and the lowest reaction rate for VAc. Pure thermal initiation or self-initiation is known to occur for Sty at elevated temperatures due to the thermal production of radicals from the monomer (Odian, 2004). The presence of thermal initiation in addition to thermal homolysis of an initiator would result in higher rates of polymerization and lower molecular weights. This is consistent with our experimental results for Sty. Relative to previous work (Salehpour and Dubé, 2007), Sty had a lower rate of polymerization compared to MMA and $B A$ at $60^{\circ} \mathrm{C}$, while it had a higher reaction rate at $120^{\circ} \mathrm{C}$ (see Fig. 4.3).

As already mentioned, solvent can affect the rate of polymerization. The effect of FAME on the rate of polymerization is shown in Figures 4.2 through 4.5 . There is a consistent pattern for all monomers: as the concentration of solvent increased, the rate of polymerization decreased. However, the intensity of this effect was different for each monomer. This can be explained by dissimilar effects of solvent on the propagation rate parameter $\left(k_{p}\right)$, the termination rate parameter $\left(k_{t}\right)$ and consequently, on the lumped rate parameter $\left(k_{p} /\left(k_{t}\right)^{1 / 2}\right)$. For example, the lumped rate parameter for Sty does not vary considerably by changing the concentration of solvent (see Fig. 4.3) which is not the case for the other monomers studied here.

In light of the experimental difficulties involving the determination of an absolute propagation rate constant (Hutchinson, et al., 1994), it is not easy to explain solvent effects on $k_{p}$. Although, some studies conducted using PLP-SEC have shown that there is a small solvent effect on $k_{p}$ for most acrylate monomers, as well as MMA and Sty (Morrison et al.,1993), there is evidence of either a radical-solvent or radical-monomer complex, which participates in propagation reactions and modifies the reactivity of the reactants. The effect is exhibited in the Arrhenius parameters for $k_{p}$, i.e., $E_{a}$ and $A$ 
(Zammit et al., 1997). The stability and reactivity of these complexes determines whether $k_{p}$ is increased or decreased compared to bulk polymerization (Burnett, 1972). Seeing that solvent complexes affect both $E_{a}$ and $A$, the absence of a solvent effect on $k_{p}$ is not strong evidence for the absence of a solvent effect on the propagation, because these two factors can cancel each other out (Zammit et al., 1997).

In systems where the formation of complexes may lead to stabilization, radicalsolvent complexes are expected to be favored. For instance, the solvent effect on the homopolymerization of VAc results in a reduced $k_{p}$. Since VAc is an unstable monomer with low reactivity, it may form stable radical-solvent complexes during the propagation step. This can cause a decrease in the rate of propagation. Therefore, in this case, the effect of solvent was mainly ascribed to the variation in $k_{p}$ with solvent concentration rather than that in $k_{t}$ (Kamachi et al., 1979).

Retardation was reported for VAc polymerization in methyl stearate and methyl oleate as a solvent at $60^{\circ} \mathrm{C}$ (Jordan et al., 1969). Methyl oleate (a major component of FAME) with one internal double bond was more rate-reducing at that temperature compared to methyl stearate which has no internal unsaturation. Moreover, an even higher $C_{f s}$ value and more retardation were observed for methyl oleate compare to methyl stearate at $90^{\circ} \mathrm{C}$ (Jordan et al., 1969). Hence, it can be hypothesized that the internal allylic bond of FAMEs makes a considerable contribution to radical-solvent complex formation. Therefore, reduction in the propagation rate constant $\left(k_{p}\right)$ may occur in the polymerization of monomers with low reactivity. This is consistent with our results for VAc polymerization, where a significant effect of solvent on the rate of polymerization was observed. Nonetheless, further studies on the existence of radical-solvent complexes 
and their influence on free-radical polymerization at elevated temperatures are necessary, since the complex might dissociate as temperature increases.

Regarding the effect on $k_{t}$, increasing the solvent concentration leads to more transfer to solvent reactions and results in shorter radicals, which move and terminate more quickly. Since $k_{t}$ is nearly always diffusion-controlled (Buback et al., 2002), a decrease in chain length leads to an increase in $k_{t}$ and therefore, to a decrease in the rate of polymerization.

In Figures 4.6 through 4.10, cumulative average molecular weight vs. conversion data together with model predictions are shown at some solvent concentrations. In general, the model shows acceptable predictions for all monomers; all observed molecular weight measurements for each monomer were low, which is normal for systems that exhibit high chain transfer to solvent rates.

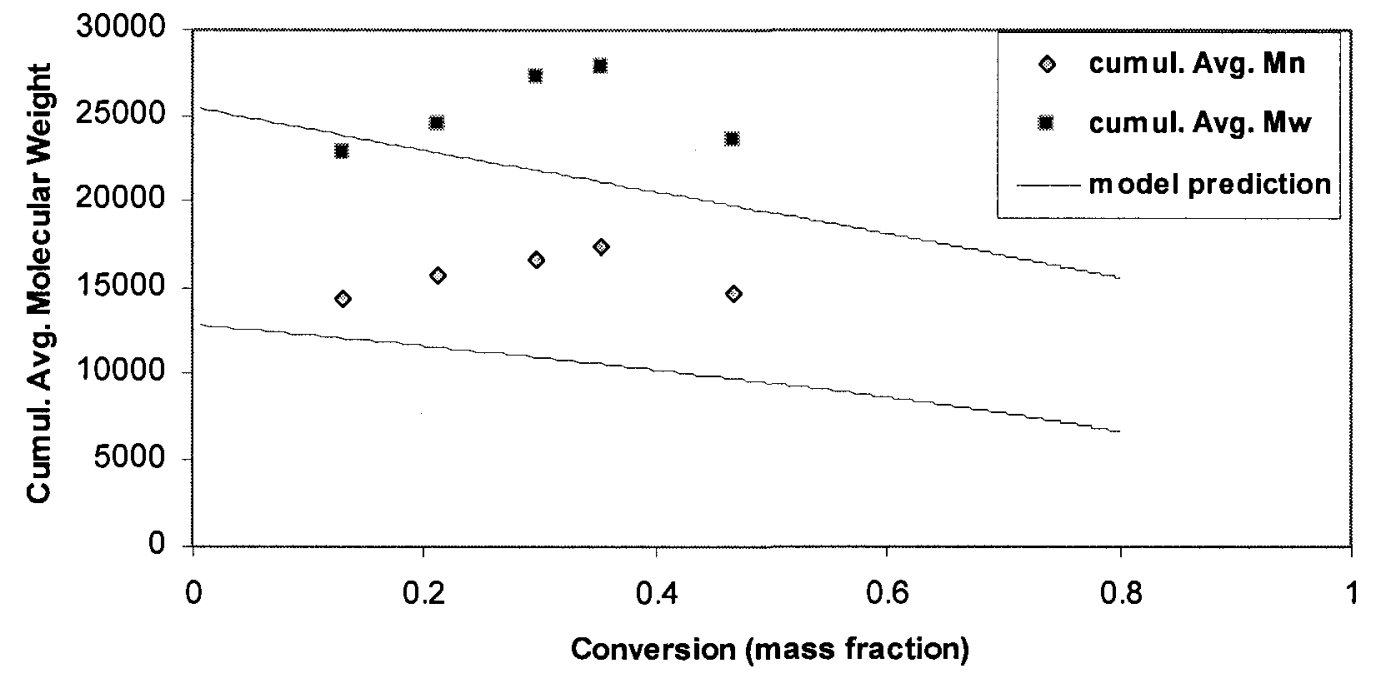

Figure 4.6 Cumulative average molecular weight versus conversion for MMA solution homopolymerization in FAME (50/50 wt \%) 


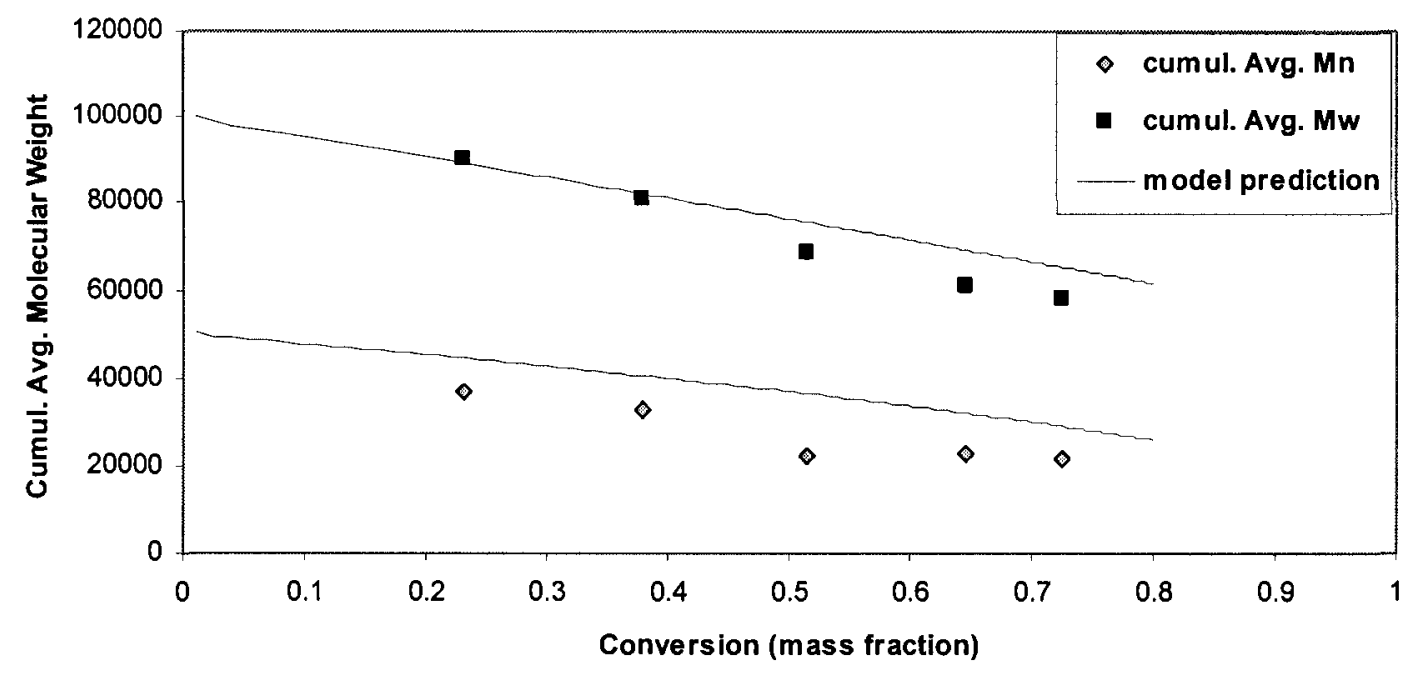

Figure 4.7 Cumulative average molecular weight versus conversion for MMA solution homopolymerization in FAME (80/20 wt \%)

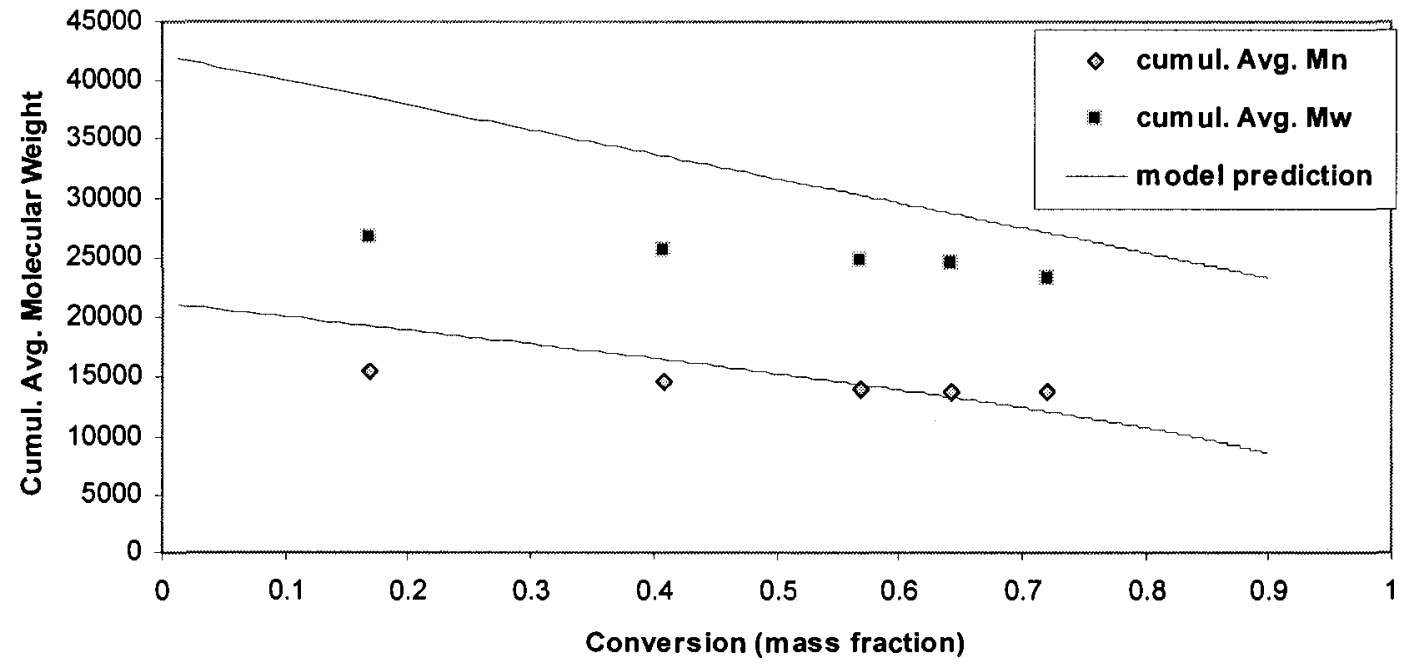

Figure 4.8 Cumulative average molecular weight versus conversion for Sty solution homopolymerization in FAME (50/50 wt \%) 


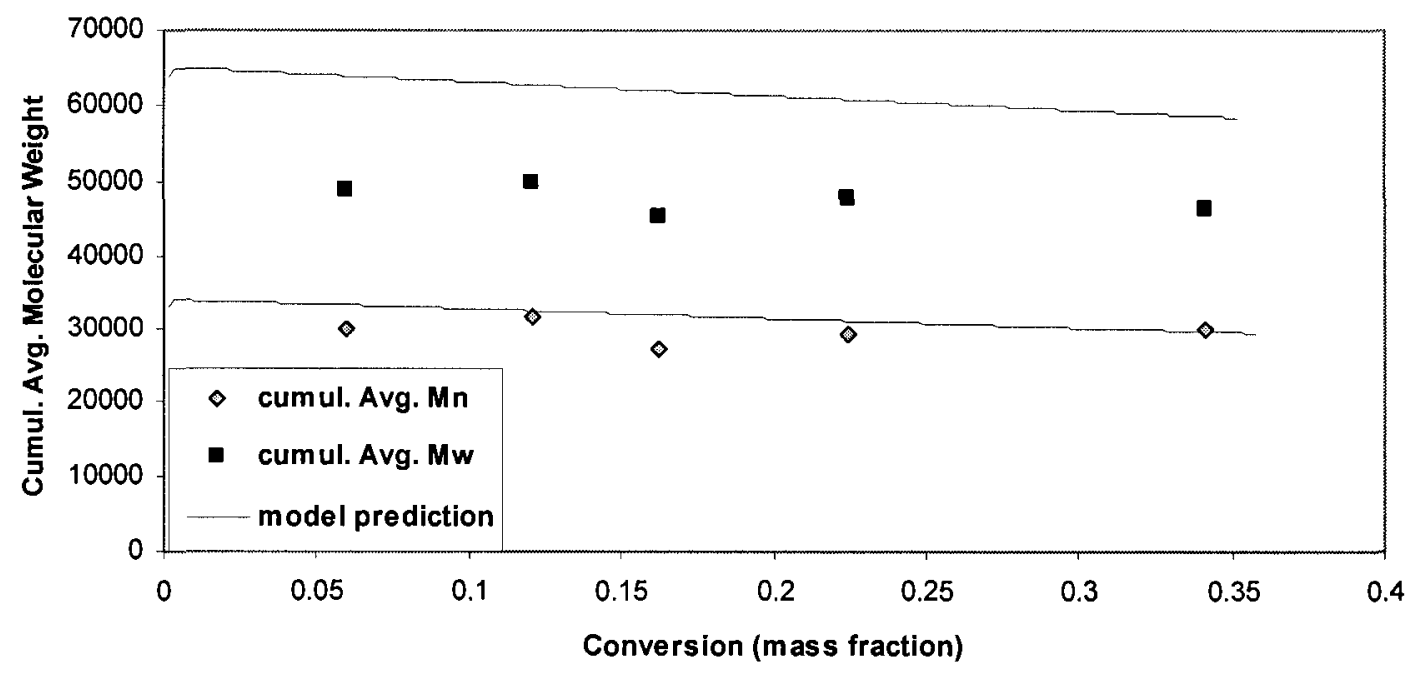

Figure 4.9 Cumulative average molecular weight versus conversion for VAc solution homopolymerization in FAME (80/20 wt \%)

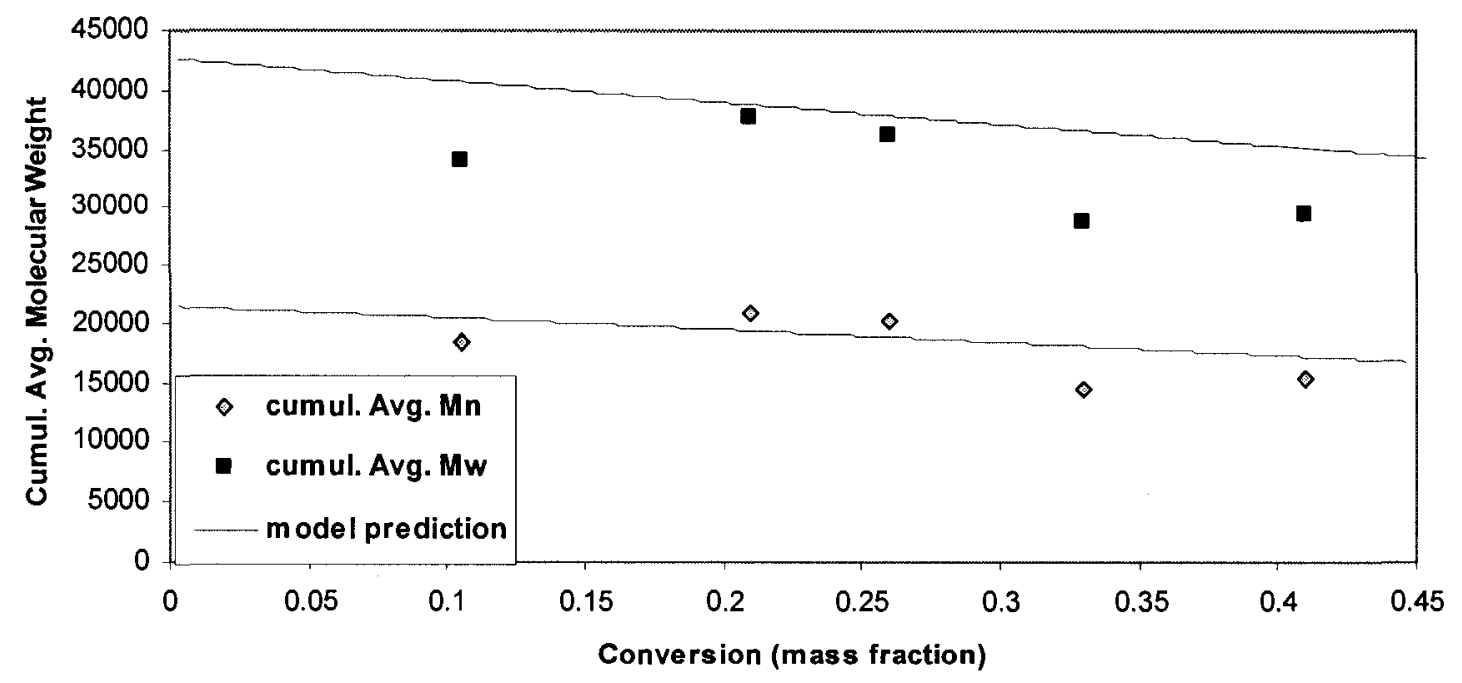

Figure 4.10 Cumulative average molecular weight versus conversion for BA solution homopolymerization in FAME (80/20 wt \%) 
In free radical polymerization, the chain length $\left(x_{n}\right)$ has the following relation to the monomer and initiator concentration (Odian, 2004):

$$
x_{n} \propto \frac{[M]}{[I]^{1 / 2}}
$$

Typically, in solution polymerization, the molecular weight vs. conversion has a maximum. The drop in molecular weight is caused by a drop in monomer concentration, which can be balanced by depletion in initiator; but as polymerization proceeds, these competing dependencies offset drops in molecular weight. With no initiator added, the drop in initiator concentration is relatively slow compared to the drop in monomer concentration, and the cumulative molecular weight constantly decreases (McManus et al., 2004). The first trend is clearly observed for PMMA molecular weight with an original feed monomer to solvent ratio of 50/50 (see Fig. 4.6) and moderately for that of $60 / 40$, but not for the high concentration of monomer ( $80 \mathrm{wt} . \%$ ) which is close to bulk polymerization system (see Fig. 4.7), however, the polymerization did not continue to high conversion. Cumulative molecular weight of polystyrene, which has high polymerization rate (see Fig. 4.3) and undergoes thermal polymerization, does not show the maximum probably due to self-initiation effect (see Fig. 4.8). Polymerization of BA and VAc was slow and only monitored in low conversion and no special trend was observed at those conversions (see Figs. 4.9 and 4.10).

\section{CONCLUSION}

The use of canola-based FAME as a solvent for homopolymerization of MMA, Sty, VAc and BA was investigated at $120^{\circ} \mathrm{C}$. A good solvent should be reasonably nonhazardous and inexpensive, but versatile; it should have low viscosity and good solubility 
properties. The results demonstrate that FAME from canola oil fulfills the requirements of a good high boiling solvent for solution polymerization of these commercially important monomers.

Previously reported solvent effects on homopolymerizations of these monomers in solution at $60^{\circ} \mathrm{C}$ (Salehpour and Dubé, 2007) were observed in this study at $120^{\circ} \mathrm{C}$ with different intensities. Chain transfer to solvent rate constants were obtained using the Mayo method. The transfer constants increased in the order: Sty $<\mathrm{BA}<\mathrm{MMA}<\mathrm{VAc}$ and were all higher than values calculated at $60^{\circ} \mathrm{C}$. The presence of FAME influenced the rate of polymerization and the effect of solvent was more pronounced for VAc polymerization, where suspected radical-solvent complexes that influence $k_{p}$ are more likely. Further study on the existence of these complexes and their effect on the rate of polymerization are recommended.

Model predictions for experimental data were done by adding new solvent data to the polymerization simulator, and incorporating the change of the lumped constant with the solvent concentration for each monomer. In all cases, model predictions for conversion and molecular weight development showed good agreement with experimental data.

Using FAME as a solvent for polymerization at elevated temperature increases the rate of reaction and results in higher productivity. On the other hand, it can decrease the polymer molecular weight, which can be undesirable. 


\section{ACKNOWLEDGMENTS}

The authors gratefully acknowledge the financial support of the Natural Science and Engineering Research Council (NSERC) of Canada.

\section{REFERENCES}

Benton, M.G. and C.S. Brazel , "Effect of Room-Temperature Ionic Liquids as Replacements for Volatile Organic Solvents in Free-Radical Polymerization", ACS Symposium Series 818, 125 (2002)

Brandrup, J., E.H. Immergut and E.A. Grulke, Eds. "Polymer Handbook", 4th Ed., Wiley-Interscience, New York (1999)

Buback, M., M. Egorov, R.G. Gilbert, V. Kaminsky, O.F. Olaj, G.T. Russell , P. Vana and G. Zifferer, "Critically Evaluated Termination Rate Coefficients for Free-Radical Polymerization, 1.The Current Situation", Macromol. Chem. Phys., 203, 2570 (2002)

Budavari, S., M. O'Neil, A. Smith and P.E. Heckelman, Eds. The Merck Index. Rahway: Merck and Co., 1989.

Burnett, G., G.G. Cameron and S.N. Joiner, "Effect of Solvent on Free Radical Polymerization of Styrene" J. Chem. Soc., 69, 322 (1972)

Clay, P.A. and R.G. Gilbert, "Molecular Weight Distributions in Free-Radical Polymerizations. 1. Model Development and Implications for Data Interpretation", Macromolecules, 28, 552 (1995)

Duan, J., Y. Shim and H.J. Kim, "Solvation in Supercritical Water", J. Chem. Phys., 20, 124, (2006)

Dubé, M.A., A.Y. Tremblay and J. Liu, "Biodiesel Production Using A Membrane Reactor" Biores. Tech., 98, 639 (2007)

F. R. Mayo, "Chain Transfer in The Polymerization of Styrene: The Reaction of Solvents with Free Radicals", J. Amer. Chem. Soc., 65, 2324, ( 1943)

Gao, J. and A. Penlidis, "A Comprehensive Simulator/Database Package for Reviewing Free-Radical Homopolymerizations" J. Macromol. Sci. Rev. Macromol. Chem. Phys., 36, 199 (1996)

Heuts, J.P.A., T.P. Davis and G.T. Russell, "Comparison of the Mayo and Chain Length Distribution Procedures for the Measurement of Chain Transfer Constants", Macromolecules, 32, 6019 (1999) 
Hu, J., Z. Du, Z. Tang and E. Min, "Study on the Solvent Power of a New Green Solvent: Biodiesel", Ind. Eng. Chem. Res. 43, 7928 (2004)

Hutchinson, R.A., J.R. Richards and M.T. Aronson, "Determination of Propagation Rate Coefficients by Pulsed-Laser Polymerization for Systems with Rapid Chain Growth: Vinyl Acetate", Macromolecules, 27, 4530 (1994)

Jordan, E.F., Jr, B. Artymyshyn and A.N. Wrigley, "Chain Transfer Constants for Vinyl Monomers Polymerized in Methyl Oleate and Methyl Stearate", J. Polym. Sci. Polym. Chem. 7, 2605 (1969)

Jovanović, R. and M.A. Dubé, "Solvent Effects in Butyl Acrylate and Vinyl Acetate Homopolymerizations in Toluene", J. Macromol. Sci. Polym. Rev., 44, 1 (2004)

Kamachi, M., D.J. Liaw and S. Nozakura, "Solvent Effect on Radical Polymerization of Vinyl Acetate” Polym. J., 12, 921, (1979)

McKenna, T.F., A. Villanueva and M. Santos, "Effect of Solvent on the Rate Constants in Solution Polymerization. Part I. Butyl Acrylate", J. Polym. Sci. Polym. Chem., 37, 589 (1999)

McKenna, T.F., A. Villanueva and M. Santos, "Effect of Solvent on the Rate Constants in Solution Polymerization. Part II. Vinyl Acetate", J. Polym. Sci. Polym. Chem., 37, 571 (1999)

McManus, N.T., G. Hsieh and A. Penlidis, "Free Radical Terpolymerization of Butyl Acrylate/Methyl Methacrylate and Alpha Methyl Styrene At High Temperature", Polymer, 45, 5837 (2004)

Mittelbach, M. and C. Remschmidt, "Biodiesel: The Comprehensive Handbook", Martin Mittelbach Paperback (2004)

Morrison, B.R., M.C. Piton, M.A. Winnik, R.G. Gilbert and D.H. Napper, "Solvent Effects on the Propagation Rate Coefficient for Free Radical Polymerization" Macromolecules, 26, 4368 (1993)

Nelson, W.M., “Are Ionic Liquids Green Solvent?”, ACS Symposium Series 818, 302002 .

Odian, G., "Principles of Polymerization", 4th Ed., John Wiley and Sons, Inc. (2004)

Quadir, M.A. and J.M. DeSimone, "Chain Growth Polymerization in Liquid and Supercritical Carbon Dioxide”, ACS Symposium Series 713, 156 (1998)

Rosen, S.L., "Fundamental Principles of Polymeric Materials," 2nd Ed., Wiley Interscience (1993) 
Salehpour, S., "Biodiesel: A Green Polymerization Solvent", M.A.Sc. Thesis, Department of Chemical Engineering, University of Ottawa, Ottawa, Ontario, Canada (2007)

Sheldon, R.A., "Green Solvents for Sustainable Organic Synthesis: State of the Art", Green Chem., 7, 267 (2005)

Sherman, J., B. Chin, P. Huibers, R. Garcia-Valls, T. Hatton, "Solvent Replacement for Green Processing”, Environ. Health Perspect., 106(Suppl 1), 253 (1998)

Zammit, M.D., T.P. Davis, G.D. Willett and K.F. O'Driscoll, "The Effect of Solvent on the Homo-Propagation Rate Coefficients of Styrene and Methyl Methacrylate" J. Polym. Sci. Polym. Chem., 35, 2311 (1997)

Zhang, Y., M.A. Dubé, D.D. McLean and M. Kates, "Biodiesel Production from Waste Cooking Oil: 2. Economic Assessment and Sensitivity Analysis" Biores. Tech., 90, 229 (2003) 
Chapter 5

PAPER III 


\title{
Solution Polymerization of Styrene using Biodiesel as a Solvent:
}

\section{Biodiesel Feedstock Effect}

\author{
Somaieh Salehpour, Marc A. Dubé*, Maya Murphy \\ Department of Chemical Engineering, University of Ottawa, \\ 161 Louis Pasteur, Ottawa, ON, KIN 6N5 Canada \\ *Marc.Dube@uOttawa.ca
}

Increasing environmental concerns regarding solvents commonly used in solution polymerization has led to a search for alternatives, such as biodiesel (a.k.a. fatty acid methyl esters or FAME). The effect of the feedstock used in biodiesel production when FAME is used as a polymerization solvent was studied for a commercially important monomer, styrene. A series of styrene homopolymerizations was carried out at different solvent concentrations for two biodiesel feedstocks: soybean oil and 50\% yellow grease $50 \%$ canola oil. Results were compared to runs from a previous study using FAME produced from canola oil. Considerable differences in the rate of polymerization were observed, while chain transfer to solvent constants had comparable values. The collected kinetic experimental data were modeled using a polymerization simulator and predictions of monomer conversion and number- and weight-average molecular weights for the investigated systems are presented. The microstructures of the final polymer products were also investigated using ${ }^{13} \mathrm{C}\left\{{ }^{1} \mathrm{H}\right\}-\mathrm{NMR}$ and ${ }^{1} \mathrm{H}$-NMR spectra. These revealed that there is no significant contribution of FAME solvent to long polymer chains. 


\section{INTRODUCTION}

Solution polymerization has been used for over half a century to produce polymers with valuable properties. The use of a solvent as a polymerization media prevents increases in viscosity by diluting the solution and prevents thermal runaway by absorbing the heat of polymerization (Rodriguez, 1996). The use of solution polymerization over the years has yielded polymers with recognized properties that are sometimes difficult to achieve with other polymerization technologies (Jovanović and Dubé, 2004). However, commonly used solvents, such as toluene and benzene, are known to be hazardous to human health and the environment. They can cause cancer, infertility and genetic disorders in individuals frequently exposed to them, and also have a negative impact on our ecosystem (Sherman et al., 1998). Growing concerns over the volatile organic content (VOC) of common solvents has led to a search for alternatives (Benton and Brazel, 2002).

A number of issues influence the choice of polymerization solvent. The solvent should be non-toxic and reasonably non-hazardous, but versatile. Water may be used as a solvent for some polymerizations; it is non-hazardous, and relatively plentiful and inexpensive. However, many monomers are insoluble in water due to its polarity. Consequently, water is generally not a good substitute for organic solvents (Duan et al., 2006). Supercritical fluids have also been suggested as an alternative (Yang et al., 2005). Although the use of extreme conditions to achieve supercritical conditions eradicates the problem of polarity, it also increases energy requirements and cost, and may lead to corrosion problems for process equipment. As a result, supercritical fluids are not universally accepted as industrially viable solvent candidates (Sherman et al., 1998). 
In the $1960 \mathrm{~s}$, the use of methyl oleate as a polymerization solvent was explored (Jordan et al., 1969). However, the high cost of the pure compound prevented its widespread application. Methyl oleate is a major component of biodiesel (fatty acid methyl esters or FAMEs), an environmentally friendly alternative to petroleum diesel. The solvent powers of biodiesel have only recently started to be investigated (Hu et al., 2004). Table 5.1 shows the toxicity, the permissible exposure limit (PEL) reported by the Occupational Safety and Health Administration (OSHA) and the price of common polymerization solvents compared to biodiesel and methyl oleate. There are clear indications from both an economic and health and safety perspective, that biodiesel may prove to be a useful solvent for polymerization.

Table 5.1 Comparison of polymerization solvents.

\begin{tabular}{|l|l|c|c|}
\hline \multicolumn{1}{|c|}{ Solvent } & \multicolumn{1}{|c|}{ Toxicity } & $\begin{array}{c}\text { OSHA PEL 8h } \\
\text { ppm }\end{array}$ & $\begin{array}{c}\text { Price } \\
\text { US\$/L }\end{array}$ \\
\hline Toluene $^{\mathrm{a}}$ & $\begin{array}{l}\text { Narcotic, liver and } \\
\text { kidney damage in } \\
\text { high concentration }\end{array}$ & 200 & 35.00 \\
\hline Benzene $^{\mathrm{a}}$ & Carcinogen & 10 & 49.00 \\
\hline Ethyl acetate $^{\mathrm{a}}$ & $\begin{array}{l}\text { Narcotic, liver and } \\
\text { kidney damage at } \\
\text { high concentrations }\end{array}$ & 400 & 46.00 \\
\hline Xylene $^{\mathrm{a}}$ & $\begin{array}{l}\text { Narcotic at high } \\
\text { concentrations }\end{array}$ & 100 & 43.00 \\
\hline Methyl oleate $^{\mathrm{a}}$ & $\begin{array}{l}\text { Non-hazardous } \\
\text { material }\end{array}$ & None & 1200.00 \\
\hline Biodiesel $^{\mathrm{b}}$ & $\begin{array}{l}\text { Non-hazardous } \\
\text { material }\end{array}$ & None & 0.60 \\
\hline
\end{tabular}

a) Sigma-Aldrich anhydrous, 99+\%, MSDS. Toxicity information from (Budavari et al., 1989: Sitting, 1991).

b) Toxicity information from (Mittelbach et al., 2004). 
Biodiesel has garnered much attention in recent years as an environmentally friendly alternative to diesel fuel. It is "carbon neutral", rapidly biodegradable and nontoxic. Biodiesel has the chemical structure of fatty acid alkyl esters (FAAE) and is produced by the transesterification of vegetable oils, animal fats or grease with an alcohol in the presence of a catalyst. The reaction scheme is shown in Figure 5.1.

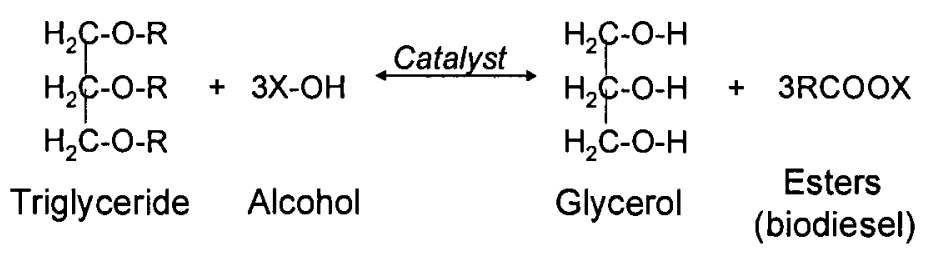

Figure 5.1 General reaction of the transesterification of triglyceride.

Biodiesel can be produced from a variety of different feedstocks. The most common feedstock worldwide is rapeseed oil (or the genetically modified form of rapeseed: canola), while that for the United States is soybean oil (Mittelbach et al., 2004). In recent years, the focus has been shifting towards the use of multiple feedstocks comprised of animal fats and waste frying oils (yellow grease), so as not to compete with food supplies as well as for economical reasons (BBI International, 2005). Biodiesel is comprised primarily of C16 and C18 methyl esters. As shown in Table 5.2, biodiesel from different sources varies in composition. Biodiesel derived from soybean oil has a higher percentage of FAME 18:2 and thus, has more double bonds than biodiesel from other feedstocks. In contrast, biodiesel derived from animal fats or yellow grease tends to have less double bonds and shorter fatty acid chain lengths than that from vegetable oil. To measure the degree of unsaturation or number of double bonds per mass of sample, iodine is introduced to the oil and it will attach over double bonds to form single bonds. 
The amount of iodine in grams that is taken up by 100 grams of the biodiesel is known as the iodine value, which is $94-120$ for canola, $120-143$ for soybean and 80-100 for yellow grease biodiesel (Knothe, 2002). A higher iodine value indicates a higher degree of unsaturation.

Table 5.2 Biodiesel fatty acid alkyl esters composition from commonly used feedstocks. Carbon chain length: number of unsaturations

\begin{tabular}{|c|c|c|c|c|c|c|c|c|c|}
\hline \multirow{2}{*}{$\begin{array}{l}\text { Biodiesel } \\
\text { Feedstock }\end{array}$} & \multirow{2}{*}{$\begin{array}{l}\text { Iodine } \\
\text { Value }\end{array}$} & \multicolumn{8}{|c|}{ FAAE Composition ${ }^{\mathrm{a}}[\mathrm{wt} . \%]$} \\
\hline & & $12: 0$ & $14: 0$ & $16: 0$ & $16: 1$ & 18:0 & $18: 1$ & $18: 2$ & $18: 3$ \\
\hline Canola & $94-120$ & - & - & $3-5$ & - & $1-2$ & $55-65$ & $20-26$ & $8-10$ \\
\hline Soybean & $120-143$ & - & - & $11-12$ & - & $3-5$ & $23-25$ & $52-56$ & $6-8$ \\
\hline $\begin{array}{l}\text { Yellow } \\
\text { Grease }\end{array}$ & $80-100$ & 0.5 & $1-3$ & $13-25$ & $0-4$ & $5-12$ & $43-52$ & $7-22$ & $0.5-3$ \\
\hline
\end{tabular}

${ }^{\text {a) }}$ From (Mittelbach et al., 2004).

The first reported study of FAME as a polymerization solvent was performed at the University of Ottawa (Salehpour and Dubé, 2007). FAME produced from canola oil feedstock was found to be successful as a solvent for the polymerization of various monomers (styrene, methyl methacrylate, butyl acrylate and vinyl acetate).

In this paper, the effect of feedstock on the use of FAME as a polymerization solvent is explored for a commercially important monomer, styrene. The rate of polymerization, the average molecular weight of polymers and the chain transfer constant were studied using FAME produced from three separate feedstocks: canola oil, soybean oil, and $50 \%$ yellow grease $/ 50 \%$ canola oil. Finally, the collected kinetic experimental data were modeled using the WATPOLY polymerization simulator (Gao and Penlidis, 1996). 


\section{EXPERIMENTAL}

\section{Materials}

Styrene monomer (99\%, inhibited by 10-15 ppm 4-tert-butylcatechol, Aldrich; StLouis, MO) was distilled at $40^{\circ} \mathrm{C}$ under vacuum. To remove the inhibitor, styrene was washed 3 times with a $10 \%(\mathrm{v} / \mathrm{v})$ sodium hydroxide solution, then washed 3 times with distilled de-ionized water and dried over calcium chloride prior to vacuum distillation. Distillations were completed a maximum of $24 \mathrm{~h}$ prior to polymerization, and the monomers were stored at $-10^{\circ} \mathrm{C}$. The initiator, 2,2-azobisisobutyronitrile (Dupont Chemicals), was recrystallized three times in absolute methanol.

FAME was produced in house by transesterification of triglyceride with methanol (99.85\% Reag. Grade, Commercial Alcohols Inc.; Brampton, ON, Canada) using sodium hydroxide catalyst (97 wt. $\% \mathrm{NaOH}, \mathrm{EMD}$ Chemicals Inc.; $\mathrm{NJ}, \mathrm{USA}$ ) at $65^{\circ} \mathrm{C}$ via a membrane reactor process (Dubé et al., 2006). A catalyst concentration of $0.5 \mathrm{wt.} \%$ based on the amount of oil and a methanol/oil ratio of 1:1 were used. FAME was produced from three different sources of triglycerides: canola oil (No Name®; Toronto, ON, Canada, purchased at a local food store), soybean oil (Mr. Goudas ${ }^{\circledR}$, Goudas Food Products; Concord, ON, Canada, purchased at a local food store) and 50\% yellow grease (supplied by Veggie Gas; Gatineau, Quebec) - 50\% canola oil (No Name ${ }^{\circledR}$; Toronto, ON, Canada, purchased at a local food store). HPLC analysis of the FAME showed no traces of triglycerides. The FAME was washed with de-ionized water and then distilled under vacuum. The resulting FAME was comprised of various fatty acid methyl esters (FAMEs). Any FAME physical properties were estimated from the composition data shown in Table 5.2. 
Hexanes (Fisher Chemicals, HPLC Grade, UV cutoff $195 \mathrm{~nm}$ ) and tetrahydrofuran (THF) (Sigma-Aldrich, HPLC Grade, $\geq 99.9 \%$ inhibitor free) were used for polymer characterization and sample work-up without further purification.

\section{Polymerization}

Polymerizations were done according to standard ampoule polymerization methods (Salehpour and Dubé, 2007). The reactions were carried out in glass ampoules (17 cm length, $0.8 \mathrm{~cm}$ outer diameter) placed in a $60^{\circ} \mathrm{C}$ water bath. The reaction conditions are described in Table 5.3. The same ratio of initiator to monomer, $0.4 \mathrm{phm}$ (parts per 100 parts by weight of monomer) of initiator was utilized. Prior to polymerization, the ampoules were degassed using three freeze-thaw cycles under vacuum and then flame-sealed. After polymerization, the polymer was extracted by precipitation in hexanes.

Table 5.3 Polymerization reaction conditions.

\begin{tabular}{|c|c|c|c|c|c|}
\hline \multicolumn{2}{|c|}{ Canola-based FAME } & \multicolumn{2}{|c|}{ Soybean-based FAME } & \multicolumn{2}{|c|}{$\begin{array}{c}50 \% \text { yellow grease }+ \\
50 \% \text { canola based FAME }\end{array}$} \\
\hline Expt. & $\begin{array}{c}\text { Styrene/FAME } \\
\text { (wt. } \%)\end{array}$ & Expt. & $\begin{array}{c}\text { Styrene/FAME } \\
(\text { wt.\%) }\end{array}$ & Expt. & $\begin{array}{c}\text { Styrene/FAME } \\
\text { (wt.\%) }\end{array}$ \\
\hline $\mathrm{Cl}$ & $50 / 50$ & $\mathrm{~S} 1$ & $50 / 50$ & Y1 & $50 / 50$ \\
\hline $\mathrm{C} 2$ & $60 / 40$ & $\mathrm{~S} 2$ & $60 / 40$ & $\mathrm{Y} 2$ & $60 / 40$ \\
\hline C3 & $80 / 20$ & $\mathrm{~S} 3$ & $80 / 20$ & Y3 & $80 / 20$ \\
\hline
\end{tabular}

${ }^{\text {a) }}$ Results were obtained from previous work (Salehpour and Dubé, 2007).

\section{Characterization}

Gravimetry was used to calculate conversion. A Waters Associates gel permeation chromatograph equipped with a Waters model 410 refractive index detector was used to 
determine the cumulative number- and weight-average molecular weights. Three Waters Ultrastyragel packed columns $\left(10^{3}, 10^{4}\right.$, and $\left.10^{6} \AA\right)$ were installed in series. Filtered THF circulating at a flow rate of $0.3 \mathrm{~mL} / \mathrm{min}$ at $38^{\circ} \mathrm{C}$ was used as eluent. Polystyrene (SHODEX, Showa, Denko, Tokyo, Japan) standards with peak molecular weights between $1.3 \times 10^{3}$ and $3.15 \times 10^{6} \mathrm{~g} / \mathrm{mol}$ were used for calibration. Standards and samples were dissolved in THF to a concentration of $0.2 \% \mathrm{w} / \mathrm{v}$ and filtered through $0.45-\mu \mathrm{m}$ filters before injection to remove any gel or impurities that may have been present. Millenium 32 software (Waters) was used for data acquisition.

${ }^{1} \mathrm{H}-\mathrm{NMR}$ and ${ }^{13} \mathrm{C}\left\{{ }^{1} \mathrm{H}\right\}$-NMR spectra were recorded at room temperature for all samples dissolved in $\mathrm{CDCl}_{3}$ (Sigma-Aldrich) with a Bruker $400-\mathrm{MHz}$ spectrometer. To refine the assignments of signals in the ${ }^{1} \mathrm{H}-\mathrm{NMR}$ and ${ }^{13} \mathrm{C}\left\{{ }^{1} \mathrm{H}\right\}-\mathrm{NMR}$ spectra, a 2D HMQC experiment was used to clarify correlations between the chemical shifts of carbon nuclei and their attached protons.

\section{RESULTS AND DISCUSSION}

\section{Chain transfer to solvent}

Studying the chain transfer to solvent constant, $C_{f s}$, is one conventional way to observe the effect of solvent on polymerization kinetics. Chain transfer can be studied quantitatively using the chain transfer to solvent constant $\left(C_{f s}\right)$ :

$C_{f s}=\frac{k_{f s}}{k_{p}}$ 
where $k_{f s}$ is the chain transfer to solvent rate parameter and $k_{p}$ is propagation rate parameter. The Mayo method (Mayo, 1943) can be used to determine the value of transfer constants from their effect on the number average degree of polymerization $\left(\bar{X}_{n}\right)$ :

$$
\frac{1}{\bar{X}_{n}}=\frac{k_{t} R_{P}}{k_{P}^{2}[M]^{2}}+C_{M}+C_{f s} \frac{[S]}{[M]}+C_{I} \frac{k_{t} R_{P}^{2}}{k_{P}^{2} f k_{d}[M]^{3}}
$$

where $\bar{X}_{n}$ is the number-average degree of polymerization, $R_{p}$ is the rate of polymerization, $k_{t}, k_{p}$ and $k_{d}$ are the termination, propagation and initiator decomposition rate coefficients, respectively. $f$ is the initiator efficiency, $[M]$ and $[S]$ are the concentration of the monomer and solvent, respectively, and $C_{f m}, C_{f s}$ and $C_{f i}$ are the transfer constants to monomer, solvent and initiator, respectively.

The last term in Eqn. 3 is negligible since a low concentration of AIBN, which has a very small $C_{l}$, was used as initiator. Variation caused by the first term of the equation was assumed to be negligible as compared to the variation caused by the chain transfer to solvent term. Nonetheless, this term will change with changes in $[S] /[M]$ because the termination rate parameter, $k_{t}$, is chain length dependent and will vary due to the effect of $[\mathrm{S}] /[\mathrm{M}]$ on the average chain length. This is a weakness of the Mayo method; however, the effect is not significant for all practical purposes (Heuts et al., 1999). Therefore, holding the first term constant, the equation can be reduced to:

$$
\frac{1}{\bar{X}_{n}}=\frac{1}{\bar{X}_{n 0}}+C_{f s} \frac{[S]}{[M]}
$$

where $\bar{X}_{n 0}$ is the number average degree of polymerization in the absence of solvent. The value of $C_{f s}$ can then be obtained from the slope of a plot of $1 / \bar{X}_{n}$ versus $[S] /[M]$ (see Fig. 5.2). The chain transfer data are summarized in Table 5.4. 


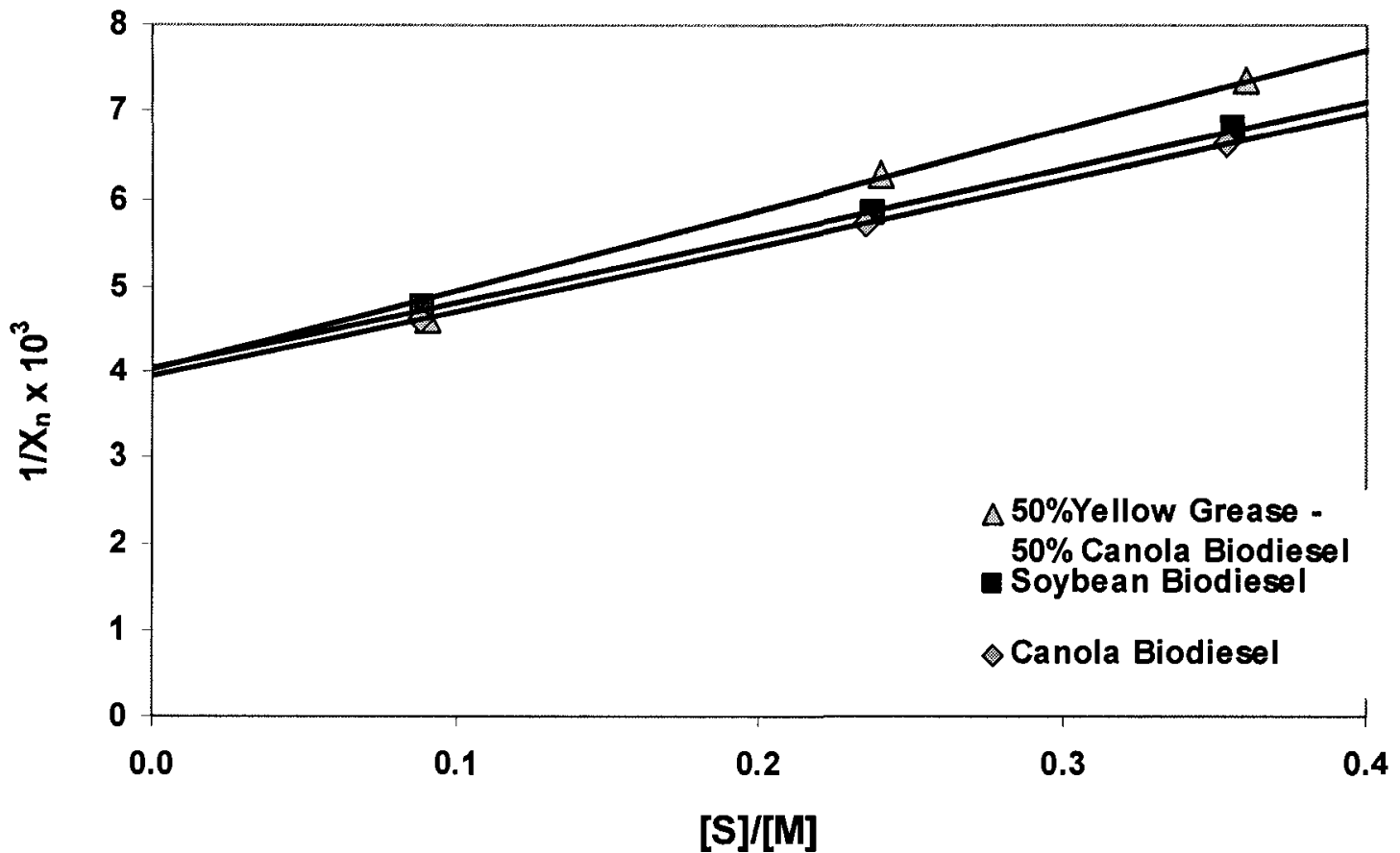

Figure 5.2 Reciprocal number-average degree of polymerization as a function of the solvent to monomer ratio for the various FAME types.

Table 5.4 Chain transfer data.

\begin{tabular}{lccccc}
\hline Experiment & $\bar{M}_{n}$ & $1 / \bar{X}_{n} \times 10^{3}$ & {$[S] /[M]$} & $\begin{array}{c}\text { Conversion, } \\
\text { (wt.\%) }\end{array}$ & $C_{s} \times 10^{4}$ \\
\hline \multicolumn{5}{c}{ Canola-based FAME } \\
C1 & 15700 & 6.62 & 0.35 & 8.27 & \\
C2 & 18200 & 5.71 & 0.23 & 11.74 & 75 \\
C3 & 22500 & 4.62 & 0.08 & 9.12 & \\
& \multicolumn{5}{c}{ Soybean-based FAME } \\
S1 & 15300 & 6.80 & 0.35 & 9.35 & \\
S2 & 17800 & 5.83 & 0.23 & 10.42 & 76 \\
S3 & 21900 & 4.75 & 0.08 & 8.06 & \\
& $50 \%$ yellow grease/50\% canola-based FAME & \\
Y1 & 14100 & 7.36 & 0.36 & 11.28 & \\
Y2 & 16500 & 6.28 & 0.24 & 6.82 & 91 \\
Y3 & 22600 & 4.60 & 0.09 & 8.09 & \\
\hline
\end{tabular}


Comparing results using FAME from different feedstocks reveals that the chain transfer constants have similar values, which are within the range of experimental error. This indicates that variation of solvents (FAME from different feedstocks) does not appear to have a significant effect on polymerization kinetics in terms of chain transfer reactions.

\section{$\underline{\text { Rate of polymerization }}$}

The overall rate of polymerization $\left(R_{p}\right)$ is defined according to the classical freeradical polymerization approach (Rodriguez, 1996):

$$
R_{p}=k_{p}\left(\frac{f k_{i}}{k_{t}}\right)^{1 / 2}[M][I]^{1 / 2}
$$

where $k_{p}, k_{d}$, and $k_{t}$ are the propagation, initiator decomposition, and termination rate parameters, respectively. $f$ is the initiator efficiency; and $[M]$ and $[I]$ are the monomer and initiator concentrations, respectively.

Conversion versus time data at three concentrations of solvent for each of the FAME feedstocks are shown in Figures 5.2 through 5.4, along with model predictions from the WATPOLY simulator. The parameters for the FAME, which include physical property data and the estimated $C_{f s}$ values, were added to the simulator's database. The model was fitted to the experimental conversion and molecular weight data by changing the lumped rate parameter $\left(k_{p} / k_{t}^{1 / 2}\right)$ for each individual monomer. As can be seen in Figures 5.3 through 5.5, within experimental error, the model demonstrates reliable predictions at lower concentration of solvent using a single "lumped" kinetic rate parameter for each solvent. Small deviations between the data and the model predictions were observed at higher solvent concentrations for FAME from canola oil and yellow 
grease/canola oil with greater deviations for FAME from soybean oil. This indicates the change in the lumped rate parameter $\left(k_{p} / k_{t}^{0.5}\right)$ with solvent concentration, which is more pronounced in the case of polymerization in soybean-based FAME that shows a higher effect of solvent on the rate of polymerization and therefore has the lowest polymerization rates. The modified parameters are $0.38,0.37,0.28$, for canola oil, soybean oil and yellow grease/canola FAME, respectively.

In all cases, the rate of polymerization decreased with increasing solvent concentration. This is consistent with Egn. 2: the dilution effect of the solvent decreases the concentration of monomer, thereby decreasing the rate of polymerization.

Solvent is also known to have an effect on the rate parameters (Jovanovic et al., 2004). Existence of either a radical-solvent or radical-monomer complex is well documented (Burnett et al., 1972, Coote et al., 1998). This complex can participate in propagation reactions and modify the reactivity of reactants. For example, $k_{p}$ is expected to decrease with increasing solvent concentration if more radical-solvent or monomersolvent complexes that inhibit the propagation reaction are formed. Nonetheless, the stability and reactivity of these complexes determines whether $k_{p}$ is increased or decreased compared to bulk polymerization (Zammit et al., 1997). The effect is exhibited in the Arrhenius parameters for $k_{p}$, i.e., $E_{a}$ and $A$. Hence, solvent can influence the propagation without showing any change in $k_{p}$ because these two factors can cancel (Zammit et al., 1997).

On the other hand, $k_{t}$ is usually diffusion controlled and expected to increase with increasing solvent concentration if the potential for chain transfer to solvent is high. 
Chain transfer stops polymer growth, thereby generating smaller, more mobile chains, which can terminate faster (Buback et al., 2002).

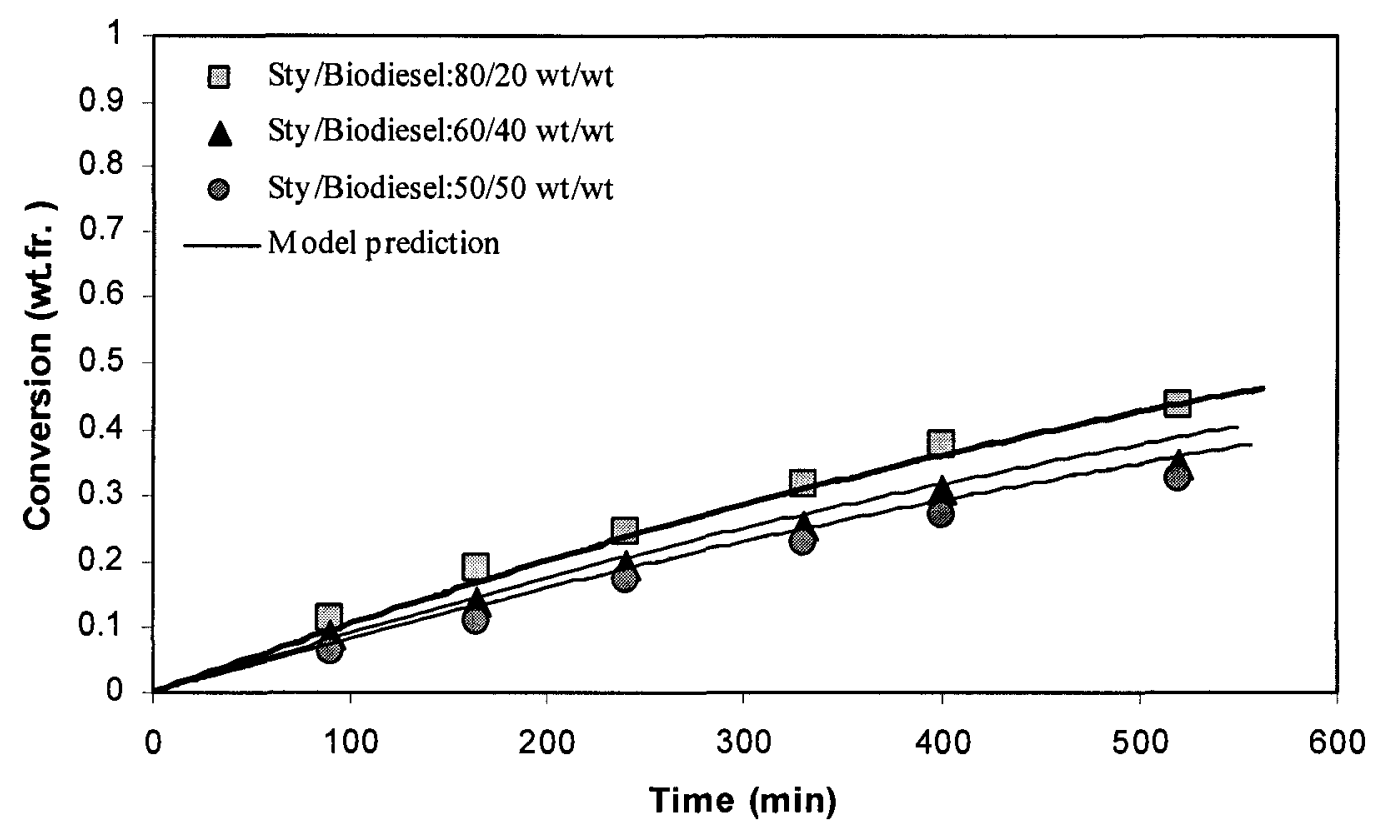

Figure 5.3 Conversion versus time for canola-based FAME.

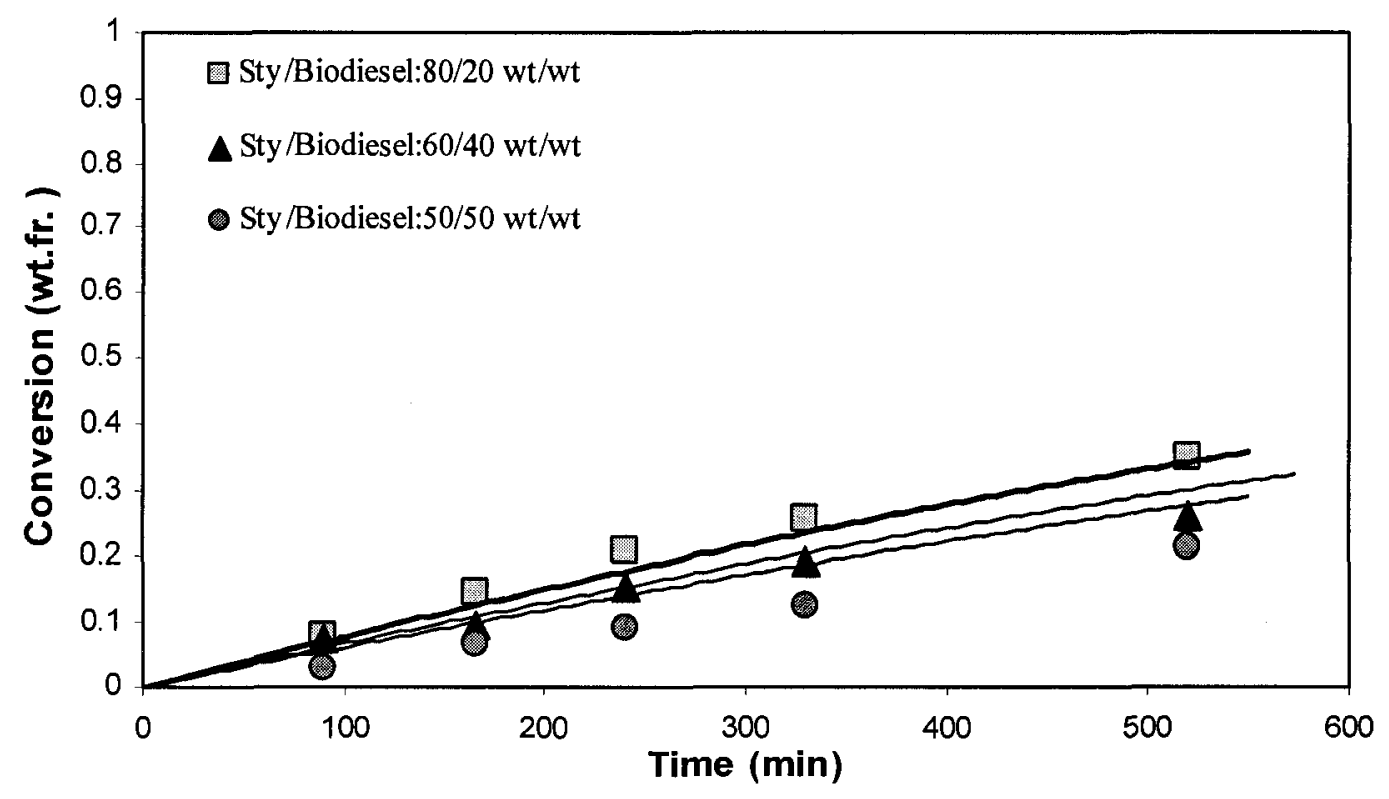

Figure 5.4 Conversion versus time for soybean-based FAME. 


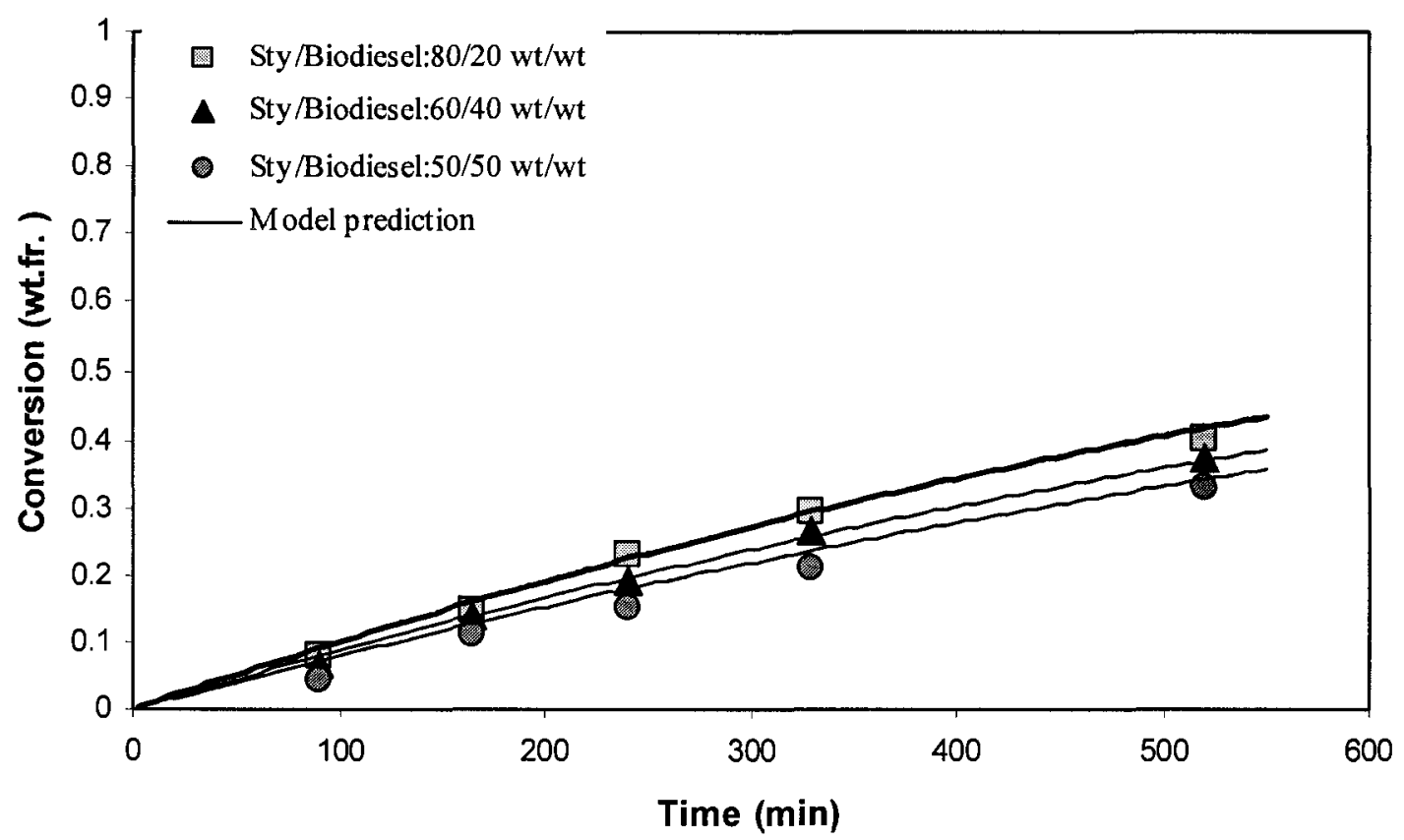

Figure 5.5 Conversion versus time for 50\% yellow grease - 50\% canola based FAME.

In Figure 5.6, the same conversion versus time data as above are shown for the three FAME types at $50 \mathrm{wt} . \%$ concentrations of solvent to highlight their differences. All other figures are available in the Appendix A.

Of the FAME types studied, FAME from a soybean oil feedstock was found to have the greatest effect on the conversion of styrene, while FAME from canola oil and that from a mixture of 50\% yellow grease and 50\% canola oil yielded comparable results. The observed difference between feedstocks is most pronounced at the highest concentration of solvent (i.e., at a styrene/FAME ratio of 50/50 wt.\%). Since the concentration of monomer was the same for all FAME feedstocks, the observed difference between polymerization rates cannot be explained by the dilution effect alone. 
Thus, the solvent itself must have been a major contributing factor, and the FAME feedstock must have affected the rate parameters.

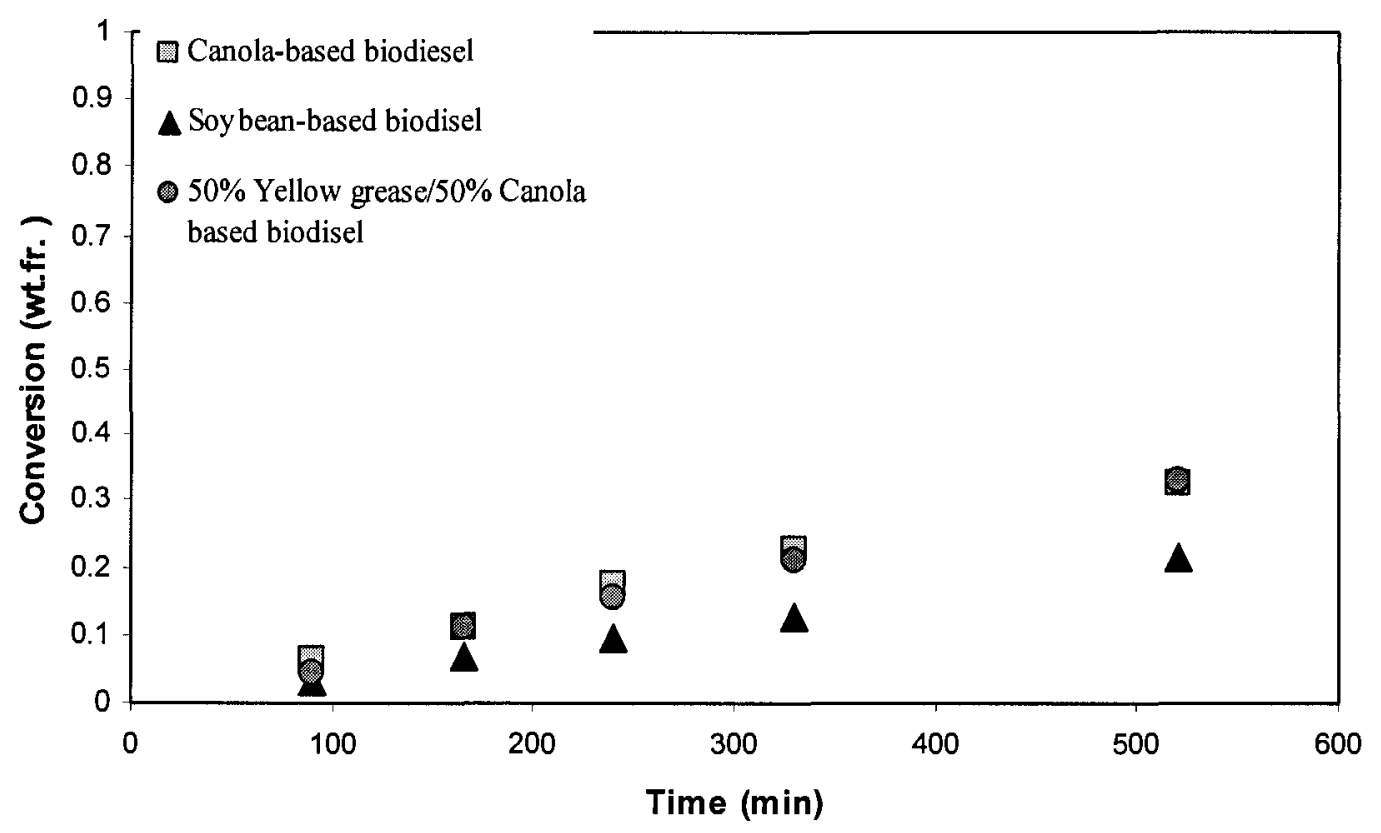

Figure 5.6 Conversion versus time for 50/50 wt $\%$ monomer/FAME.

The significant differences in rates of polymerization, molecular weights and chain transfer constants between the experiments using different FAME solvents may be attributed to variations in their FAMEs composition and consequently to their degree of unsaturation or iodine value (see Table 5.2, where the alkyl is a methyl group). FAME derived from soybean oil has a higher percentage of double bonds in the fatty acid chains of the esters (120-143 iodine value). The presence of these double bonds is hypothesized to play a role in decreasing the rate of polymerization due to the formation of monomersolvent or radical-solvent complexes. These complexes are known to inhibit the polymerization propagation reaction (Coote et al., 1998) and this is consistent with our experimental results.

Molecular weights 
In most of the experiments, the average molecular weight of the polymer remained roughly constant with increasing conversion. Figure 5.7 shows $M_{w}$ as a function of conversion for soybean-based FAME, along with model predictions. The model shows acceptable prediction for most concentrations.

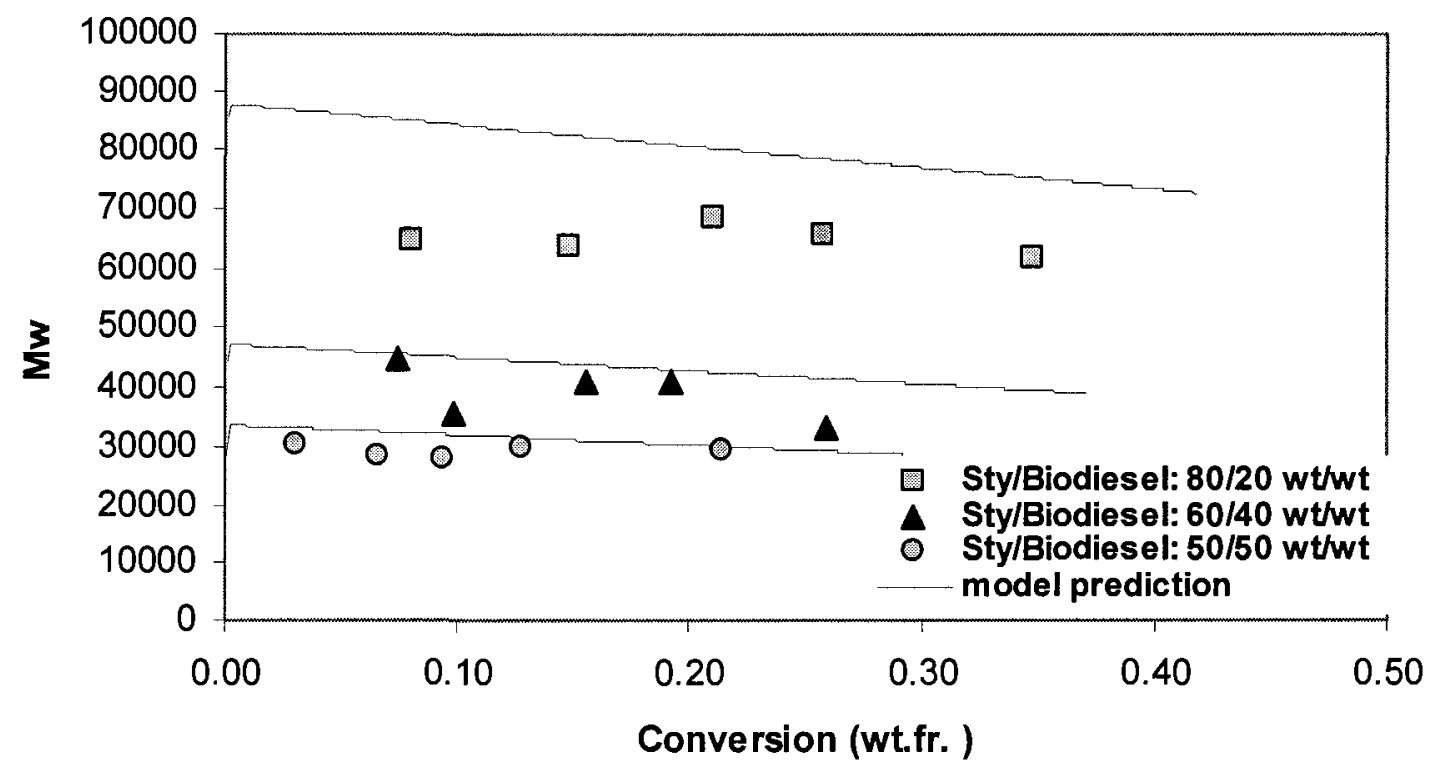

Figure 5.7 Weight-average molecular weight versus conversion for soybean-based FAME.

As expected, due to chain transfer potential, $M_{w}$ increased with decreasing solvent concentration. The less solvent present, the less there was potential for chain transfer to solvent. Growth of the polymer chains was consequently less inhibited, yielding polymers of greater average molecular weight.

NMR Analysis

A ${ }^{1}$ H-NMR investigation for determining the effect of different FAMEs on the final polymer product was performed for all polymer samples including samples from the previous study using canola-based FAME. The acquisition of spectra by this method is fast but diagnostic signals for individual compounds may overlap. Therefore, 
supplementary analyses were made with ${ }^{13} \mathrm{C}\left\{{ }^{1} \mathrm{H}\right\}-\mathrm{NMR}$ for samples generated at $50 \mathrm{wt} . \%$ solvent concentration. To achieve a better comparison and distinguish any contribution of solvent to polymer microstructure, ${ }^{1} \mathrm{H}-\mathrm{NMR}$ and ${ }^{13} \mathrm{C}-\mathrm{NMR}$ analyses were performed on all FAME samples and a sample of polystyrene, which was polymerized in a solvent-free medium at similar experimental conditions. In addition, selected samples were examined by heteronuclear multiple quantum coherence (HSQC), which is a two-dimensional NMR analysis.

In Figures 5.8 through 5.12, ${ }^{1} \mathrm{H}-\mathrm{NMR}$ and ${ }^{13} \mathrm{C}\left\{{ }^{1} \mathrm{H}\right\}$-NMR spectra of polystyrene samples obtained from solution polymerization in three different FAMEs are presented. Comparing the spectra for different polymer samples, both ${ }^{1} \mathrm{H}-\mathrm{NMR}$ and ${ }^{13} \mathrm{C}\left\{{ }^{1} \mathrm{H}\right\}$-NMR polymer chain signals are very similar within the range of experimental error.

In ${ }^{1} \mathrm{H}-\mathrm{NMR}$ spectra, peaks occur mainly at 1-3 ppm for aliphatic moieties and in 6.5-8 ppm for aromatic moieties of the polystyrene chains. In ${ }^{13} \mathrm{C}\left\{{ }^{1} \mathrm{H}\right\}$-NMR spectra, backbone resonances are closely spaced at $40-45 \mathrm{ppm}$, while aromatic resonances are presented as a cluster at $125-130 \mathrm{ppm}$ and one peak at approximately $145 \mathrm{ppm}$ for the aromatic carbon which is attached to the polymer backbone. 


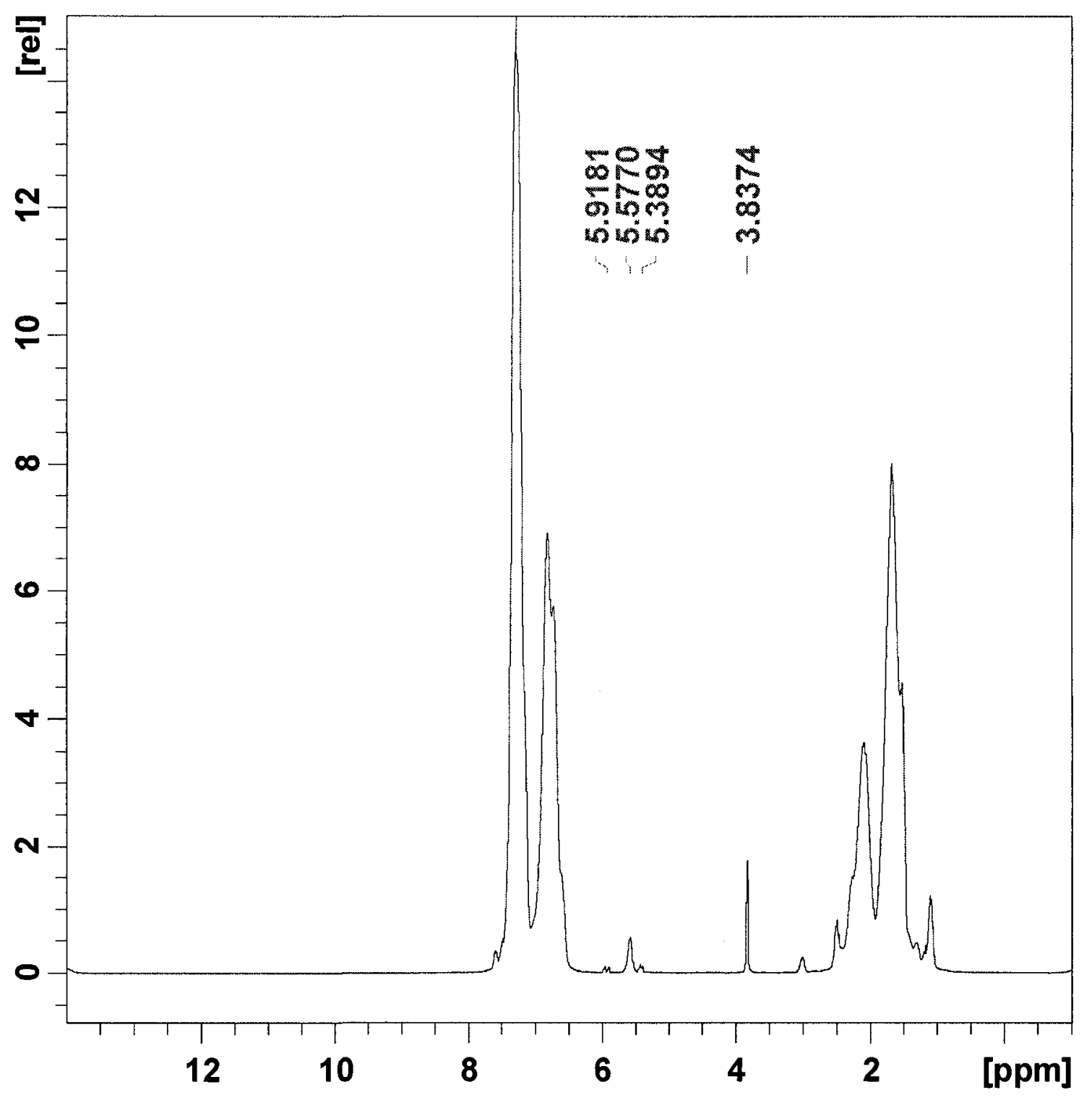

Figure 5.8 ${ }^{1} \mathrm{H}-\mathrm{NMR}$ spectrum of polystyrene in $\mathrm{CDCl}_{3}$. Polymerization was performed in canola-based FAME. 


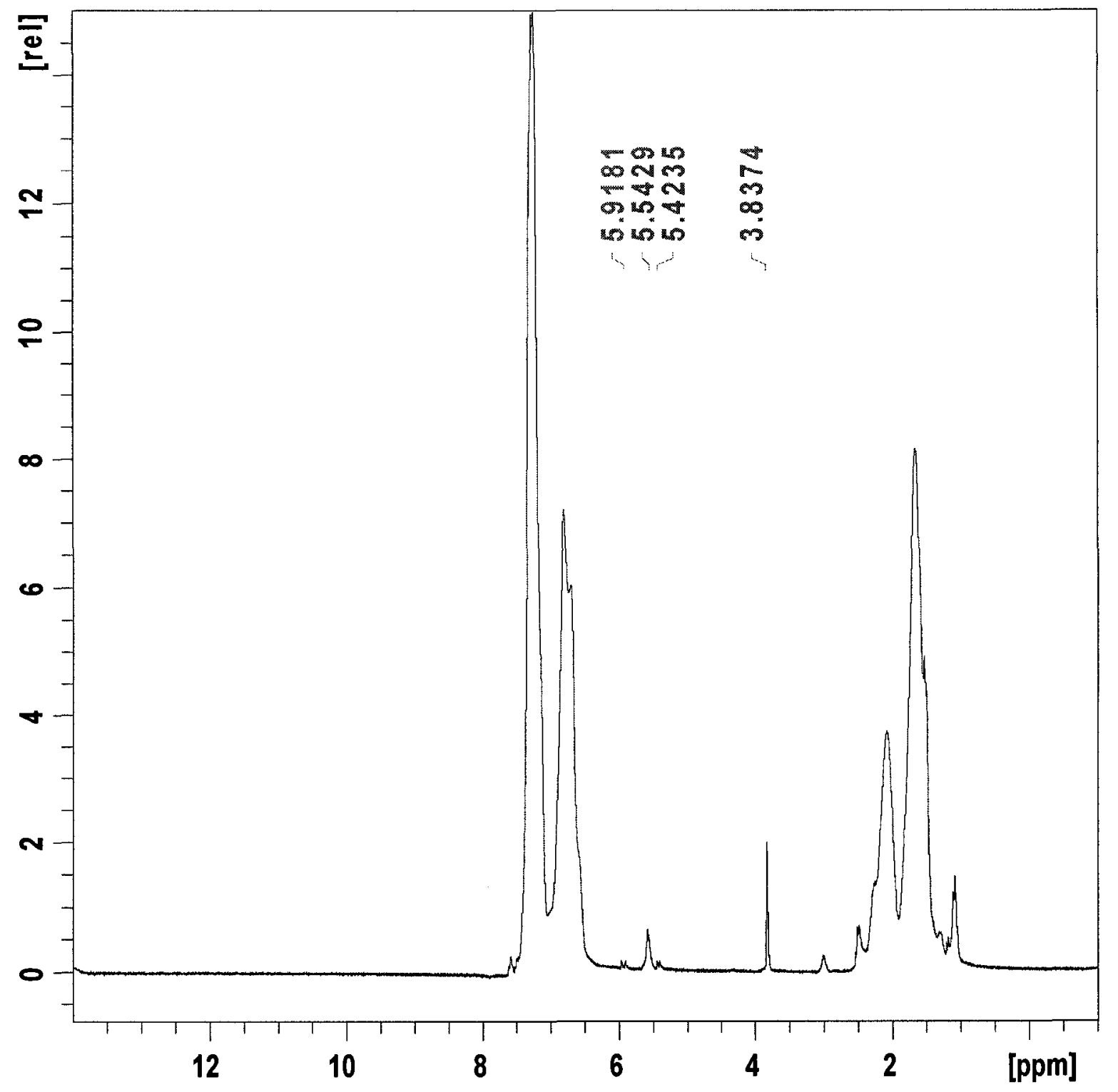

Figure 5.9 ${ }^{1} \mathrm{H}-\mathrm{NMR}$ spectrum of polystyrene in $\mathrm{CDCl}_{3}$. Polymerization was performed in soybean-based FAME. 


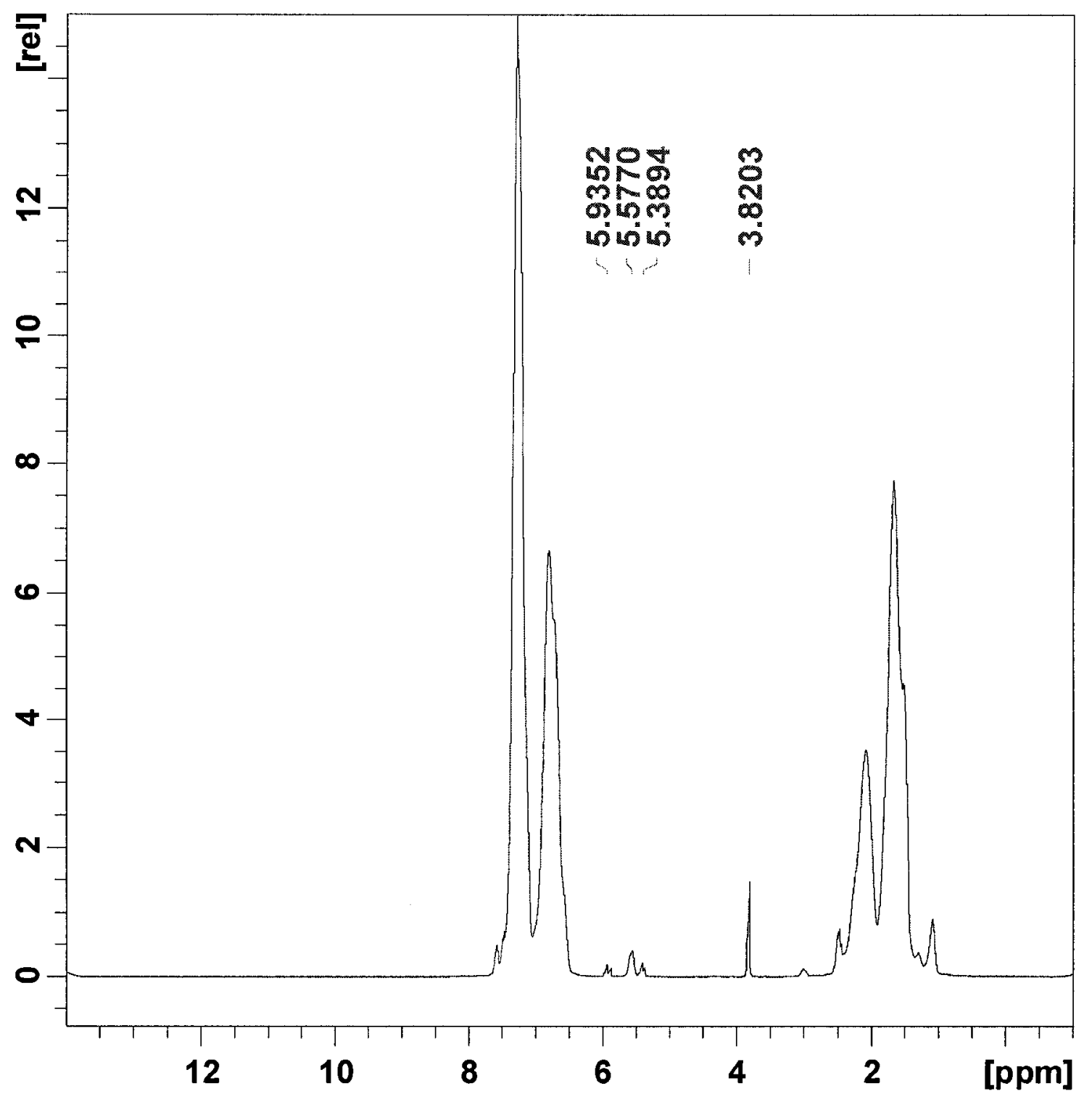

Figure 5.10 ${ }^{1} \mathrm{H}-\mathrm{NMR}$ spectrum of polystyrene in $\mathrm{CDCl}_{3}$. Polymerization was performed in $50 \%$ yellow grease - $50 \%$ canola-based FAME. 


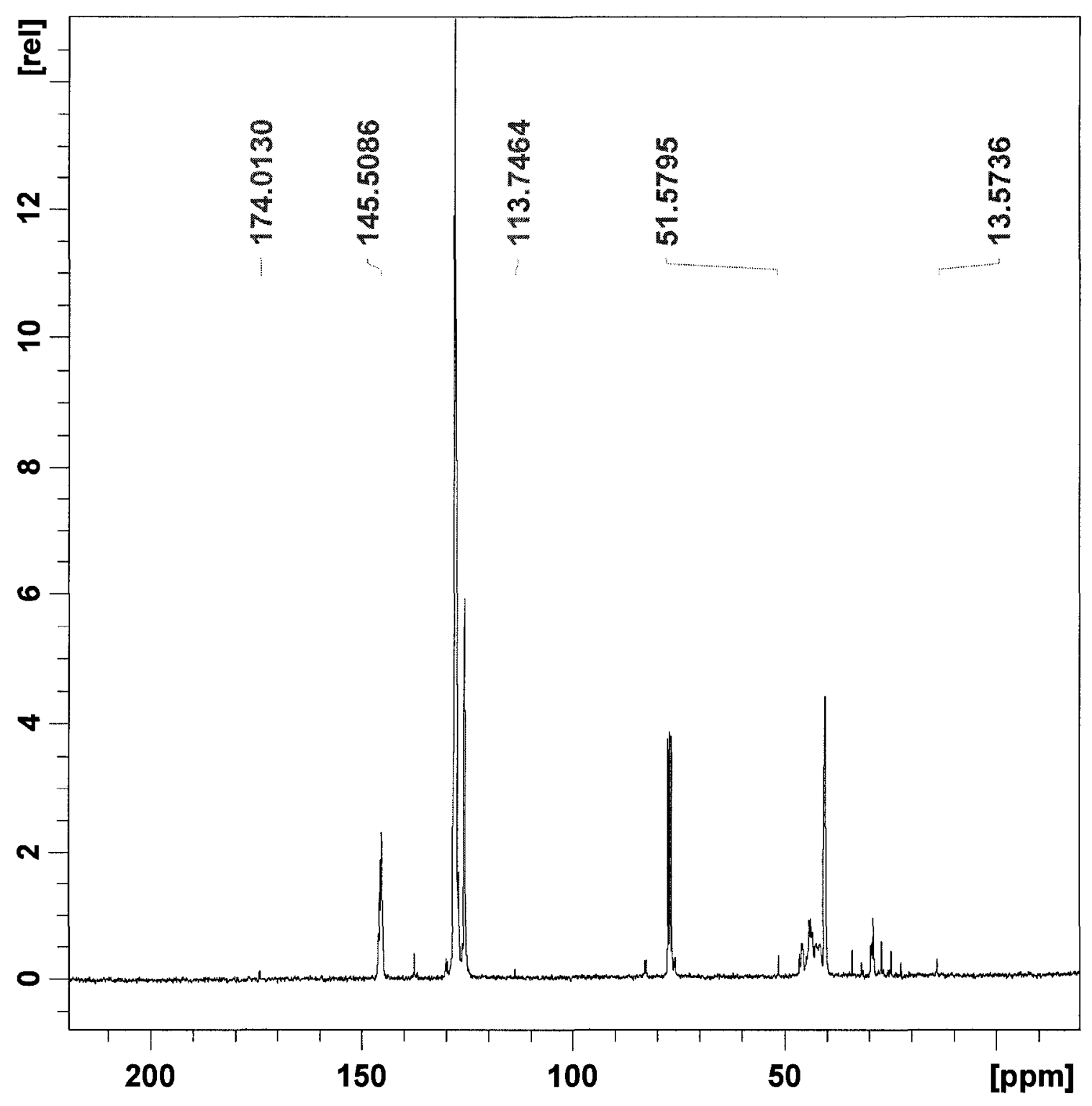

Figure $5.11{ }^{13} \mathrm{C}\left\{{ }^{1} \mathrm{H}\right\}$-NMR spectrum of polystyrene in $\mathrm{CDCl}_{3}$. Polymerization was performed in canola-based FAME. 


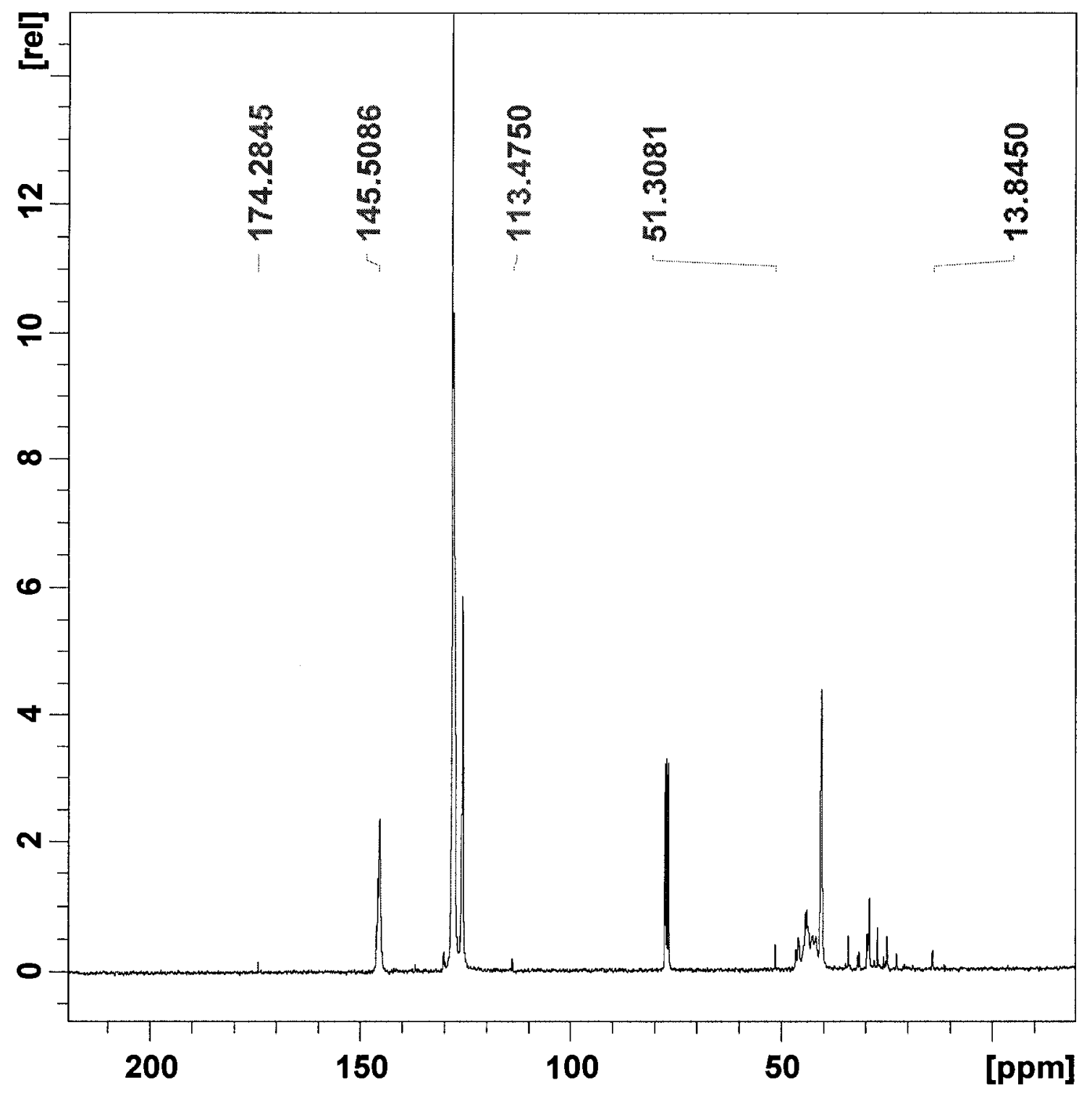

Figure $5.12{ }^{13} \mathrm{C}\left\{{ }^{1} \mathrm{H}\right\}-\mathrm{NMR}$ spectrum of polystyrene in $\mathrm{CDCl}_{3}$. Polymerization was performed in soybean-based FAME. 


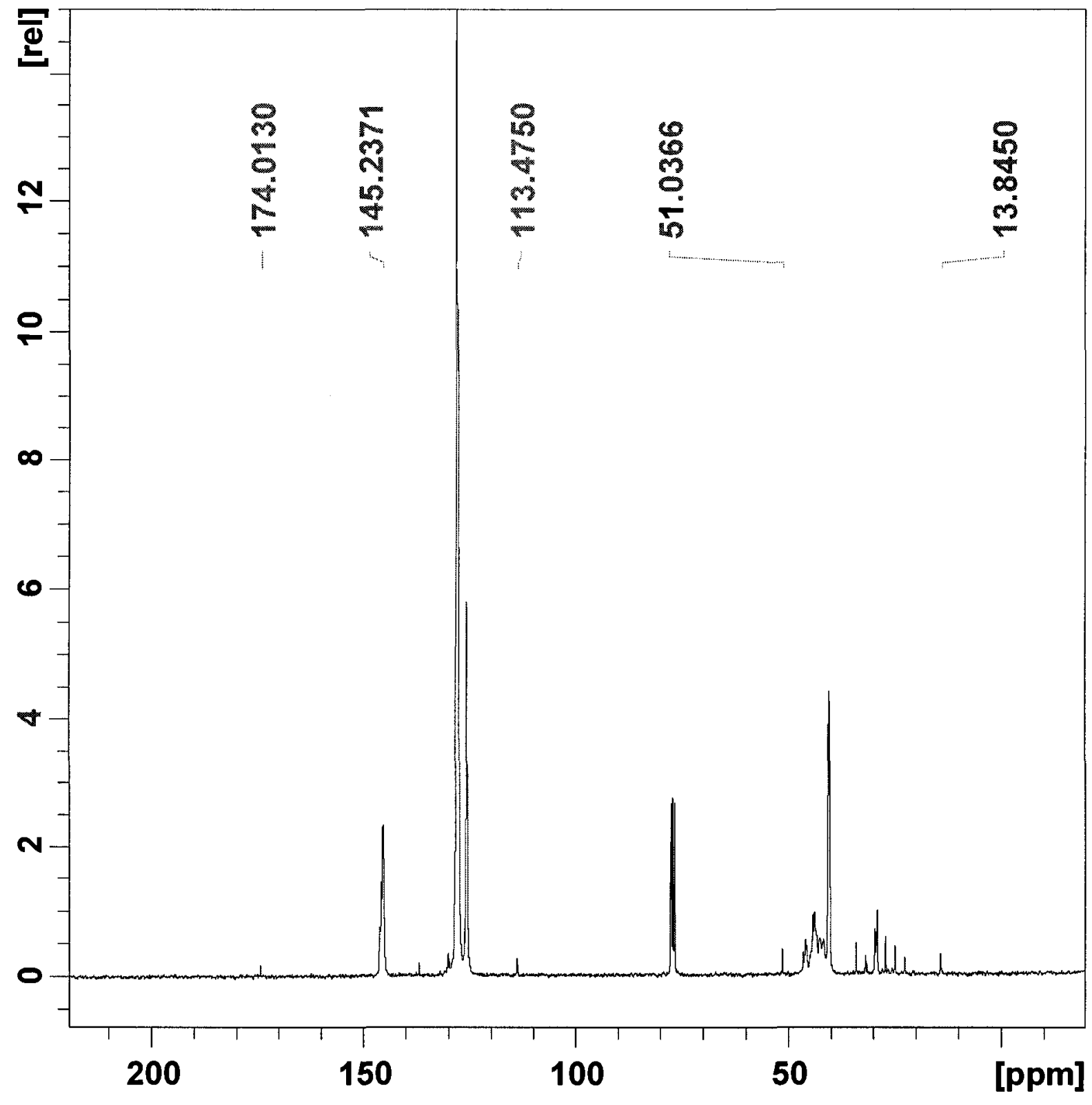

Figure $5.13{ }^{13} \mathrm{C}\left\{{ }^{1} \mathrm{H}\right\}$-NMR spectrum of polystyrene in $\mathrm{CDCl}_{3}$. Polymerization was performed in $50 \%$ yellow grease - $50 \%$ canola-based FAME. 
There are other small but distinguishable peaks in all polymer spectra, which are not overlapped with the polymer chain signals and can be assigned to FAMEs structures clearly. Resonances of internal double bonds of FAMEs appear at about $5.5 \mathrm{ppm}$ in the ${ }^{1} \mathrm{H}-\mathrm{NMR}$ spectra. Regarding ${ }^{13} \mathrm{C}-\mathrm{NMR}$ spectra, a signal at about $14 \mathrm{ppm}$ was assigned to the methyl groups at the end of each chain in saturated or unsaturated FAMEs chains, which is well separated from other signals. Another well-defined resonance was assigned to the carbonyl group at about $173 \mathrm{ppm}$ in the ${ }^{13} \mathrm{C}-\mathrm{NMR}$ spectra. Moreover, there is a resonance for the carbon, which is attached to the acyl group, at about $51 \mathrm{ppm}$. This can be confirmed by a signal in all samples' HMQC spectrum and arises at the intercept of the signal at about $51 \mathrm{ppm}$ on the ${ }^{13} \mathrm{C}$ axis and 3.8 on the ${ }^{1} \mathrm{H}$ axis, confirming the presence of the $\mathrm{OCH}_{3}$ chain end groups. Hence, assignment of this signal to any tertiary carbon or carbon of a methylene group is thwarted. Tertiary carbons without an aromatic attachment can appear in our system as a result of transfer to internal double bonds of FAMEs and initiation of new polymer chains by solvent radicals. The resonances for tertiary carbons are expected to be at $30-50 \mathrm{ppm}$. On the other hand, methylene groups attached to acyl groups can appear when transfer to solvent takes place at a terminal methyl group and initiation of new polymer chains starts from that point. The signals for this carbon are expected to be at 50-90 ppm. The lack of these signals means that, if at all present, these carbons have a concentration lower than the signal-tonoise ratio or overlap with other resonances. However, the ratio of the intensity of the mentioned peaks, assigned to FAME in each polymer sample spectrum, is the same as the ratio of the intensity of these peaks in the corresponding FAME spectrum within the range of experimental error. Therefore, it can be concluded that these small peaks are 
only related to residual FAME solvent in the polymer samples and not due to copolymerization or contribution of solvent as an initiator in the polymer chain.

\section{CONCLUSIONS}

FAME derived from canola oil, soybean oil and yellow grease-canola feedstocks all met the requirements of solution polymerization solvents for the homopolymerization of styrene. The rates of polymerization in FAME from canola oil and 50\% yellow grease$50 \%$ canola oil were similar, while that for soybean-based FAME was significantly lower. These differences may be attributed to variations in their FAMEs composition and consequently degree of unsaturation. Chain transfer to solvent parameters were similar within the range of experimental errors. Model predictions showed reasonable agreement with experimental data when new solvent data and changes in "lumped" rate parameter $\left(k_{p} / k_{t}^{1 / 2}\right)$ were incorporated into the model. A study of ${ }^{13} \mathrm{C}\left\{{ }^{1} \mathrm{H}\right\}$-NMR and ${ }^{1} \mathrm{H}-\mathrm{NMR}$ spectra shows no significant contribution of FAME to polymer chains. However, further investigation into the mechanism of chain transfer to FAME is recommended.

The positive findings in this paper for FAME from all the feedstocks are particularly significant when considering other factors. From an ecological perspective, FAME provides an environmentally friendly alternative to common solvents. In addition, using FAME from waste feedstocks helps sustainable development. From an industrial perspective, FAME can be used at elevated temperatures because of its high boiling point, which would increase the rate of the reaction, thereby increasing productivity. Polymers of specific desired molecular weights can be obtained by adjusting the concentration of FAME. 


\section{ACKNOWLEDGMENTS}

The authors gratefully acknowledge the financial support of the Natural Science and Engineering Research Council (NSERC) of Canada.

\section{REFERENCES}

BBI International, “U.S. \& Canada Biodiesel Plant Map", Salida, CO, (2005).

Benton, M.G. and C.S. Brazel , "Effect of Room-Temperature Ionic Liquids as Replacements for Volatile Organic Solvents in Free-Radical Polymerization", ACS Symposium Series 818, 125 (2002)

Buback, M., M. Egorov, R.G. Gilbert, V. Kaminsky, O.F. Olaj, G.T. Russell , P. Vana and G. Zifferer, "Critically Evaluated Termination Rate Coefficients for Free-Radical Polymerization,1.The Current Situation", Macromol. Chem. Phys., 203, 2570 (2002)

Budavari, S., M. O'Neil, A. Smith and P. E. Heckelman, "The Merck Index.", Rahway: Merck and Co., (1989).

Burnett, G., G.G. Cameron and S.N. Joiner, "Effect of Solvent on Free Radical Polymerization of Styrene" J. Chem. Soc., 69, 322 (1972)

Coote, M.L., T. P. Davis, B. Klumperman and M. J. J. Monteiro, "A Mechanistic Perspective on Solvent Effect in Free-Radical Copolymerization", Macromol. Sci. Rev. Macromol. Chem. Phys. C38, 567 (1998).

Duan, J., Y. Shim and H.J. Kim, "Solvation in Supercritical Water", J. Chem. Phys., 20, $124,(2006)$

Dubé, M.A., A.Y. Tremblay and J. Liu, "Biodiesel Production using a Membrane Reactor", Biores. Tech. 98, 639-647 (2006). 
Gao, J. and A. Penlidis, "A Comprehensive Simulator/Database Package for Reviewing Free-Radical Homopolymerizations” J. Macromol. Sci. Rev. Macromol. Chem. Phys., 36, 199 (1996)

Hensley, D.R., S.D. Goodrich, A.Y. Huckstep, H.J. Harwood and P.L. Rinaldi, "2DINADEQUATE NMR Evidence for Termination Mechanism of Styrene Free-Radical Polymerization", Macromolecules, 28, 1591 (1995)

Heuts, J.P.A., T.P. Davis and G.T. Russell, "Comparison of the Mayo and Chain Length Distribution Procedures for the Measurement of Chain Transfer Constant", Macromolecules, 32, 6019 (1999)

Hu, J., Z. Du, Z. Tang, and E. Min, "Study on the Solvent Power of a New Green Solvent: Biodiesel”, Ind. Eng. Chem. Res. 43, 7928-7931 (2004).

Jordan, E. F. Jr, B. Artymyshyn and A. N. Wrigley, "Chain Transfer Constants for Vinyl Monomers Polymerized in Methyl Oleate and Methyl Stearate", J. Polym. Sci. Polym. Chem. 7, 2605-2620 (1969).

Jovanović, R. and M.A. Dubé, "Solvent Effects in Butyl Acrylate and Vinyl Acetate Homopolymerizations in Toluene", J. Macromol. Sci. Polym. Rev., 44, 1 (2004)

Jovanovic, R. and M.A. Dubé, "Solvent Effects in Butyl Acrylate and Vinyl Acetate Homopolymerizations in Toluene”, J. Appl. Polym. Sci. 94, 871-876 (2004).

Knothe, G., "Structure Indices in FA Chemistry. How Relevant is the Iodine Value?" J. Am. Oil Chem. Soc., 79, 9, 847 (2002)

Mayo, F.R., "Chain Transfer in the Polymerization of Styrene: The Reaction of Solvents with Free Radicals", J. Amer. Chem. Soc. 65, 2324 (1943)

Mittelbach, M. and C. Remschmidt, "Biodiesel: The Comprehensive Handbook", Martin Mittelbach (2004)

Rodriguez, F., "Principles of Polymer Systems", $4^{\text {th }}$ ed., Taylor \& Francis, Washington, D.C. (1996)

Salehpour, S. and M.A. Dubé, "Using Biodiesel as a Polymerization Solvent at Elevated Temperature", to be submitted (2007) 
Salehpour, S., "Biodiesel: A Green Polymerization Solvent", M.A.Sc. Thesis, Department of Chemical Engineering, University of Ottawa, Ottawa, Ontario, Canada (2007)

Sherman, J., B. Chin, P. Huibers, R. Garcia-Valls and T. Hatton, "Solvent Replacement for Green Processing”, Environ. Health Perspect., 106(Suppl 1), 253 (1998)

Sitting, M., "Handbook of Toxic and Hazardous Chemicals and Carcinogens", 3 rd ed., Noyes Publications, Park Ridge, N.J. (1991)

Yang, Z. and W. Pan, "Ionic liquids: Green Solvents for Nonaqueous Biocatalysis", Enzyme Microb. Technol. 37, 19 (2005).

Zammit, M.D., T.P. Davis, G.D. Willett and K.F. O'Driscoll, "The Effect of Solvent on the Homo-Propagation Rate Coefficients of Styrene and Methyl Methacrylate", J. Polym. Sci. Polym. Chem., 35, 2311 (1997) 
Chapter 6

GENERAL DISCUSSION 


\section{GENERAL DISCUSSION}

Biodiesel fulfills the requirements of a good solvent; it is environmentally benign and has low volatility, low viscosity and good solubility. Hence, in an effort to achieve cleaner technologies by reducing volatile organic content (VOC) of various polymer processes, fatty acid methyl ester (FAME or biodiesel) was used as an alternative to traditional polymerization solvents. The suitability of FAME as a "green" polymerization solvent was evaluated and the effects of FAME on polymerization kinetics were investigated.

The effect of solvent on polymerization kinetics can be investigated by studying the chain transfer to solvent constant, $C_{f s}$, defined as the ratio of the chain transfer rate constant to the propagation constant (for more details see chapter 3). Solution polymerizations of four commercially important monomers (i.e, methacrylate (MMA), styrene, butyl acrylate (BA) and vinyl acetate (VAc)) were studied using FAME produced from canola oil as a polymerization solvent at 60 and $120^{\circ} \mathrm{C}$.

Different solvent concentrations were used and $\mathrm{c}$ hain transfer to solvent rate constants were obtained using the Mayo method and were found to be related in the increasing order: MMA $<$ Sty $<\mathrm{BA}<\mathrm{VAc}$ at $60^{\circ} \mathrm{C}$ and Sty $<\mathrm{BA}<\mathrm{MMA}<\mathrm{VAc}$ at $120^{\circ} \mathrm{C}$. All estimated values of transfer to solvent constants were higher at $120^{\circ} \mathrm{C}$ compared to polymerization at $60^{\circ} \mathrm{C}$. At $120^{\circ} \mathrm{C}$, all polymers were soluble while precipitation polymerization of MMA was observed at $60^{\circ} \mathrm{C}$. This accounts for the difference in order of the $C_{f s}$ value for MMA at different temperatures. At $120^{\circ} \mathrm{C}$ chain transfer constants for MMA and BA were comparable and the chain transfer constant for any compound increased in order of increasing radical reactivity in the chain transfer 
reaction. However, MMA presented the lowest transfer constant at $60^{\circ} \mathrm{C}$, which is expected due to the precipitation polymerization mechanism it underwent (Eastwood, 1967). Retardation of VAc at both temperatures and considerable thermal polymerization of Sty at $120^{\circ} \mathrm{C}$ occurred. A Mayo plot of two important polymers, MMA and Sty, are presented in Figure 6.1.

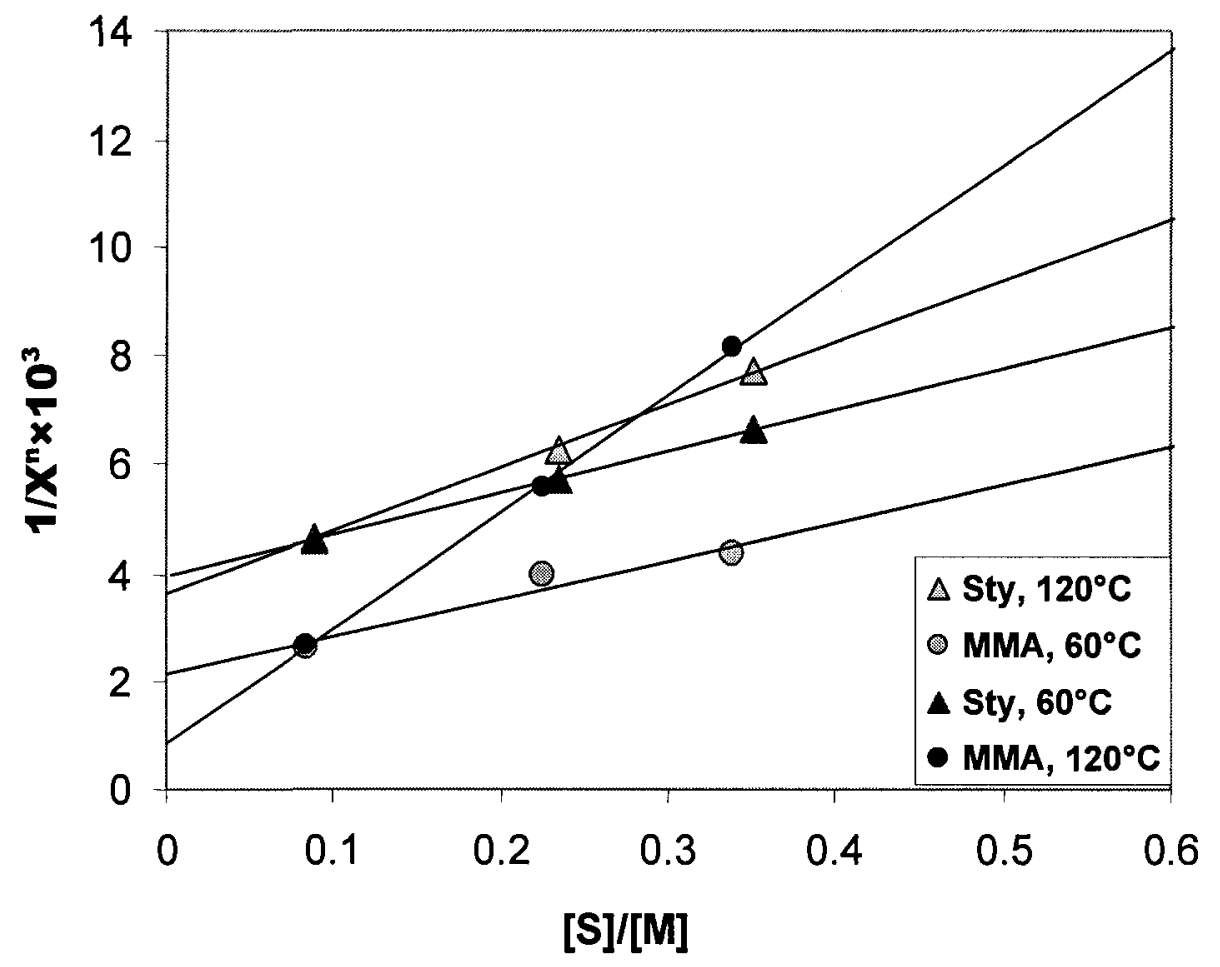

Figure 6.1: Mayo plot - reciprocal number-average degree of polymerization versus the solvent/monomer ratio for Sty and MMA polymerized in canola-based FAME at 60 and $120^{\circ} \mathrm{C}$.

Physical property data of the FAME as well as the chain transfer to solvent rate parameters were incorporated into the WATPOLY polymerization simulator database and all experimental data were modelled. Model fits were improved by manipulating the individual lumped rate parameter $\left(k_{p} / k_{l}^{1 / 2}\right)$ data for each polymer system, where $k_{p}$ is the 
propagation rate parameter and $k_{t}$ is the termination rate parameter. The presence of FAME solvent was observed to affect the kinetic reaction rate parameters and therefore the rates of polymerization at these temperatures. The propagation rate parameter, $k_{p}$, could be affected by the existence of radical-solvent complexes, which participate in propagation reactions (Zammit et al., 1997). On the other hand, an increase in $k_{t}$ occurred by increasing the solvent concentration because of more transfer to solvent reactions and therefore, the generation of shorter and more mobile chains which terminate faster (Buback et al., 2002). The absolute values of the individual propagation and termination rate parameters can only be obtained using more complex techniques such as pulsed laser polymerization (PLP) (Hutchinson et al. 1994). Regardless of the effect of solvent on the individual rate parameters, the "lumped" kinetic rate parameter $\left(k_{p} / k_{t}^{1 / 2}\right)$ for each monomer was modified to fit the experimental conversion data at each concentration. The agreement between the experimental data and the model predictions was satisfactory. As a representation of typical results, model predictions of the reaction rates and cumulative weight-average molecular weights along with the experimental data are presented in Figures 6.2 and 6.3 for Sty polymerization at $120^{\circ} \mathrm{C}$. The model predictions appear to correctly to describe the trends in the data and the model fits are not unreasonable. 


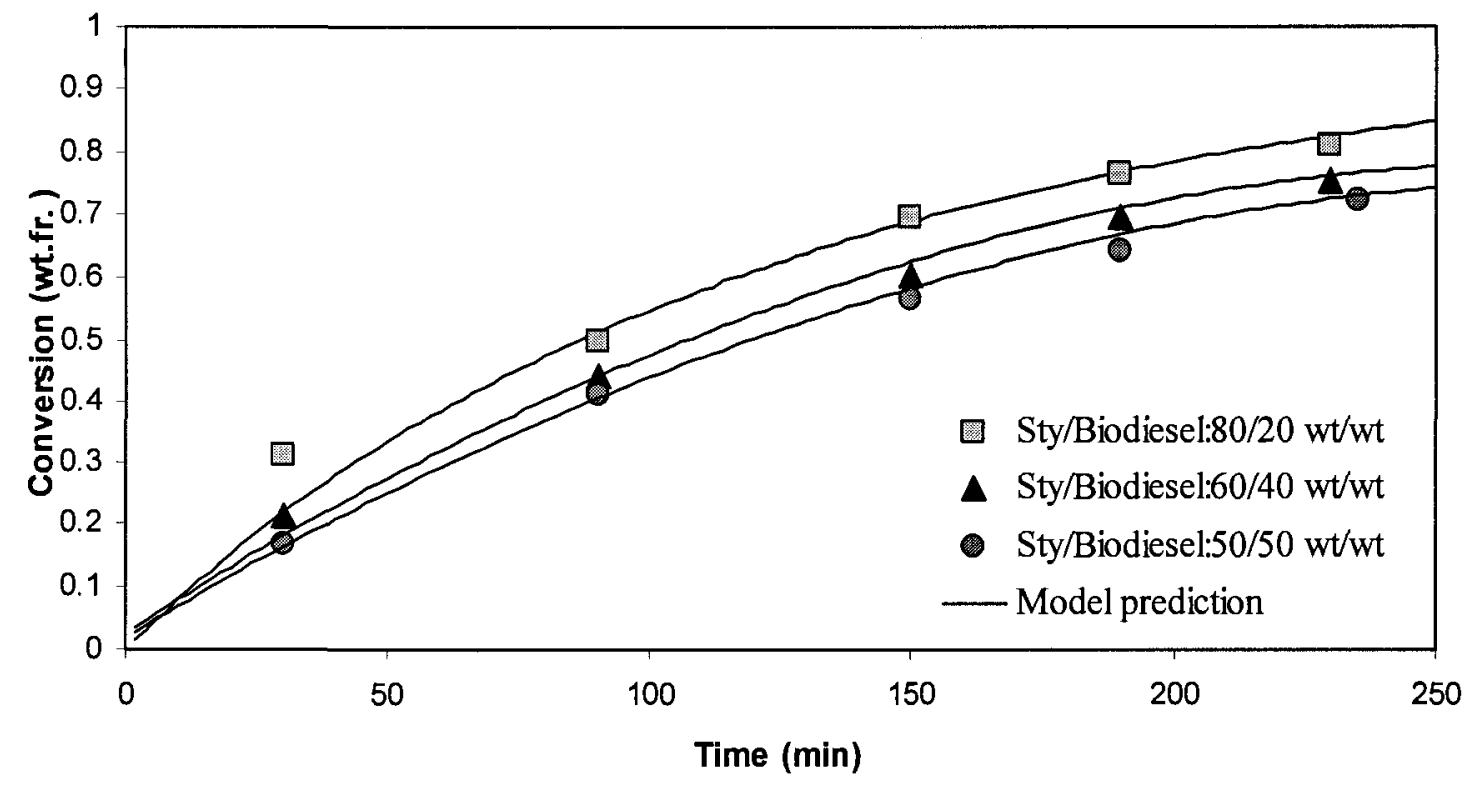

Figure 6.2: Sty homopolymerization in biodiesel: Conversion versus time at different solvent concentrations.

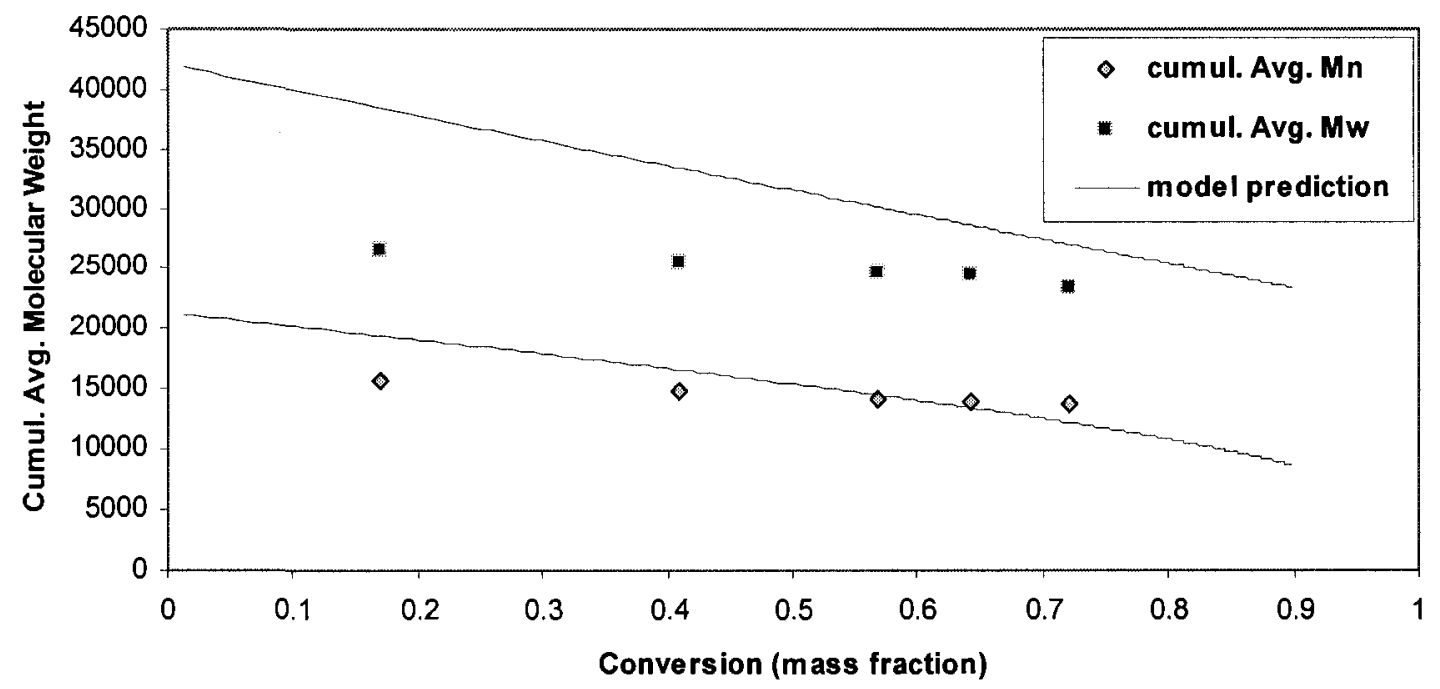

Figure 6.3: Cumulative average molecular weight versus conversion for Sty solution homopolymerization in biodiesel (50/50 wt \%) 
There is interest in carrying out polymerizations at elevated temperatures. This strategy leads to higher reaction rates, and consequently shorter reaction times and lower viscosity, which can dissipate autoacceleration effects (McManus et al., 2004). Moreover, High temperature polymerization enables the production of low molecular weight polymers without the use of chain transfer agents. The results from polymerization at $120^{\circ} \mathrm{C}$ demonstrate that FAME from canola oil fulfills the requirements of a good high boiling solvent for solution polymerization at elevated temperatures.

Currently, there is growing interest toward the use of multiple biodiesel feedstocks in order to avoid competition with food supplies as well as for economic reasons. Therefore, to investigate the effect of different feedstocks used in FAME production, Sty polymerization at $60^{\circ} \mathrm{C}$ in FAME from different feedstocks was studied. FAMEs produced from soybean oil and 50\% yellow grease-50\% canola oil were used as polymerization solvents and results were compared to runs at $60^{\circ} \mathrm{C}$ in canola-based FAME. These different feedstocks have a dissimilar degree of saturation, which is reflected in the iodine values for the FAME (i.e., 94-120 for canola, 120-143 for soybean and 80-100 for yellow grease based FAME).

Chain transfer to solvent constants were measured for polymerization in each FAME type and no statistically significant differences were observed between the values obtained from each feedstock. Alternatively, the rates of polymerization were influenced by the degree of saturation of each FAME solvent. Polymerization in soybean-based FAME, with the highest degree of unsaturation, presented the lowest reaction rate while the rate of polymerization in canola-based FAME and 50\% yellow grease-50\% canola based were comparable to each other (see Figure 6.4). This difference was attributed to 
variations in FAME composition and consequently to the degree of unsaturation or iodine value of the FAME. Soybean-based biodiesel had a higher percentage of double bonds in the fatty acid chains of the esters; this could result in a higher decrease in the rate of polymerization due to the formation of more monomer-solvent or radical-solvent complexes. Modelling was performed by using a single lumped rate constant for polymerization in each solvent to predict the cumulative average molecular weights and reaction rates. Model predictions of reaction rates and molecular weights demonstrated good agreement with experimental data.

One important question that can arise relates to how the FAME solvent is involved in the chain transfer reaction mechanism. Thus the microstructure of the final polymer products would be of interest and this could be studied using ${ }^{13} \mathrm{C}\left\{{ }^{1} \mathrm{H}\right\}-\mathrm{NMR}$ and ${ }^{1} \mathrm{H}-\mathrm{NMR}$ analyses. The study of spectra of polystyrene polymerized in FAME from different feedstocks, postulated no evident contribution of FAME in the long chain polymer samples (for more information see Chapter 5). Oligomers or very short chain polymers, could have existed, but might have been lost during the extraction procedure. 


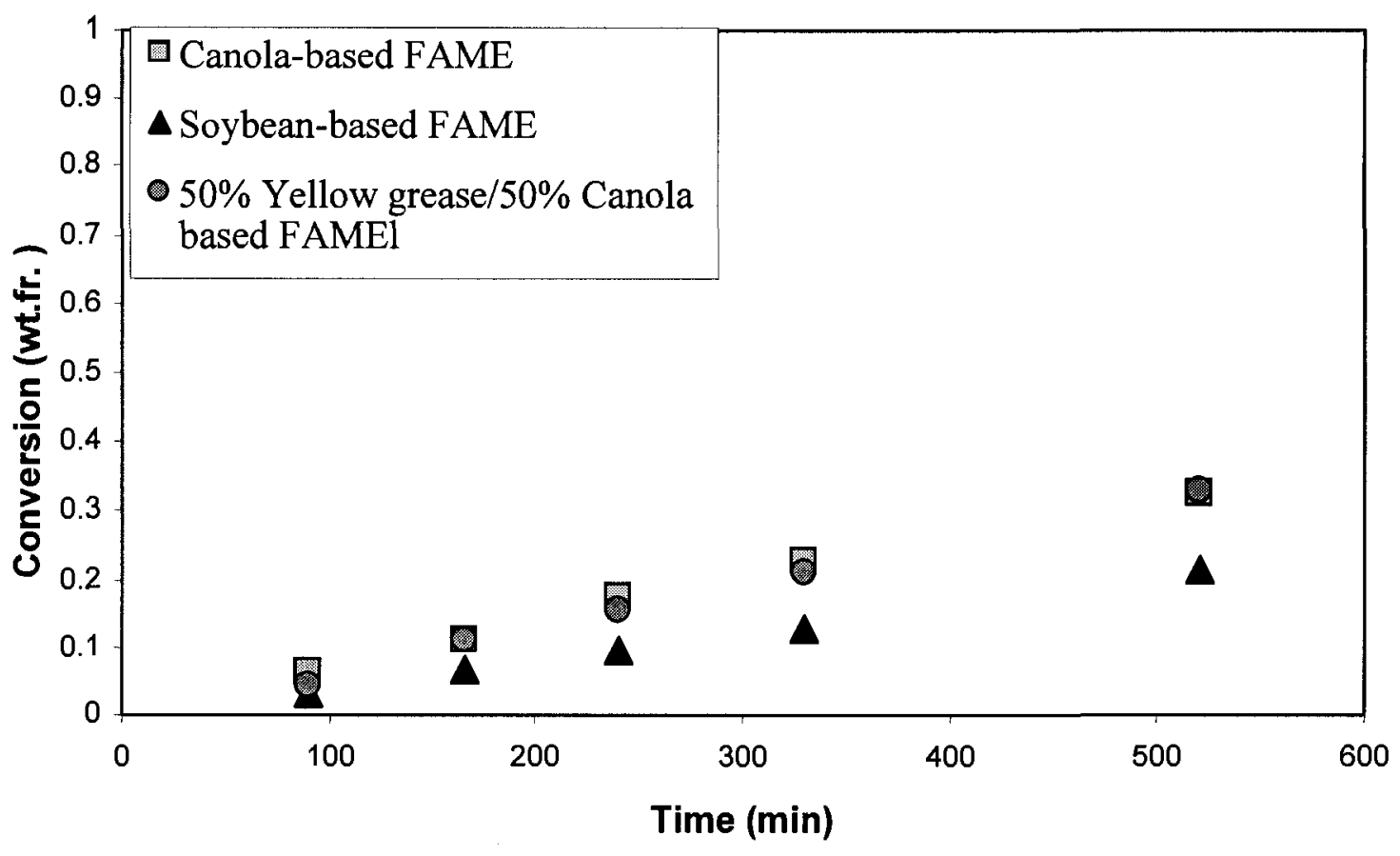

Figure 6.4: Conversion versus time for 50/50 wt\% monomer/FAME.

The results obtained in this study allowed us to assess the effect of different FAMEs on polymerization kinetics different temperatures. Solvent effects on the rate of polymerization and considerable chain transfer to solvent constants were observed.

\section{CONCLUSIONS AND RECOMMENDATIONS}

The use of FAME or biodiesel as a "green" polymerization solvent with good solubility, low viscosity and high boiling point was studied and fulfilled the requirements of a solution polymerization solvent in different cases. Therefore, the "environmental friendliness" of FAME, coupled with its effectiveness as a polymerization medium, makes it an attractive alternative to traditional polymerization solvents.

This thesis provides subject matter for further studies: 
1. Since the lumped rate constant cannot reveal the effect of solvent on individual termination and propagation rate parameters, for a better understanding of polymerization kinetics, further investigation on the absolute rate parameters for each monomer in FAME is recommended, e.g., using the PLP method mentioned above.

2. To study the effect of internal double bonds of different FAMEs on polymerization rate, the existence of radical-solvent or monomer-solvent complexes for each monomer at different temperatures and investigation on mechanism of forming these complexes is recommended. These complexes can affect the propagation rate and consequently polymerization rate but may dissociate at high temperatures. Also the effect can vary with monomer reactivity.

3. Polymerization and copolymerization at higher temperatures for monomers without low ceiling temperatures is recommended. Because biodiesel has a high boiling point (e.g., $326^{\circ} \mathrm{C}$ for canola-based biodiesel), it will not create a hazard in the workplace due to evaporation and reactions can be carried out at elevated temperatures without fear of excessive pressure build-up. For example, acrylic polymers such as poly(butyl acrylate) are the base resin component for many automotive coatings, which are made at high temperatures $\left(140-180^{\circ} \mathrm{C}\right)$ via solution polymerization in xylene which is toxic and boils at $140^{\circ} \mathrm{C}$ (Quan et al., 2005).

4. Because biodiesel can have dissimilar contributions to the polymer microstructure of different polymers, ${ }^{13} \mathrm{C}\left\{{ }^{1} \mathrm{H}\right\}-\mathrm{NMR}$ and ${ }^{1} \mathrm{H}-\mathrm{NMR}$ studies on other polymer products is recommended. In addition, polymer products with very diverse 
molecular weights can be produced using different initiator concentrations and should be examined by NMR analyses to observe the existence of the solvent moieties in the polymer chains.

5. A study on the effect of FAME from other common feedstocks and using other commercial monomers such as acrylamide and ethyl acrylate is recommended.

\section{REFERENCES}

Buback, M., M. Egorov, R.G. Gilbert , V. Kaminsky, O.F. Olaj, G.T. Russell , P. Vana and G. Zifferer, "Critically Evaluated Termination Rate Coefficients for Free-Radical Polymerization, 1.The Current Situation", Macromol. Chem. Phys., 203, 2570 (2002)

Eastwood. G.C., "Encyclopedia of Polymer Science and Technology", Vol. 7, Interscience, New York (1967)

Hutchinson, R.A., J.R. Richards and M.T. Aronson, "Determination of propagation rate coefficients by pulsed-laser polymerization for systems with rapid chain growth: Vinyl acetate", Macromolecules, 27, 4530 (1994)

McManus, N.T., G. Hsieh and A. Penlidis, "Free Radical Terpolymerization of Butyl Acrylate/Methyl Methacrylate and Alpha Methyl Styrene At High Temperature", Polymer, 45, 5837 (2004)

Quan, A., M. Soroush, M.C. Grady, E. Hansen and W.J. Simonsick, "High-Temperature homopolymerization of Ethyl Acrylate and n-Butyl Acrylate: Polymer Characterization", Macromolecules, 38, 7619 (2005)

Zammit, M.D., T.P. Davis, G.D. Willett and K.F. O'driscoll, "The Effect of Solvent on the Homo-Propagation Rate Coefficients of Styrene and Methyl Methacrylate" J. Polym. Sci. Polym. Chem., 35, 2311 (1997) 
Appendix A

EXPERIMENTAL DATA AND MODEL PREDICTIONS 


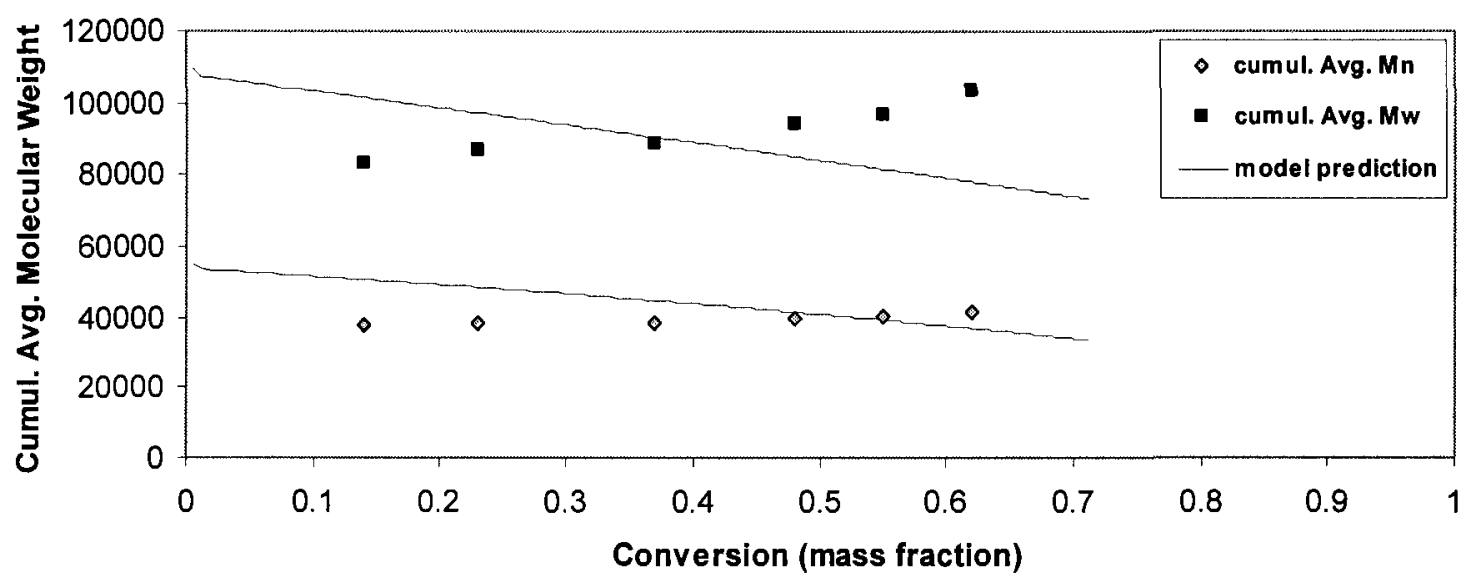

Figure A.1 Cumulative average molecular weight versus conversion for MMA solution homopolymerization in $\mathrm{FAME}$ at $60^{\circ} \mathrm{C}(80 / 20 \mathrm{wt} \%)$

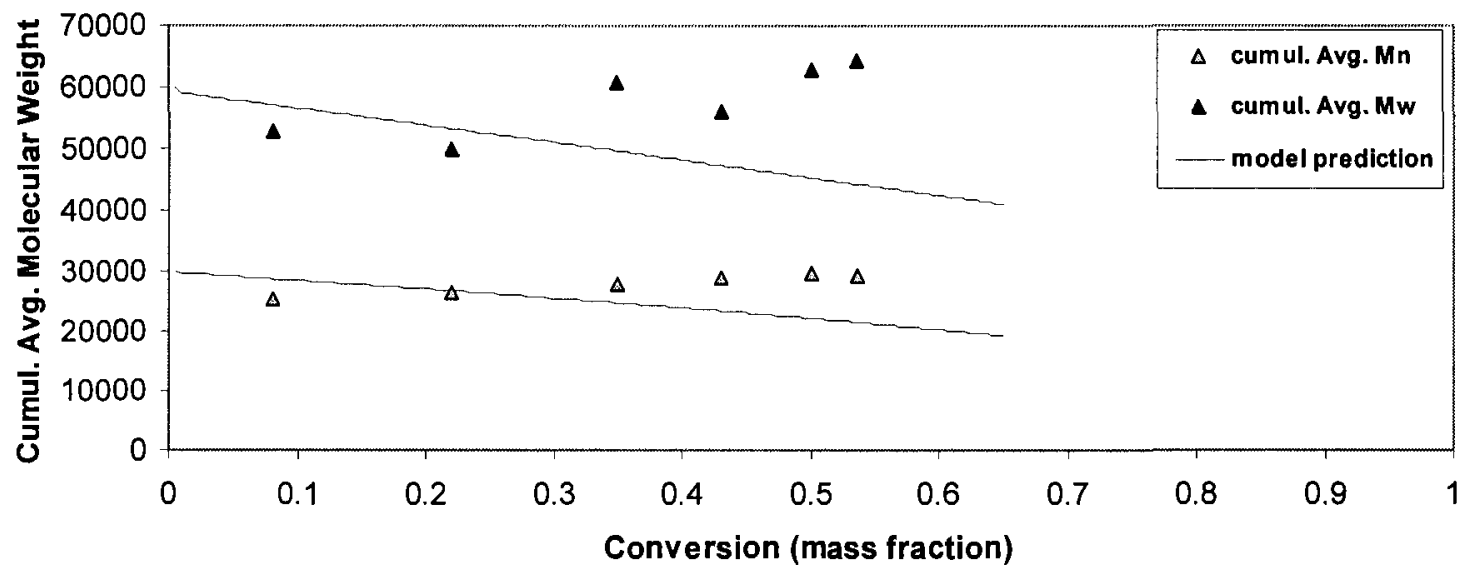

Figure A.2 Cumulative average molecular weight versus conversion for MMA solution homopolymerization in FAME at $60^{\circ} \mathrm{C}(60 / 40 \mathrm{wt} \%)$ 


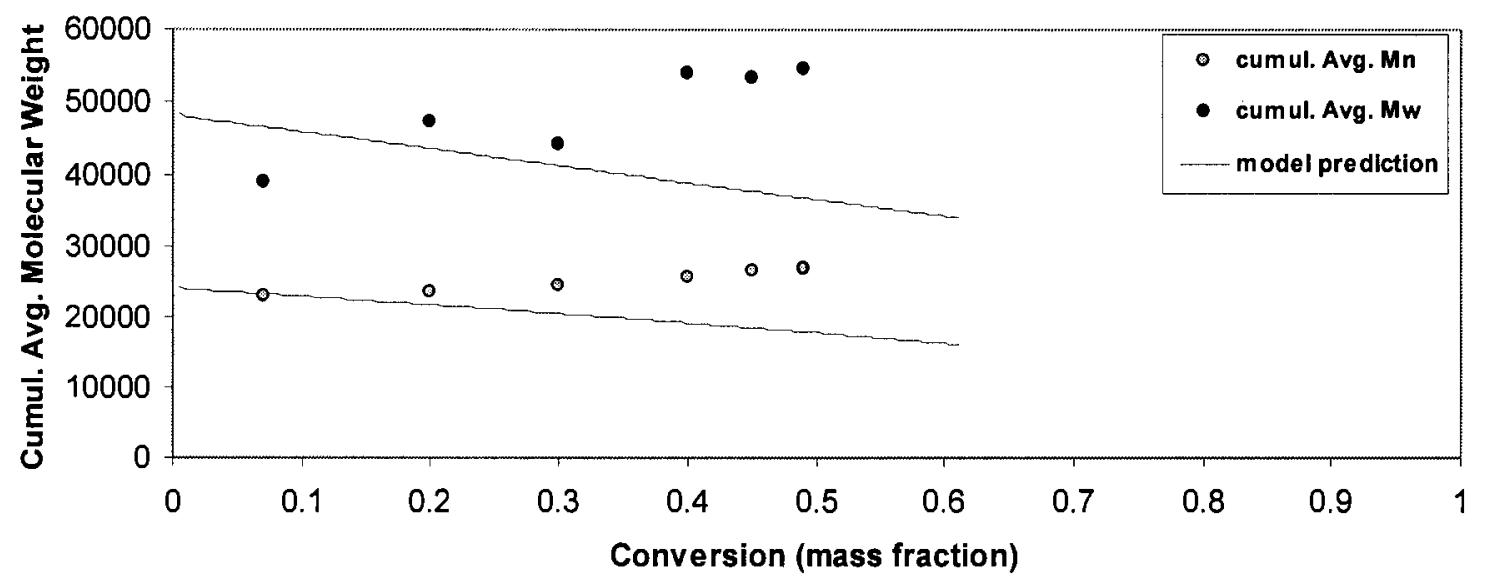

Figure A.3 Cumulative average molecular weight versus conversion for MMA solution homopolymerization in FAME at $60^{\circ} \mathrm{C}(50 / 50 \mathrm{wt} \%)$

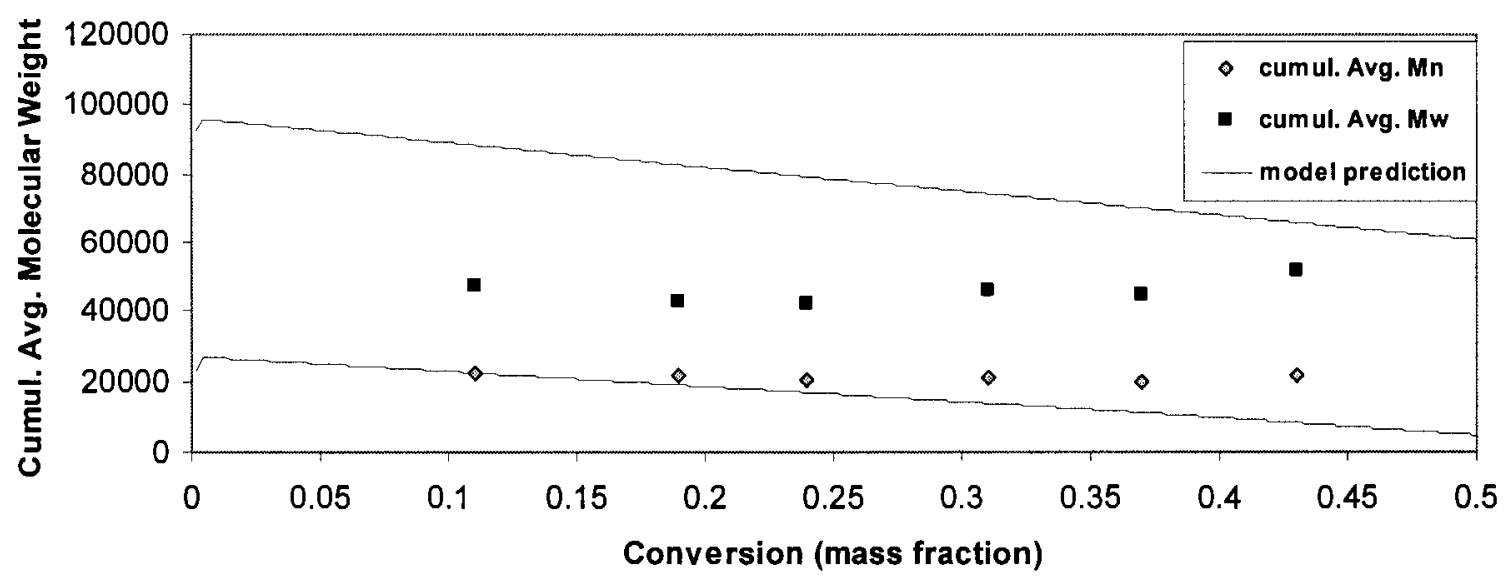

Figure A.4 Cumulative average molecular weight versus conversion for Sty solution homopolymerization in FAME at $60^{\circ} \mathrm{C}(80 / 20 \mathrm{wt} \%)$ 


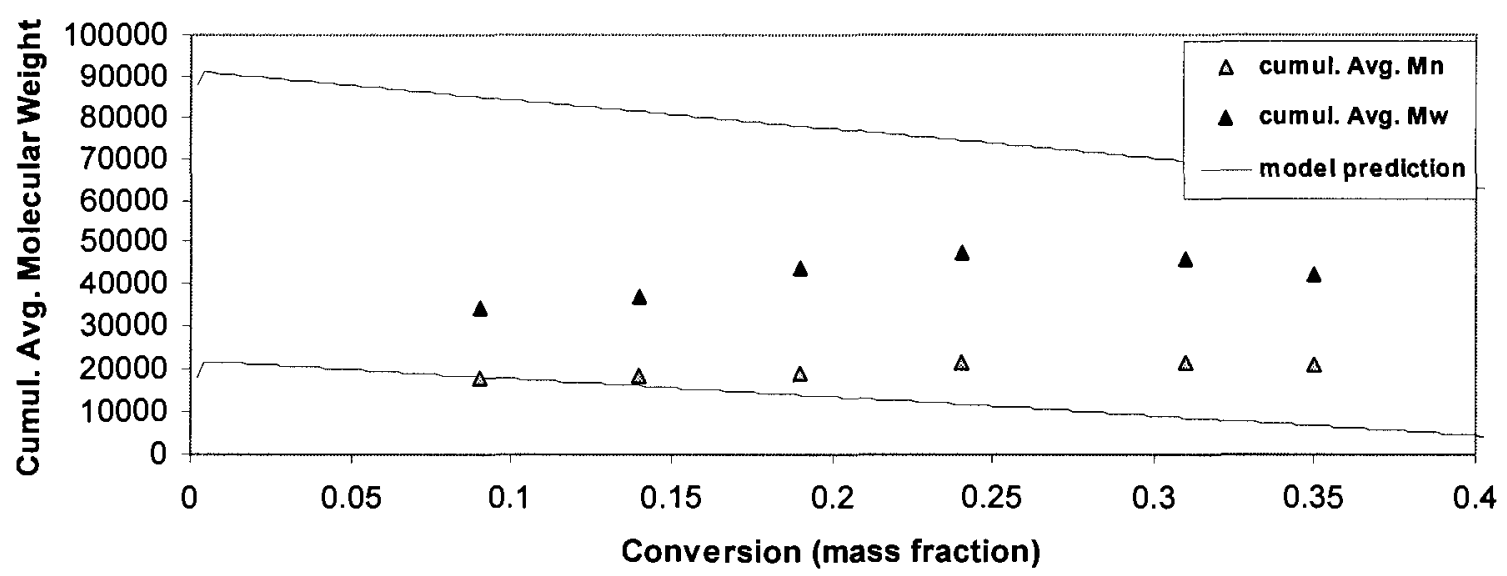

Figure A.5 Cumulative average molecular weight versus conversion for Sty solution homopolymerization in FAME at $60^{\circ} \mathrm{C}(60 / 40 \mathrm{wt} \%)$

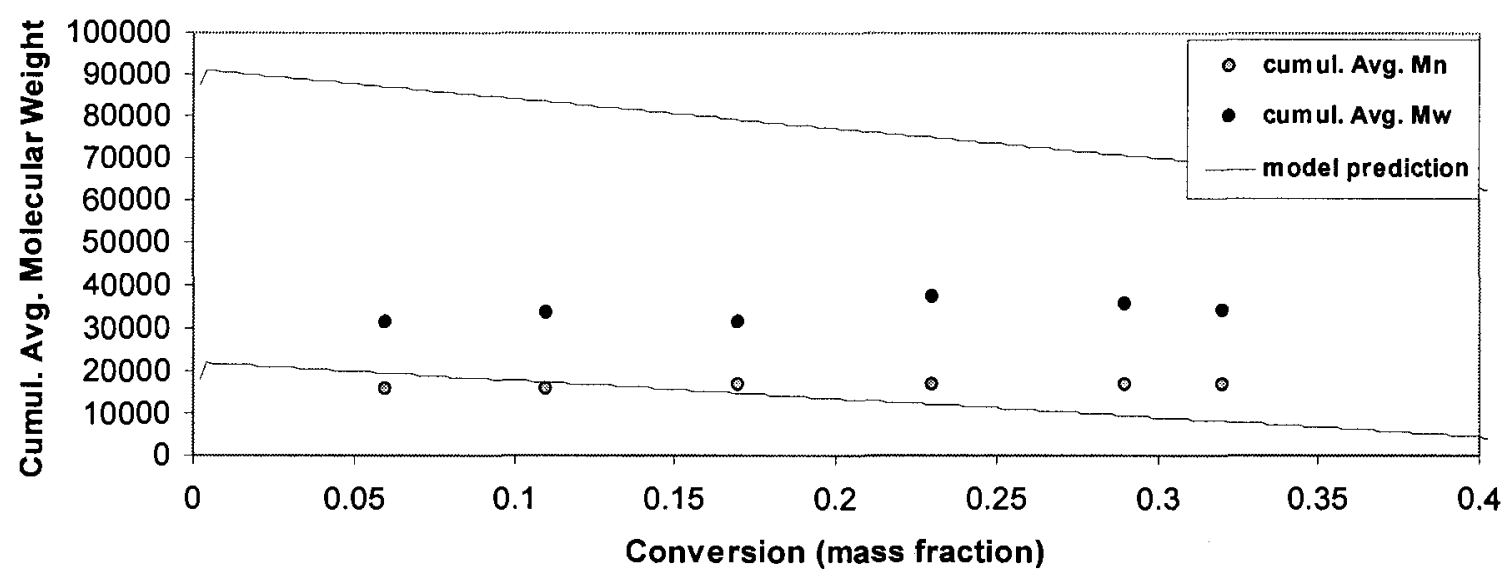

Figure A.6 Cumulative average molecular weight versus conversion for Sty solution homopolymerization in FAME at $60^{\circ} \mathrm{C}(50 / 50 \mathrm{wt} \%)$ 


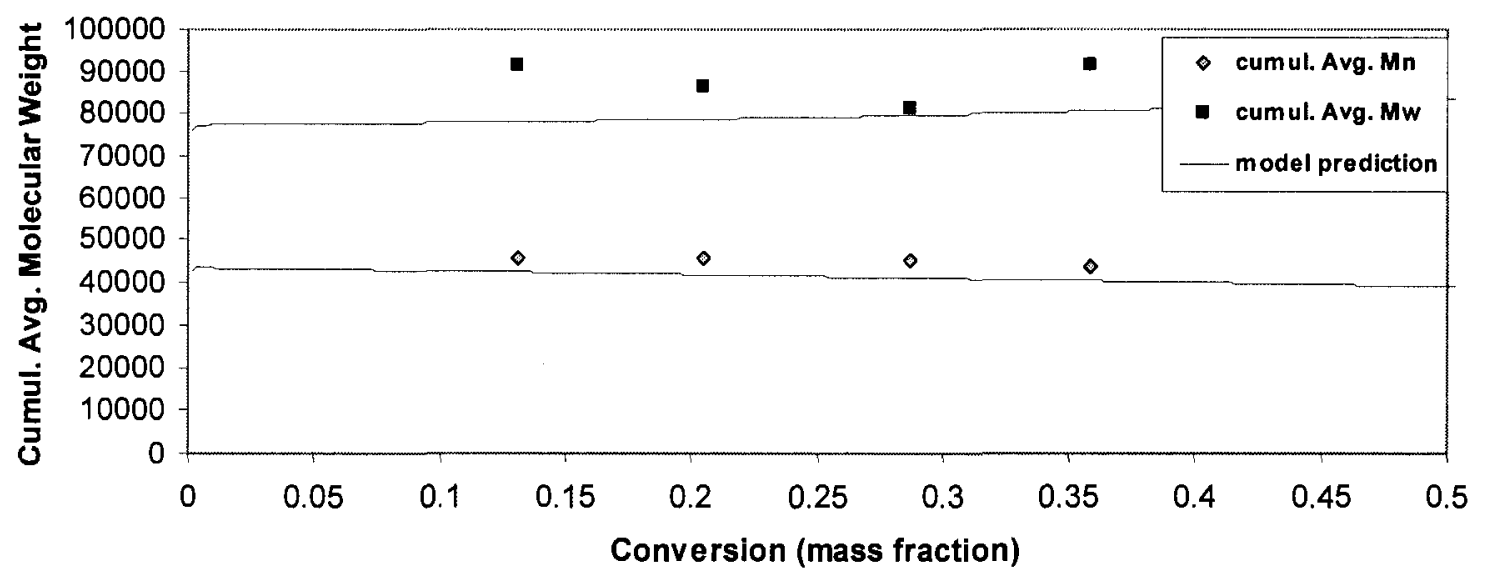

Figure A.7 Cumulative average molecular weight versus conversion for VAc solution homopolymerization in FAME at $60^{\circ} \mathrm{C}(80 / 20 \mathrm{wt} \%)$

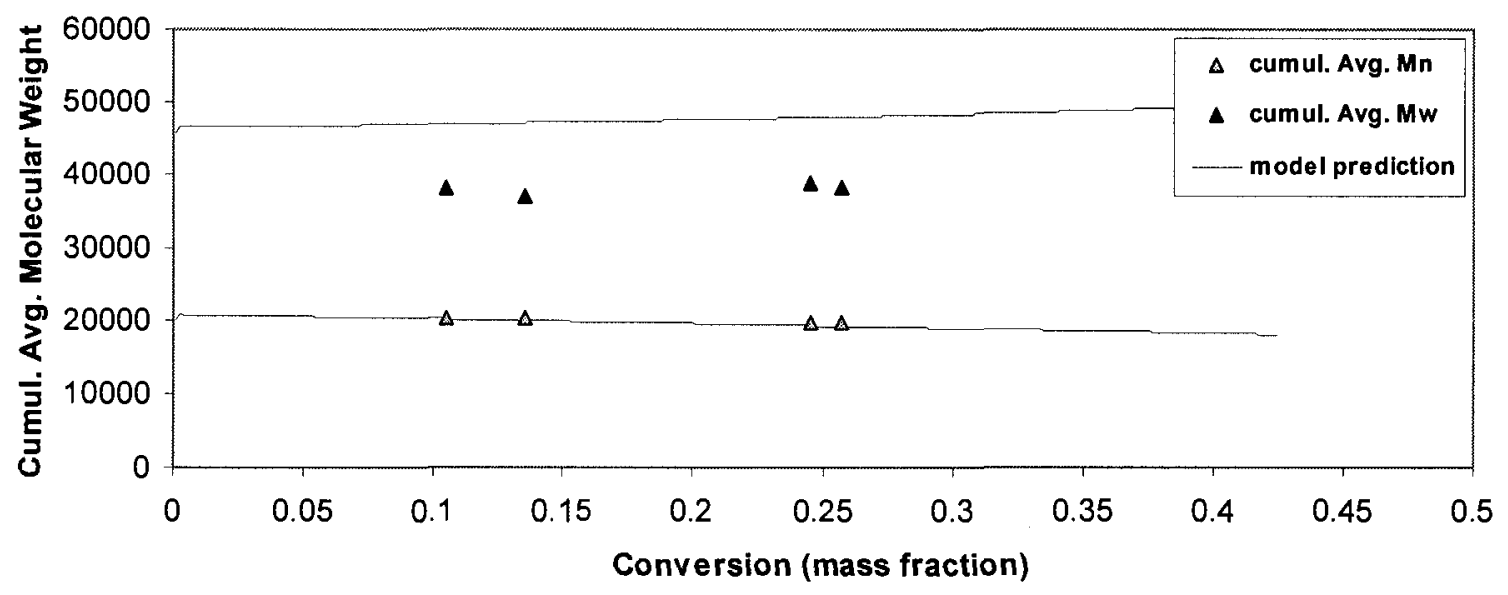

Figure A.8 Cumulative average molecular weight versus conversion for VAc solution homopolymerization in FAME at $60^{\circ} \mathrm{C}(60 / 40 \mathrm{wt} \%)$ 


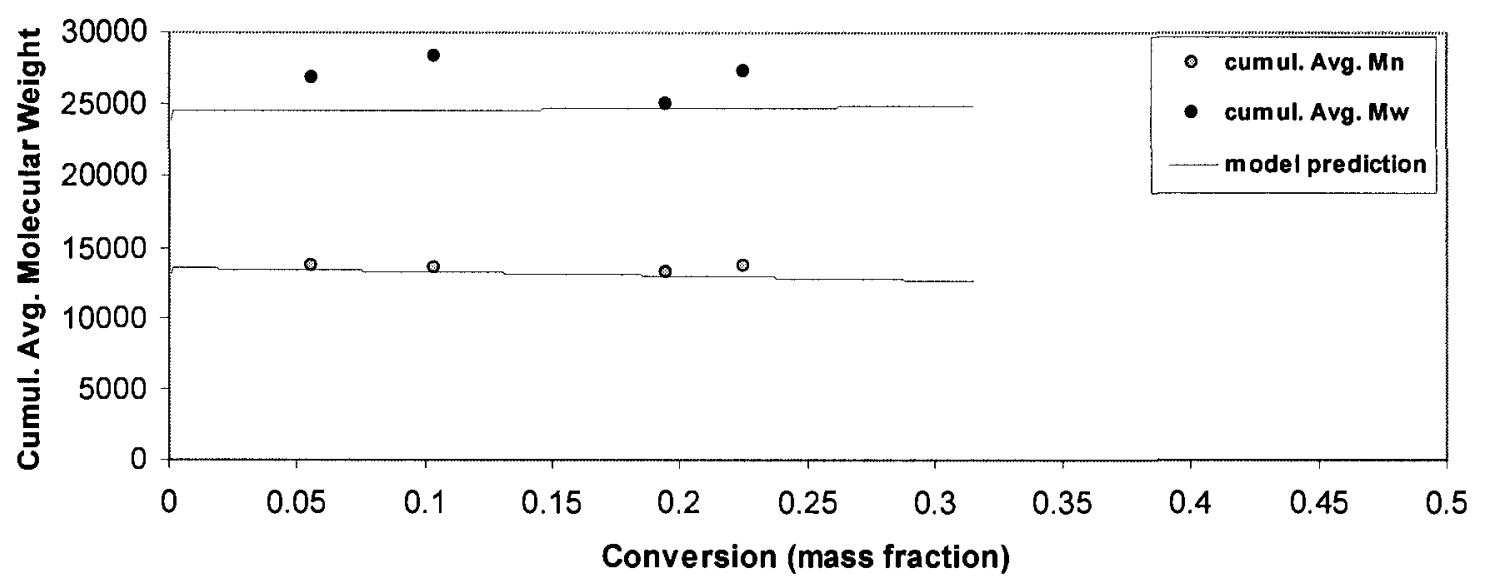

Figure A.9 Cumulative average molecular weight versus conversion for VAc solution homopolymerization in FAME at $60^{\circ} \mathrm{C}(50 / 50 \mathrm{wt} \%)$

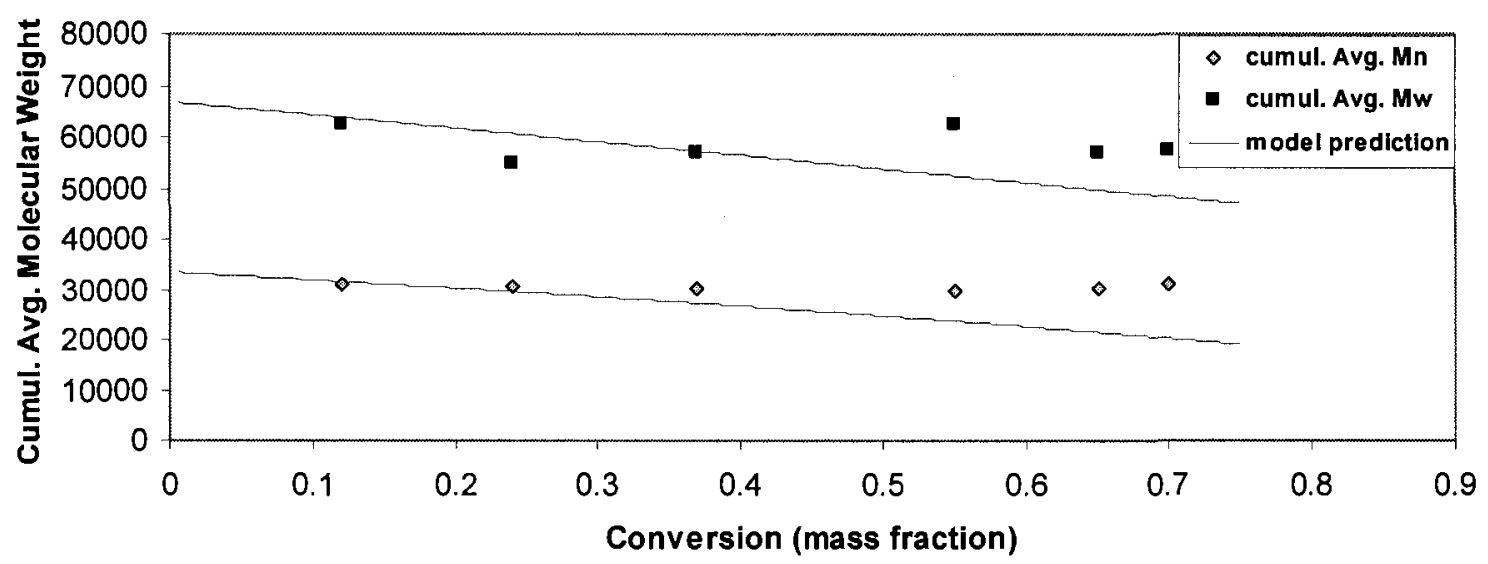

Figure A.10 Cumulative average molecular weight versus conversion for BA solution homopolymerization in FAME at $60^{\circ} \mathrm{C}(80 / 20 \mathrm{wt} \%)$ 


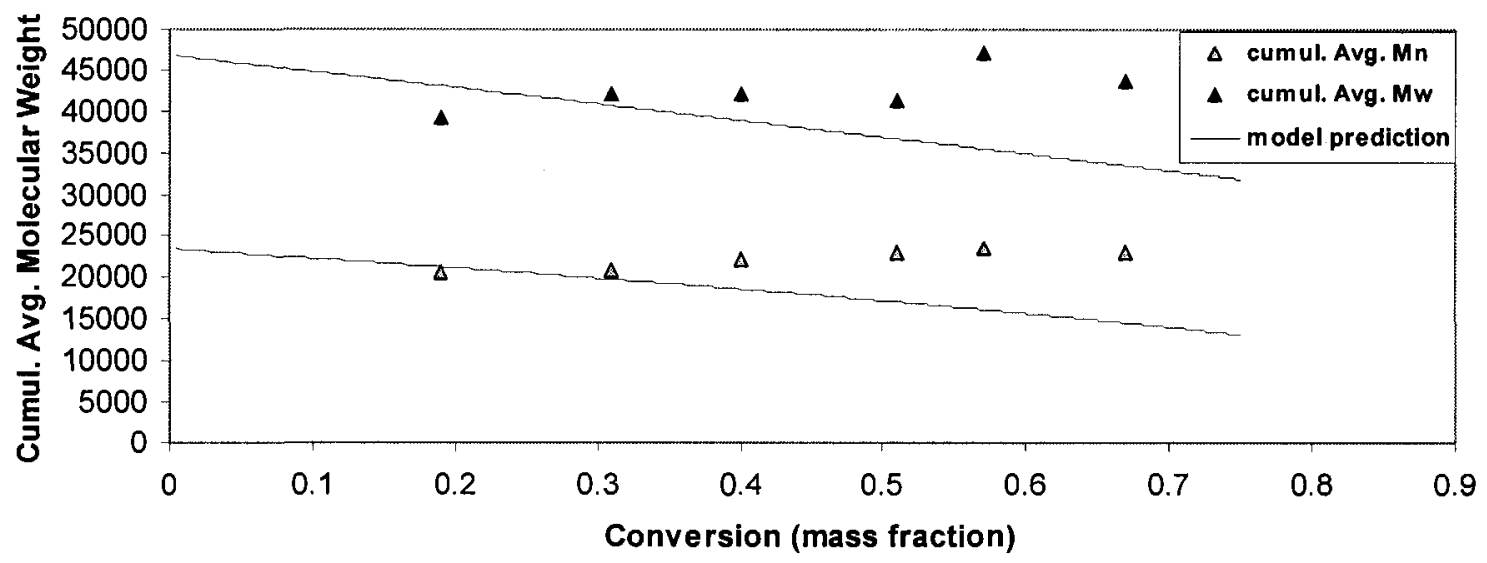

Figure A.11 Cumulative average molecular weight versus conversion for BA solution homopolymerization in FAME at $60^{\circ} \mathrm{C}(60 / 40 \mathrm{wt} \%)$

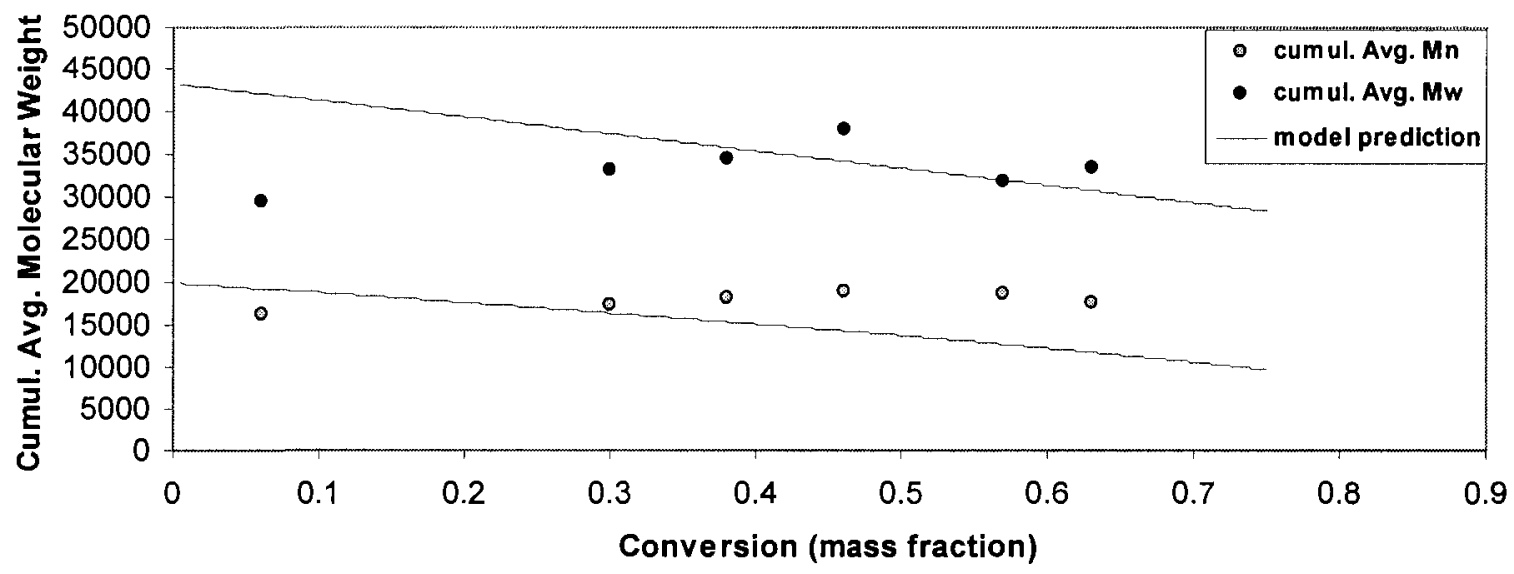

Figure A.12 Cumulative average molecular weight versus conversion for BA solution homopolymerization in FAME at $60^{\circ} \mathrm{C}(50 / 50 \mathrm{wt} \%)$ 


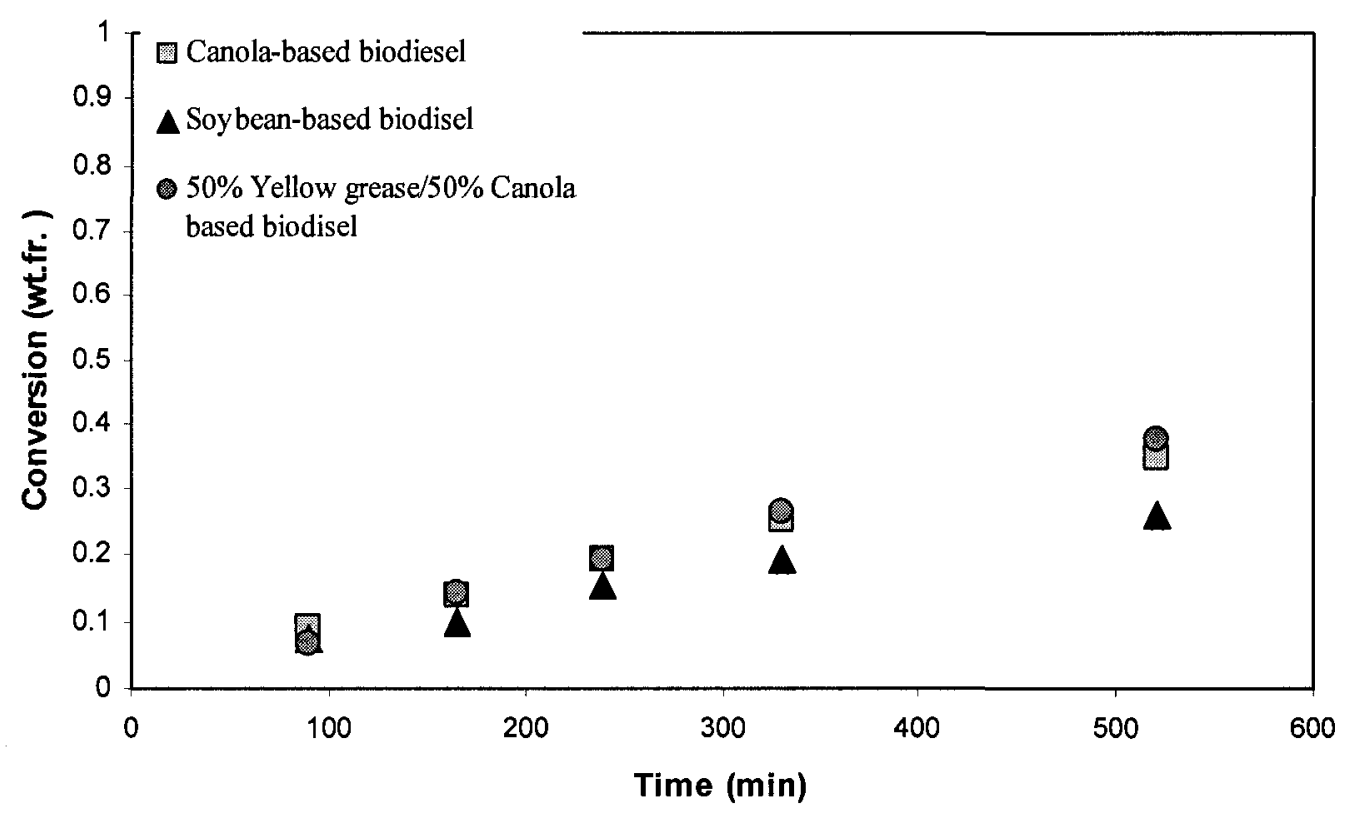

Figure A.13 Conversion versus time for 60/40 wt $\%$ monomer/FAME.

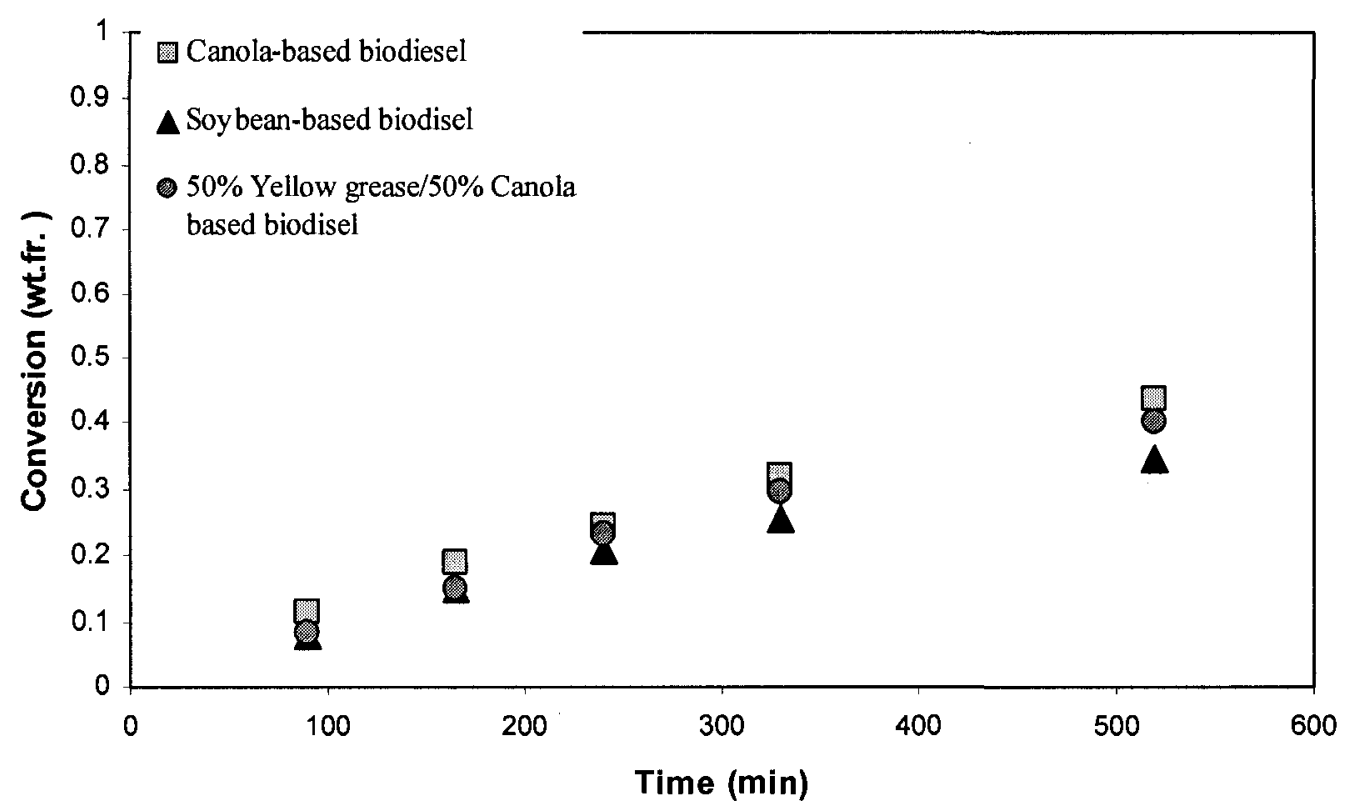

Figure A.14 Conversion versus time for $80 / 20 \mathrm{wt} \%$ monomer/FAME. 